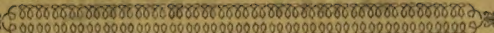 \\ VERZEICHNISS \\ DER \\ IN DER SCHWEIZ

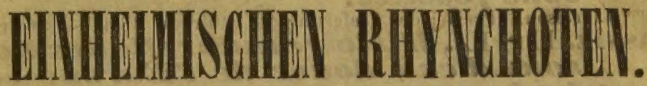

(Hemiptera Hinn.)

Mitglied der Gesellschaft naturforschender Freunde in Bern, der aligemeinen schvveizerischen Gesellsehaft für die gesammien Naturrvissenschafton, und des

00220200000
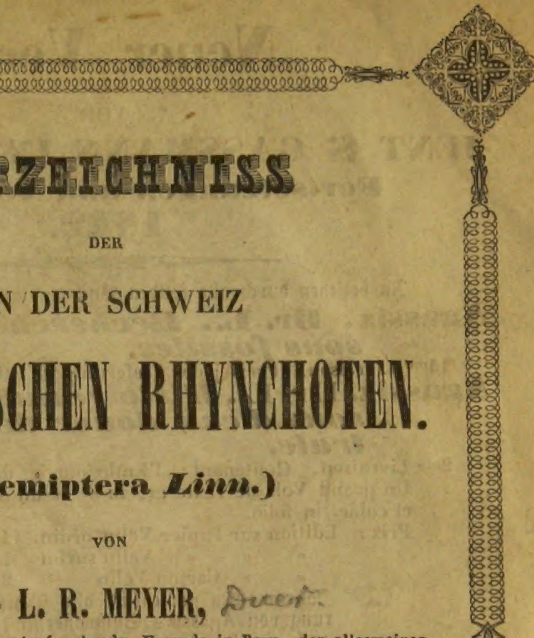 \\ L. R. MEYER, Ducer?
}

Mit 7 colorirten Steindrucktafeln.

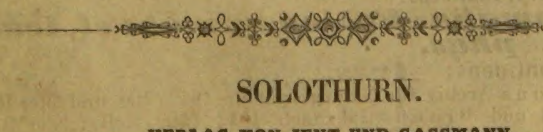

VERYAG VON JENT UND GASSMANN.

1948. 


\section{Neuer Verlag}

Von

\section{JENT \& GASSMANN IN SOLOTHURN. Fortsetzungen und Neuigkeiten. 1812.}

Bu beziehen burd) alle foliden Budhandungen : Agassin, Dr. De, Hecherches sur les Pois-

14me Livraison. Preis jeder lieferung 10 Rthlr. $-18 \mathrm{fl}-36 \mathrm{tr}$.

Agassiv, Dr. H., Histoire naturelle des Poissoms d'eau douce de burope cenbrale.

2me Livraison. Contenant: l'Embriologie des Salmons par C. Vog t. Un grand Vol. de Texte gr. in-80 et un Atlas de 16 planches lithogr.
et color. in-folio.

Prix : Edition sur Papier Velin ordin. $10 f_{2}$ Rthlr, $-18 \mathrm{fl},-36 \mathrm{ffr}$.

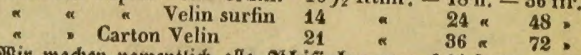

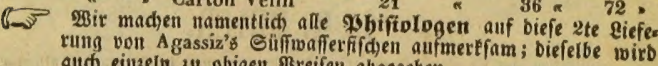

\section{A oragcio and einzein zit obigen Breifen abgegeben. \\ Agassiz, Dr. L., Mlonographies d' Echino-} dermes vivams el fossiles. 2me Livraison. Contenant les Scutelles. $111 / 3 \mathrm{Rthlr}-19 \mathrm{fl}-40 \mathrm{fr}$. par M. Desor. 7 Rthlr. $-12 \mathrm{fl}$. $24 \mathrm{fr}$.

4me Livraison. Contenant l'Anatomie du genre Echinus par M. Valentin. 7 Rthlr. - $12 \mathrm{fl}$. $-24 \mathrm{fr}$.

Die t te siefetung diefer Monograpbien (les Salénies) eríchien im voriaen Safre, und toftet 2 Rtift: 20 ggt. $-5 \mathrm{ft},-10 \mathrm{ft}$. Gebe Eleferung biloet

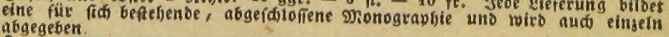

\section{Agassiz, Dr. I., Etudes critiques sur tes} Mollowimes possiles.

2me Livraison. Contenant les Myes du Jura et de la Craie Suisse ter Partie 14 Rthlr. - 24 fl. $-48 \mathrm{fr}$.

Die exfet Rteferung, entfaitend: les Trigonies du Jura et de la Craie Suisse,

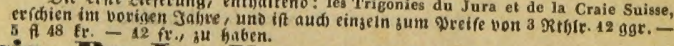

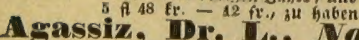

Continens Nomina Systematica gomenclator aDologreas, fossilium. Fasc. I, continens:

\section{Hamalia, Echinotermata et Acale-
phas.}

\section{Fasc. II., continens: Aves.}

W ie $g$ m a n $\mathbf{n} s$ Archiv für Naturgeschichte 1842 (2tes und 3tes Heft), Leonhards und Bronns Jahrbuch 1842 (Ltes Heft), die Revue Zoologique par la Société Cuvierienne, Paris 1842, und viele andere deutsche, französische und e nglische Zeitschriften haben schon der 1ten lieferung mit Ruhm erwähnt, die fleissige sorgfältige Arbeit sehr gelobt und auch das Verdienstvolle derselben, durch welche so vielen Wïnschen entsprochen wird, gehörig gewürdigt und anerkannt.

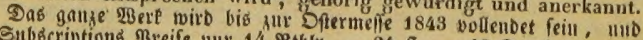

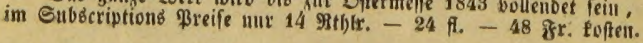




\title{
VDREDICHNISS
}

DER

\author{
IN DER SCHWEIZ
}

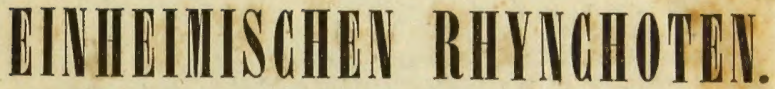

\section{(Hemiptera Linn.)}

\section{VoN \\ L. R. MEYER,}

Mitglied der Gesellschaft naturforsehender Freunde in Bern, der allgemeinen schweizerischen Gesellsehaft für die gesammten Naturvissenschaften, und des entomologischen Vereing zu Steltin.

$\rightarrow 2020080$

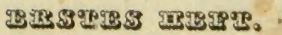

DHE FAUIME DER CAPSHN.

Mit 7 colorirten Steindrucktafeln.

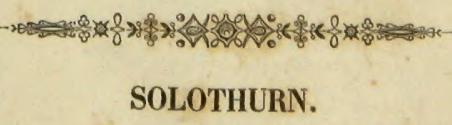

184. 
Ent

27/10 /18

QL523 Ed
C2M6

Ent.2225 
Seinem hochgeschätzten Freunde und Collegen,

$$
\text { dem Herrn }
$$

\title{
अ.
}

Professor der Zoologie und vergleichenden Anatomie zu Genf,

Dem eifrigen, gründlid)en und um die gefonmte Entomologie fo bod)uerdienten forfder,

widmet

\section{aus reiner Verelnrung}

\author{
dieses erste Heft
}

exgebenft 


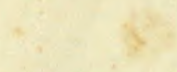

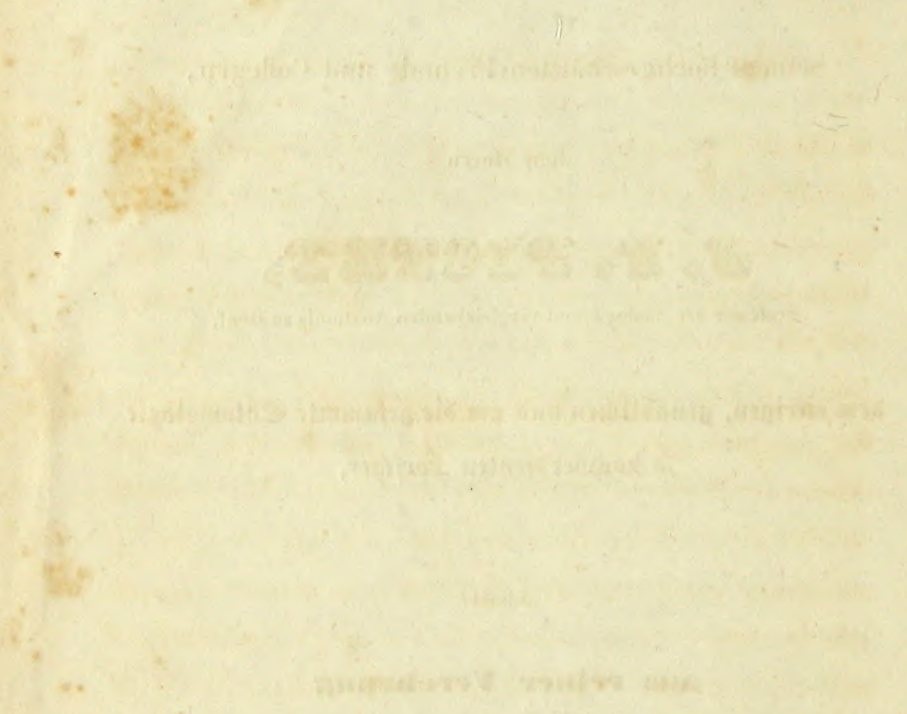


In der Sitzung der schweizerischen Gesellschaft für die gesammten Naturwissenschaften in Lugano, im Jahr 1853, wurde beschlossen, die Zoologen aufzufordern, eine möglichst vollständige Fauna der Schweiz zu bearbeiten. Diese Aufgabe wurde bereits für die Wirbelthiere durch Professor Schinz, für die Mollusken durch Herrn Charpentier, für die Coleopteren durch Herrn Professor Heer gelöst. Allein noch bleiben die übrigen Ordnungen der Insekten, so wie auch die Ringelwürmer, die Crustaceen, Arachniden und Zoophyten übrig. Zwar haben die meisten Ordnungen ihre Bearbeiter unter den Mitgliedern der Gesellschaft, so z. B. die Orthopteren an Herrn Dr. Imhoof in Basel ; für die Lepidopteren finden sich mehrere Liebhaber ; die Dipteren bearbeitet Herr Bremi in Zürich, die Hymenopteren die Herren Imhoof und Mieg in Basel; die Neuropteren beschäftigen vorzüglich Herrn Professor Julius Pictet in Genf, der schon vortreffliche Arbeiten darüber geliefert hat. Herr Nicolet in Neuenburg gibt so eben eine Monographie der Podurellen heraus. Mit der Ordnung der schweizerischen Rhynchoten beschäftigte sich bis dahin in der Schweiz Niemand ausschliesslich, obgleich diese Ordnung in den neuesten Zeiten mehrere Entomologen, namentlich in 
Deutschland, bearbeiten; und doch ist dieselbe auch bei uns sehr reich. Die Rhynchoten sind in mancher Beziehung höchst merkwürdig und selbst für unsere Oekonomie nicht unwichtig. Zwar im gemeinen Leben verachtet und verhasst, bieten sie dem Naturforscher durch ihre Lebensart und durch ihre auffallenden Kontraste eine Fülle der anzichendsten Beobachtungen dar. Herr Meyer wandte alle seine Mussestunden diesem Studium zu ; es gelang ihm, eine grosse Menge neuer Arten zu entdecken und ein sehr reichhaltiges Verzeichniss schweizerischer Arten aufzustellen, welche er den Entomologen bekannt machen will. Seine Arbeit ist mit schönen und getreuen Zeichnungen geziert, welche den Meister und ächten Forscher bewähren. Das Werk hätte daher ohne weitere Empfehlung auftreten können, da es sich selbst bezeichnet nnd mit Vergnügen aufgenommen werden wird. So viel glaube ich mit völliger Ueberzeugung aussprechen zu dürfen, es gehört unter die am fleissigst bearbeiteten und besten, welche wirklich bestehen, und wird gewiss von Kennern als solches gewürdigt und anerkannt werden. Möge Herrn Meyer's Fleiss durch diese Anerkennung die Belohnung finden, welche er verdient.

Zü̈rсн, im Juni 1842. 


\section{VOR WORT'}

Keine Insektenforschung ist bis jetzt von unsern Entomologen weniger beachtet worden, als diejenige der Schnabelkerfe (Rhynchota); was Sulzer, Füessli und Schellenberg uns darüber in kärglichen Bruchstücken hinterlassen haben, verdient im Vergleich mit den kurz darauf erfolgten Leistungen im Auslande, eines Fabricius, Fallèn, und Latreille, keiner Erwähnung. Füiessli in seinem Verzeichniss der ihm bekannten schweizerischen Inselten (Zürich 1775) kannte im Ganzen nur 90 Arten, wovon 50 Cimiciden, 19 Cicadarien und 21 Phytophthiren. Die Artenkenntniss, so wie ein systematischer Ueberblick fehlte unseren damaligen Vorfahren ganz, und nur hier und da wurden auffallende Einzelnheiten, gleich Edelsteinen, aus dem gesammten Bereiche herausgerissen, weil irgend ein physiologisches Problem sowohl den Naturforscher als den Oekonomen zu einer näheren Ergründung angereğt hatte.

Die unermüdeten Beobachtungen eines Bonnet, Réaumur, Degéer, über das wundervolle Leben der Blattläuse, hatten indess, bei der eben aufkeimenden Wissenschaft, schon mächtig die Liebe für entomologische Studien erweckt; allein mögen es schiefe Ansichten unserer damaligen Beobachter, Nichtwürdigung der meist unscheinbaren Formen und Vorurtheile gegen das Wanzengeschlecht überhaupt, das seltene Auffinden der ersten Stadien, das wenig Auffallende der Metamorphosen oder die schwierige Erziehung und Conservation einzelner Rhynchoten-Familien gewesen 
sein, es wurden ihre Arbeiten unvollendet zu Grabe getragen, und kein schweizerischer Entomologe hat seit jener Zeit um diesen Theil der einheimischen Insektenkunde weder als Faunist, noch als Monograph sich ausschliesslich bekümmert. Die Folge davon ist daher jetzt :

Ein fühlbarer Mangel an Sammlungen und wissenschaftlichen Notizen, welcher die Artenkenntniss erschwert und nur langsam, mit vielen Hindernissen, den Faunisten einem Resultate mühsamer Bestimmungen entgegenführt. Obgleich ich nun, aus besonderer Vorliebe für die Rhynchotenkunde, es mir zur Aufgabe gemacht habe, die schweizerischen Arten, so weit sie mir bekannt geworden, aufzuzählen, so erwarte Niemand eine gleichwerthige Arbeit mit Heer's Fauna Coleopt. oder einer Flora von Hegetschweiler u. s. w. , sondern einen ersten, schwachen Versuch einer Grundlage, ohne die entferntesten Ansprüche auf Vollständigkeit, indem auch ich keine andere Anerkennung erwarten darf, als dass meine weit fähigeren Kollegen mit Nachsicht die vielen Mängel mit meinen guten Bestrebungen ausgleichen mögen.

In anatomische Details über die Rhynchoten mich einzulassen, und eine dahin bezügliche Schilderung voranzustellen, wäre hier weder der Ort, noch ist es je meine Tendenz gewesen; dagegen kämpfte es lange in mir, ob ich ein Rhynchotenverzeichniss der ganzen Schweiz, oder vorläufig nur dasjenige meines beschränkteren, heimathlichen Bodens, des Emmenthals, entwerfen sollte. Letzteres, nachdem ich das ganze Thal nach aller Möglichleit an Arten erschöpft hatte, war bereits voriges Jahr ausgearbeitet, als mir in Zürich an der Versammlung der schweizerischen naturforschenden Gesellschaft nicht nur eine Menge neuer, einheimischer Arten, sondern auch durch die nähere Bekanntschaft der thätigsten Entomologen 
so viele objektive und wissenschaftliche Mittheilungen zu Theil wurden, dass ich den Entschluss fasste, mein Verzeichniss auf die granze Schweiz auszudehnen, um ein desto reichhaltigeres Cader einer Rhynchoten-Fauna zu erlangen. Was mir bis jetzt unbelannt oder unzugänghlich geblieben, hofle ich später in einem Suplemente nachfolģen zu lassen.

Auf diesem Fusse allein liönnen wir der Kenntniss der cinheimischen Arten allmälig näher liommen, und indem ich das bereits Erfahrene hier öffentlich meinen Freunden und Follegen, den Herren Dr. Imho/f in Basel, Menzel in Gelterlinden, Bremi und Prof. Ireer in Zürich, Seiler in Schaffhausen, Major Amstein in Malans, Buess in Genf und Coppier in Bonneville, verdanle, bitte ich sie, auch ferner durch ihre Mittheilungen in diesem Gebiete mir hülfreich an die IIand zu ģehen.

Die Ilerausgabe dieser Fauna geschicht nun nach folgendem Plane :

1) Sie erseheint lieferungsweise in zwanglosen IIeften, wovon ein jedes wenigstens eine Famille, und wenn es der Umlang erlaubt, cine ganze Zunft enthalten soll.

2) Es wird das System von Prof. Burmeister zum Grunde gelegt, in der Art jedoch, dass ich nicht an die Reihenfolge der Zünfte und Familien mich binden, sondern diese je nach dem Bestande meiner materiellen IIülfsmittel herausgeben werde. - Demnach licfere ich zuerst die Ahtheilung der Ilemiptera heteroptera Latr., (ich nenne sie in der Folge blos Cimiciden, unter welchem Namen zwar Latreille nur einige Familien zusammenfasste), und beginne dieselbe mit der V. Familie der Geocoren, den Capsinen, als der artenreichsten, und in welcher auch meine Sammlung; am vollstindigsten ist. Ein systematisches Register 
in Burmeister's Reihenfolge wird dann am Ende erscheinen.

5) Jede in der Schweiz einheimische Art, welehe irgendwo schon beschrieben oder abgebildet ist, wird blos mit einer kurzen deutsehen Diagnose und mit den dazu gehörigen Citaten und Synonimen anģeführt, dann folgen die Angaben über geographisches und periodisches Vorkommen in der Schweiz, so weit mir solches bekannt geworden *). Unter sich ähnliche, dubiose und ganz neue Arten sollen auch mit einer deutschen, vergleichenden Beschreiloung auseinandergesetzt und abgebildet werden.

*) In das Bereich der schweizerischen Fauna habe ich übriggens auch alle diejenigen Arten aufgenommen, welche mir durch IIr. Prot. Coppier in Bonneville aus dem Gebiete von Faucigny und Chablais zugänglich geworden sind, obschon jene Gegend nicht mehr innerhalb der politischen Grenzen der Schweiz grehört, so kann sie doch naturhistorisch durch keine Scheidelinic von dem Becken des Genfersec's getrennt werden.

Burgdonf, im Juni 1842. 


\section{Ueber die wanzenartigen IRhynchoten (Cimi- ciden, Ifemiptera heteroptera thatr.) in Algemeinen.}

Die Cimiciden bilden eine grosse, durch ihren Gesammibau deutlich und scharf geschicdene Abtheilung der Rhynchoten, welche Latreille, unter dem Namen IIemiptera heteroptera, einer andern, gleichwerthigen Abtheilung, IIemiptera homoptera, gegenüberstellte. Die ersteren sind es also, welche für jetzt uns beschäftigen sollen.

Sie theilen sich durch die Natur selbst wieder in zwei Ilauptgruppen oder Zünfte : Landwanzen, Geocores, und Wasserwanzen, Hydrocores. Beider Zünfte äussere Hauptcharaktere sind : Die eigene gekreuzte Lage der aus zwei getrennten Substanzen, dem lederartigen Theil und dem hautartigen Anlıang, bestehenden Flügeldecken; ein meistens kleiner Kopf, dessen Spitze sich abwärts nach hinten in einen beweglichen und gegliederten Saugrüssel umbiegt, in welchem die Mundtheile in Form von Borsten liegen, 5 - bis 5̈gliederige, oft geknickte Fülıler; dümne Beine nit 2 bis 5 Tarsengliedern; ein ausnehmend verschieden gebildeter Thorax, durch ein eben so verschieden gebildetes oder auch ganz fehlendes Schildchen (Scutellum) mit dem Ilinterleib verbunden; und endlich eine stets unvollkommene Verwandlung. 


\section{$-12-$}

Durch den Bau ihrer Mundtheile sind die Wanzen zu ihrer Ernährung auf blosses Aussaugen thierischer und vegetabilischer Säfte angewiesen, und stehen aus diesem Grunde im Range organischer Vollkommenheit weit unter den Colcopteren und noch tiefer unter den Ilymenopteren, welche letztere mit höher ausgebildeten Organen auch weit mehr Instinkt und Intelligenz verrathen. Die Wanzen sind theils Lauf-, theils Schwimmthiere; und obschon die meisten auch zum Fliegen gefaltete, hautartige Flügel unter den Decken besitzen, so haben doch diese Motionsorgane weder die leichte Entwickelungsfähigkeit, noch den Zweck, sie zu eigentlichen Schwebthieren zu gestalten, indem ihr Flug niemals anhaltend, sondern blos als eine momentane Hülfe und Erleichterung zu betrachten ist.

Ueber die ersten Stadien wissen wir sehr Weniges. Die Verwandlung ist bei allen unvollkommen. Das junge Thier, wie es dem Ei entschlüpft, hat schon die Gestalt des ausgewachsenen, nur statt der Flügel und Decken kleine Rudimente, mehrentheils auch ein Tarsenglied oder zwei weniger, bewegt sich aber auf gleiche Weise, nährt sich durch alle Stadien hindurch, und es ist schwer zu entscheiden, ob man bis zu seiner vollkommenen Entwicklung es Larve oder Puppe nennen soll.

Betrachten wir das Verhältniss dieser Thiere zur Aussenwolt in Bezug der klimatischen Wirkung im Allgemeinen, so zeigt sich auch hier wieder die bekannte Regel der ganzen organischen Schöpfung, dass tropische Gegenden weit grössere, vollkommenere, prachtvollere Formen une Kolorite hervorbringen, als unsere gemässigten und kalten Zonen. Auch scheint unter eben jenen heissen Hlimmels- 
strichen die Natur auf den gleichen Typen in weit grösserer Manigfaltigkeit, bei uns dagegen in verhältnissmässig mehr Formen sich versucht, und Grösse, Schönheit und Artenmenge weniger berücksichtigt zu haben. Doch tragen schon unseres üdlich europäischen Cimiciden an sich das Gepräge einer üppigen Farbenpracht, und die den Süden Europa's charakterisirenden Scutelleriten, Pentatomiden, Reduvinen, Coreoden und Lygaeoden lassen oft ihre nahe Verwandtschaft mit afrikanischen und asiatischen Gattungen nicht melır verkennen.

Früher glaubte ich für die vertikale Verbreitung der Ilemipteren bestimmte Regionen bezeichnen zu können ; allein diese Vertheilung auf verschiedene Höhen, wie IIeer bei den Coleopteren sie beobachtete, fand ich bei unserer Ordnung ganz unzulässig, und derPhysiologie dieser Geschöpfe darum entgegen, weil sie melır Bewohner des Flach- und Hügellandes sind, und die Alpen so wenig eigenthümliche Arten beherbergen, dass ihre Fauna im eigentlichen Sinne des Wortes mir nur als eine Verkümmerung der tieferen Regionen vorkam. - Selbst auch in Bezug der horizontalen Verbreitung ist es im Einzelnen noch unmöglich, Grenzen auszumitteln, und in meinen Angaben für die Schweiz musste ich mich darauf beschränken, nur alle mir bekannten Stellen anzugeben, wo ich die Arten selbst aufgefunden, oder die mir von bewährten Sammlern mit Einsendung der Exemplare angezeigt wurden. - Es geben also meine Lokalitätsangaben nur Winke über das Charakteristische der Wohnplätze, über die Beschaffenheit des Bodens, der Vegetation, des Klima's, des Geländes überhaupt, in welchem die Arten mehr oder weniger einheimisch und vor- 


\section{- 14}

herrschend auftreten, und der wissenschaftliche Gewinn, der hieraus hervorgeht, kann sich nur insofern ergeben, als der Beobachter die nämlichen Arten unter ähnlichen Verhältnissen auch anderwärts wieder findet und durchgreifende Resultate darüber auffassen kann. Gleichwohl sind solche Angaben im Bereiche einer Fauna von unverkennbarem Werthe, und wenn auch schon zuweilen bei neuen oder selir seltenen Arten ich dic Fundorte mit einer, oft kleinlichen, Genauigkeit angezeigt habe, so wird dem Sammler das Wiederauffinden nur um so leichter, und für die Kenntniss der geographischen Verbreitung ist jedenfalls mehr gethan, als wenn z. B. Fabricius uns kurzweg sagt: "habilat in Europa plantis".

In Europa scheinen mir übrigens die Cimiciden weit weniger, als andere Insckten nur strichweise vertheilt, oder auf bestimmte geographische Punkte beschränkt zu sein, sondern ihr mehr oder minder häufiges Auftreten an verschiedenen Stellen scheint eher von einem analogen Zustande der höheren Pflanzenwelt abzuhängen. Daher besitzt der Norden am wenigsten eigenthümliche Arten; seine meisten Rhynchoten sind auch im Süden Europa's einheimisch. Ganz anders ist das Verhältniss in umgekehrten Falle. Südfrankreich, Spanien, Portugal und Italien haben auch nördliche Arten, und unsere Schweiz vereinigt aus allen diesen Faunen so Verschiedenartiges, dass, wann einst unsere Hochthäler und Juraverzweigungen in dem Maasse hemipterologisch erforscht sein werden, wie es bisher blos in anderen zoologischen Zweigen geschah, allem Anschein nach dieser Theil der einheimischen Fauna eine ausserordentliche Reichhaltigkeit an Arten her- 
ausstellen wird; fanden wir ja doch auf unserem kleinen Flächenraume schon über zwei Drittheile aller in Europa bis jetzt bekannt gewordenen Cimicidenarten.

Vergleichen wir das Zahlenverhältniss aller bis jetzt bekannten und beschriebenen Cimiciden, so ergibt sich folgende Uebersicht :

Wir kennen bis jetzt in Europa an . . 540 Species, auf dem übrigen Erdball noch etwa . . 1480 ”

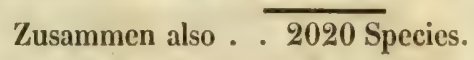

Ilievon vertheilen sich die Familien, wie folgt: In der Schweiz. In Europa überhaupt. In den übrigen

\begin{tabular}{|c|c|c|c|c|c|}
\hline Notonectici & . & 10 & . & 18 & . . \\
\hline Nepini . & . & 3 & . & 6 & 55 \\
\hline Galgulini & & - & . & 1 & 10 \\
\hline IIydrodromic & & 9 & . & 20 & 25 \\
\hline Riparii & & 7 & . & 25 & - \\
\hline Reduvini & . & 13 & . & 29 & 319 \\
\hline Membranacei & & 36 & . & $65^{\circ}$ & 47 \\
\hline Capsini. & & 123 & . & . 160 & 63 \\
\hline Lygoeodes & ${ }^{\circ}$ & 65 & - & 75 & 145 \\
\hline Coreodes. & . & 52 & . & 52 & .555 \\
\hline Scutati & . & 60 & . & 89 & . 496 \\
\hline
\end{tabular}

Auffallend sind hier die Missverhältnisse bei den Galgulinen, Nepiniden, Reduvinen, Coreoden und Scutaten, welche den Europäern an Artenzahl weit überlegen sind. Ziemlich gleich über alle Erdstriche vertheilt, sind die Ilydrodromiciden. Dagegen sind wieder in Europa artenreicher : die Notonecticiden, die Membranaceen, die Capsinen, welche letztere einen Drittheil aller europäischen 
Wanzen ausmachen, und besonders die Riparien, welche unserem Welttheil, und zwar den gemässigten und nördlichen Klimaten, eigenthümlich sind. Unter den Membranaceen haben wir die Tingiditen und Araden vorherrsehend. Von letzteren sind ausser in Europa und Nordamerika noch keine Arten bekannt; und endlich unter den Lygæoden war das Genus Anthocoris (Rhynarius IIhn.) bis jetzt einzig unserem Weltheil vorbehalten:

Es ist allerdings anzunchmen, dass obige Vertheilung auf die übrigen Weltheile in ihrer Wirklichkeit wohl zu schwach angegeben ist, und dass durch die vielen, jetat reisenden Zoologen diese Zahl noch um ein Bedeutendes anwachsen wird; allein im gleichen Verhältnisse kann es sich auch in Europa noch herausstellen, wo grosse Länderstrecken in zoologischer Beziehung noch lange nicht erschöptt sind.

\section{Weber die systematische Wintheilung.}

Bei dem grossen Anwachs der in neuester Zeit bekannt gewordenen Rhynchoten war eine schärfere Sichtung der Gruppen, als solche von Linné, Fabricius und späteren Systematikern aufgestellt worden, ein dringendes Bedürfniss. Nach vielen, zum Theil sehr misslungenen Versuchen erschien im Jahr 1855 im 2 ten Bande von Burmeister's Handbuch der Entomologie eine Anordnung, die, obschon wie alles Zeitliche, auch seither durch neue Entdeckungen wieder mangelhaft geworden, dennoch jetzt allgemein angenommen, und als die beste Grundlage zu befolgen ist. 
Hier folgt die Uebersicht seiner Zünfte sämmtlicher Rhynchoten, hernach diejenige der Familie der Cimiciden besonders.

A. Flügel fehlen. Fühler 5̈gliederig. 1ste Zunft:

B. Flügel vorhanden.

pediculina.

a) Flügel ohne Zellen, dem Weibchen gewöhnlich fehlend. Fühler 6-25gliederig. 2te Zunft:

b) Flügel mit Zellen.

coccine.

1) Mundöffnung zurückgezogen, so dass der Schnabel am Grunde des Kopfes entspringt. Füsse 2 gliederig, Fühler lang, 5 -10gliederig. 5te Zunft: Phythophohires. Füsse 5gliederig, Füller klein, borstenförmig, 5-6gliederig. LteZunft: Cicadinu.

2) Mundöffnung nach vorn gerückt, so dass der Schnabel am Vorderrande des Kopfes entspringt. Fühler klein, in Gruben unter den

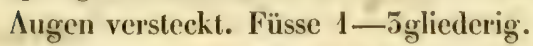
šte Zunft: Arydrocores.

Fühler gross, deutich hervortretend, wenigstens hallb so lang als der Leil). Füsse meist 5 gliederig. 6te Zunft: Geocores.

Uebersicht der Familien der 5̈ten und 6ten Zunft: die

\section{Cimeiciden.}

A. IIydrocores. Wasserwanzen.

a) Ohne Nebenaugen.

Vorderbeine keine Raubfüsse. Iste Familie:

Notonectiei. 
Vorderbeine Raubfüsse. 2te Familie: Nepissi.

b) Mit Nebenaugen. 5̈te Familie: Calgulimi.

B. Geocores. Landwanzen.

A. Schnabelscheide 5yliederig. Keine Haflappen neben den Krallen.

a) Schnabel mehr oder weniger abstehend, nie in einer Rinne versteckt.

1) Kopf olne halsförmige Zusammenschnürung hinter den Augen.

Kralle klein, in einem Ausschnitte vor der Spitze des letzten Fussgliedes. Lte Familie:

Iydrodromiex.

Krallen gross, frei, unmittelbar an der Spitze.

5̌te Familie: Riparid.

2) Kopf mit frei sichtbarer halsförmiger Verengung hinter den Augen. 6te Familie:

Ieduvind.

b) Schnabel versteckt in einer Rinne an der Kehle,

Glieder von gleicher Länge. 7te Familie:

Thembranaced.

B. Schnabelscheide 4gliederig. Neben den Krallen sitzen 2 kleine Haftlappen.

a) Schildehen klein, erreicht die Mitte des Ilinterleibes nicht.

1. Fühler borstenförmig, das letzte Glied haarfein. Keine Nebenaugen. 8te Familie:

Capsine.

2. Fühler faden - oder keulenförmig. Nebenaugen meistens vorhanden.

- Fühler an der Unterseite des Kopfes eingelenkt.

9te Familic: Lygaeodes. 
- Fühler an der Oberseite des Kopfes eingelenkt.

10te Familie: Coreodes.

b) Schildchen gross, reicht bis zur Mitte des Hinterleibs oder darüber hinaus. 11te Familie:

Scutati.

Hier muss ich nur bemerken, dass, weil Burmeister die Zünfte als getrennte, selbstständige Abtheilungen behandelt, die Zahlordnung seiner Familien auch bei den Geocoren wieder mit 1 anfängt, so dass unsere 11 te Familie der Cimiciden bei ihm die 8te der Geocoren ist. -

\section{Ueber den Fang und die Conservation der Cimiciden.}

Zum Sammeln dieser Thiere eignet sich mehr oder weniger jede Jahreszeit, je nach den Familien, Gattungen oder Arten, deren Erscheinungsperioden verschieden sind. Einige finden sich das ganze Jahr hindurch unter Moos, Baumrinden, Steinen u. s. w. wie Nabis, Pachymerus und Mananthia. Viele erscheinen nur im ersten Frühjahre, andere blos im Sommer, einige erst in den letzten Ilerbsttagen, wie Lopus tunicatus Germ. und noch andere rom ersten Frühjahre hinweg bis Ende Octobers in allen Verwandlungsstufen und in ununterbrochener Fortpllanzung, wie Lygaus equestris, Ieterogaster claviculus, Aelia aceuminata, Nabis subapterus und die meisten Anthocoris-Arten. Der grösste Theil jedoch zeigt sich in den Monaten Mai, Juni, Juli und August.

Un diese Zeit besuche man schon des Morgens nach $9 \mathrm{Uhr}$, sobald der Thau abgetrocknet ist, sonnigte, blumenreiche Feldbörder, die Abhänge abgeholzter Waldhïgel, wo Unkraut aller Art in grosser Menge wuchert 
und die Winde nicht hingelangen; ferner unebene Pflantstellen, insonders wo kleine Bäche oder feuchte Thalgründe mit Weidengebüsch sich in der Nähe befinden, lichte Waldplätze, wo viel Ginster, Ileidekraut, Weidrich, Nesseln u. dgl. wachsen, grosse Gartenanlagen mit üppigen Gesträuchen, die Ufer stiller Gewässer, im Schilfe, auf feuchtem Sande, auch in verwilderten Gräben und Felsschluchten, die noch von der Sonne beschienen werden, macht sich in der Regel eine sehr gute Ausbeute. Im ersten Frülijahre und zu Ende des Herbstes suche man unter der Rinde gefïllter Baumstöcke und unter losen Steinhaufen. - Im Winter bei gelindem Wetter unter Moos, Rinden, Brettern und Laub. - $\Lambda$ n allen solchen Stellen findet man Landwanzen. - Die Wasserwanzen erhascht man auf kleinen Teichen und Tümpeln, auch im Schlamm zwischen den Binsen. - Dergleichen StelIen besuche man wohlansgerüstet mit folgenden Geräthschaften :

11) ein Garn (Schöpler) ron dichter, starker, weisser Leinwand, in Form eines Schmetterlingsgarnes, doch weniger tief. - Mit diesem Schöpfer wird in allem Marschieren seitwärts über das Gras und die Gebüsche hinweg gemäht, wobei Alles in den Sack fällt. Hat man cinige Züge gethan, so nimmt man :

b) eine blecherne Büchse, deren Deckel sich in einen Hals ausmündet, der noch einen Zoll innerhalb hinabgeht und oben mit einem Kork verschlossen wird. Im Raume liegt einStück verschrumpftes, weisses Seidenpapier, damit die Insecten in dessen Falten sich verkriechen und gegenseitig nicht beschädigen können. - 
Indem man nun den Stock des Schöpfers zwischen die Beine nimmt und das Garn offen behält, fïhrt man mit der Büchse behutsam hinein und sucht die an allen Seiten heraufkriechenden Cimiciden durch die Halsöffnung fallen zu lassen, bis die ganze Ausbeute ersehöpft ist und man den Kork wieder versehliessen kann. - Diese Fangart gilt besonders bei kleinern, weichen und sehr zerbrechlichen Arten, z. B. den Capsinen, Tingiditen, Anthocoris u. s. w. Grössere, stark gebaute und solide Arten, wie Coreoden, Seutelleriten, Lygæoden u. dgl. können entweder in eine besondere Büchse mit Moos geworfen, oder sogleich beim Fange aufgesteckt und gelegentlich mit Schwefeläther getödtet werden. - Bei Hause angelangt, werden sämmtliche Büchsen etwa 2 Minuten lang in heisses Wasser getaucht, die darin erstickten Thiere hernach auf ein weisses Papier geleert und nach einer Stunde ungefähr, wann ihre weichern Theile etwas mehr Consistenz erhalten haben. mit Gummi auf kurze, zugespitzle Papierstreifchen geklebt, die zuvor schon in 2 Drittel Höhe an Stecknadeln gebracht sind. - Sind die Thiere fest angetrocknet, so werden mit einem Ilaarpinsel Fühler und Beine auswärts gestrichen. Manche Entomologen zichen vor, ohne Unterschied grrosse wie kleine Arten aufzustecken, allein, abgerechnet, dass es bei den Letzlern sehr schwierig ist, ohne die Flïgeldecken zu verspreizen und den durehgestochenen Theil zu verletzen, oder die Zeichnung zu verdecken, ist auch noch der Einwurf zu machen, dass der geringste Ansatz von Grünspan bei so kleinen Arten nicht so leicht wieder z.n entfernen ist und somit das Exemplar unbrauchar macht. Bei mehrtägigen Excursionen oder bei sehr schwülem 


\section{- $22-$}

Wetter darf man die Cimiciden nicht zu lange in der Büchse lassen, weil durch die grosse Anzahl von Individuen die Ausdünstung darin so stark würde, dass die kleineren Arten an den nassen, innern Wänden anklebten und sich völlig zu Grunde richteten. Entweder besorge man jeden Abend die gemachte Ausbeute zurecht, oder man führe eine kleine Schachtel mit mehreren Schichten weisser Seidenwatte mit sich, zwischen welchen die todten Insekten sich lange frisch erhalten. Ist die Ausbeute aufgesteckt oder aufgeklebt, so lässt man sie bei Hause b’-10 Tage, auf Reisen wenigstens immer die Nacht über in den offenen Schachteln austrocknen. Mittlerweilen werden die Arten bestimmt und entweder auf den Zetteln selbst oder in einer besondern Kontrolle die nöthigen Notizen über Fundort, Erscheinungszeit, mehr oder minder häufiges Vorkommen u. s. w. angemerkt und endlich nach jedem beliebigen Systeme in die Sammlung geordnet. - Die Cimiciden beim Fange in Weingeist zu werfen, taugt durchaus nichts, denn von unseren europäischen Arten werden dadurch die meisten in der Farbe verändert, und die Membran schlägt sich um oder klebt verschrumpft wie nasses Papier zusammen. Hinsichtlich der Exemplare sei man nicht zu strenge gegen einzelne Fehler und glaube ja nicht, dass z. B. eine Wanze, welcher ein Füller oder ein Bein fehlt, für das Studium nicht gleichwohl brauchbar sei. Die Capsinen sind so zart gebaut, dass bei dem leisesten Anfassen Fühler und Beine abfallen und es wirklich einiger Uebung und Fertigkeit erfordert um solche vollständig zu erhalten.

Unbrauchbar wird ein Exemplar erst dann, wann 2 analoge Theile ihm ganz fehlen, wenn die Membran zer- 
rissen oder die Behaarung der Decken abgerieben ist. In letzterem Falle kann man in den Bestimmungen sehr leicht irre werden.

Was nun die Bestimmung selbst anbetrifft, so ist hier wie in der gesammten Entomologie die grösste Behutsamkeit zu empfehlen; denn so lange wir nicht eine umfassende, möglichst vollständige Monographie der Cimiciden besitzen, werden wir aus Fabricius, Wolff, Fallèn, IIahn u. s. w. uns nicht immer genügende Ueberzeugung verschaffen können, und desshalb werden oft identische Arten von verschiedenen Autoren unter eben so verschiedenen Namen bekannt gemacht, was eben den Uebelstand der Synonimie hervorbringt.

Ferner sind auch folgende Punkte wohl zu berück-e sichtigen, wenn der Hemipterolog nicht zu voreilig in neu Benennungen verfallen will :

1) Mehrere Arten, besonders die grünen Capsinen der Gruppe Lygus Hhn., verändern nach dem Tode diese Farbe entweder ganz oder nur stellenweise in Gelb. Gewölnnlich wird es der Kopf, der Grund des Thorax, der Aussenrand des Clavus und die Beine. - So mag z. B. der IIaln'sche Lygus icterocephalus aus einem Capsus nassatus oder pabulinus entstanden sein.

2) Andere Arten, besonders die Pachymeren, werden öhlicht, und alle hellen Farben nehmen dadurch einen dunkeln, fettglänzenden Ton an, der die bunteste Zeichnung unkenntlich macht.

5) Bei den Arten aus der Gruppe von Capsus magnicornis, pulserulentus, ambigmus, Gyllenhalii u. \&. w. 
gehen leicht die goldgelben, schuppenartigen Härchen auf den Elytern weg, die dann glänzend, schwarz oder braun erscheinen.

4) Einige findet man in der Regel mit unentwickelter oder ganz fehlender Membran, wie Pachymerus pictus, staphylinoides, Rhopalus miriformis, und Aphanus pallipes. Andere ausnahmsweise (gegen die Regel ihrer Art) mit Membran und Flügeln, wie Plalynolus apterus.

5) Mehrere Galtungen, vorzüglich die Pentatomiden und Capsinen, zeigen eine besondere Neigung zum Varieren, und zwar bis ins Unkenntliche. Gewisse Varietäten finden sich bei mehreren Arten sogar konstant, sowohl an besondern Lokalitäten, als überall anderwärts mit der Stammart vermengt. — Dass solcher Varietäten früher und noch jetzt eine Menge zu eigenen Arten erhoben wurden, ist daher keineswegs auffallend, wenn sie nur nach einzelnen Exemplaren oline Vergleichung beschrieben wurden. Dahin gehören z. B. Capsus tricolor varielas von Caps. danicus; Capsus flavicollis var. von ater; Capsus umbellatarum Panz. var. von pratensis; Capsus lateralis und marginatus IIhn. var. von unifuscialus; Capsus rufipes und trifasciatus var. von elaIus. Pentatoma Eryngii germ. var. von nigricorne. - Noch andere zeigen keine so beständigen, sich gleich bleibenden Abweichungen, sondern varieren ohne scheinbare Eimflüsse ins Unendliche. Z. B. Corizus crassicornis, Miris lasigalus, calcaratus und virens, Plylocoris populi, Capsus furcalus, 
varipennis, roseus, variabilis, varians, Anthocoris nemorum, Eurydema oleraceum und mehrere andere.

Bei allen solchen Abweichungen ist es nothwendig, eine möglichst grosse Anzahl von Individuen einzusammeln, um durch genaue Vergleichung derselben mit der Stammart sich den Typus einzuprägen.

Wissenschaftliche Abhandlungen, Systeme, Faunen und Abbildungen von Cimiciden aller $W$ eltgegenden finden sich in einer grossen Anzahl von Schriften, von denen hier nur die bekanntesten der Anciennetät nach erwähnt werden, nämlich :

1. Frisch, Beschreibung von allerlei Insekten in Deutschland. 1750. in $4^{\circ}$. mit Abbildungen.

2. Reaumur, Ménoires pour servir à l'histoire des Insectes. VI vol, in $4^{\circ}$. mit Kupf. Paris 1754-1742. —im 5ten Band einige Cimiciden.

5. Rossi, P. Fauna etrusca insectorum. Liburni 1741. $4^{\circ}$. c. fig.

4. Rösel von Rosenhof, Monalliche Insektenbelustigungen. 4 vol. in $4^{\circ}$. Nürnberg 1746-1761. - Der 5te Band enthält einige Cimiciden.

§. Scheffer, J. Ch. Icones Insectorum cirea Ratisbonam indigenorum. 5 vol. in $4^{\circ}$. Ratisb. 1769.

6. Linné, Systema naturac. Edil. XII. $8^{\circ}$. Holmix 1767.

7. De Géer, Mémoires pour servir ì l'histoire des Insectes. $7 \mathrm{vol}$. in $4^{\circ}$. avec fig. Stockholm $1752-1778$. (Der 5te Band mil Ciniciden.) Dasselbe Werk auch in deutscher Sprache, übersetzt von Götze. 
8. Geoffroy, Histoire abregée des Insectes, qui se trouvent aux environs de Paris. $4^{\circ}$. Paris 1762.

9. Sulzer, J. II. Die Kennzeichen der Insekten. $4^{\circ}$.Zürich 1761. mit col. Kupfern.

10. - Abgekürzte Geschichte der Insekten. $4^{\circ}$. Winterthur 1776-1789. 2 Theile mit Kupfern.

11. Scopoli, J. A. Entomologia carniolica. 1 vol. in $8^{\circ}$. Vindob. 1765.

12. Drury, Illustrations of natural history. London $\mathbf{1 7 7 0}$ -1782.3 vol. in $4^{\circ}$. mit schönen Abbildungen.

15. Stoll, C. Répresentation exactement coloriée d'après nature des Cigales et des Punaises. in $4^{\circ}$. Amsterd. 1780. (Enthält meistens exotische Arten.) Auch in holländischer Sprache.

- Natuurlyke Afbeeldingen de Cicaden en Wanzen. $4^{\circ}$. Amsterd. 1780.

14. Schrank, Fr.v. Paula, Enumeratio Insectorum Austrix indigen: -1 vol. in $8^{\circ}$. cum fig. Vienn. 1781.

15. - Fauna boica. $8^{\circ}$. Ingolstadt 1801-1803. - Der 3te Theil enthält Insekten.

16. Coquebert, J. A. Hllustratio iconographica insectorum, quæ in museis Parisinis observavit et in lucem edidit J. C. Fabricius. in fol. Paris 1799-1804.

17. Thunberg, Dissertatio entomologica novas insectorum species sistens. $4^{\circ}$. Upsalix 1783.

18. - Dissertatio insectorum hemipterorum tria genera illustrante. $4^{\circ}$. Upsaliæ 1825.

19. Fabricius, Entomologia systematica. 4 vol. in $8^{\circ}$. Ilafnix 1794.

20. - Systema Rhyngotorum. 1 vol. in $8^{\circ}$. Brunsviga 1801 . 
21. Latreille, Genera crustaceorum et insectorum. I vol. in $8^{\circ}$. cum fig. Paris 1806-1807. - Vielleicht das gediegenste Werk in systematischer Beziehung. 22. Palisot de Beauvais, Insectes recueillis en Afrique et en Amérique. in fol. avec pl. enlum. Paris 1805. 25. Illiger, J. Ch. G. Magazin für Insektenkunde. 7 vol. in $8^{\circ}$. Braunschweig 1801-1807. - Enthält Mchreres über Cimiciden.

24. Lamark, J. B. Système des animaux sans vertèbres. Paris 1801.1 vol. in $8^{\circ}$.

23. - Histoire naturelle des animaux sans vertèbres. 7 vol. in $8^{\circ}$ Paris $1815-1822$.

26. Fallèn, MonographiaCimicum Suecix.in8 $8^{\circ}$.Hafn.1807.

27. - Hemiptera Suecix. Lund. 1819. 10 Hefte.

28. - Hydrocorides et NaucoridesSuecix. $8^{\circ}$. Lund. 1814.

29. Schellenberg, Das Geschlecht der Land- und Wasserwanzen nach ihren Familien. 8. Zürich 1800.

50. Panzer, $F \cdot \boldsymbol{W}$. Fauna insectorum Germanix, oder Deutschlands Insekten. Bis jetzt 180 Hefte, jedes mit 24 color. Kupfertafeln. Vom 110 ten Hefte an von Dr. IIerrich Schäffer. - Enthält viele Abbildungen von Cimiciden.

31. Wolff, J.F. Icones Cimicum descriptionibus illustratæ. Erlangen 1800-1811. $4^{\circ}$. mit 20 Kupfertafeln.

32. Sahlbery, C.P. Observat. quaed. histor. Notonectidum etc. $4^{\circ}$. Abore 1809.

33. Germar, E.F. Magazin für Entomologie. Halle 181 है. 4 Bde.

54. - u. Ahrens. Fauna insectorum Europæ. Hall. 1815. Bis jetzt 21 Hefte. 
53. Germar, E. F. Zeitschrift für die Entomologie. Leipz. 1859. Der 1ste Band wurde eröffnet mit einer Monographie der Schildwanzen.

56. Schilling, Beiträge zur Entomologie Schlesiens.

37. Eschscholtz, Entomographien in den naturwissenschaftlichen Abhandlungen aus Dorpat. $8^{\circ}$. Berlin 1823.

58. Curlis, Brittish Entomology. Vol. I-XVI. with pl. London 182/4-1858. - Wohl das crste Prachtwerk der Entomologie.

59. II alen, Icones ad monographiam Cimicum. Norimb. 1825.

40. - Die wanzenartigen Insekten, getreu nach der Natur abgebildet und beschrieben. $8^{\circ}$. Nürnberg. Bis jetzt 52 IIefte, jedes mit 6 color. Kupfert. Vom 1 İten Hefte an fortgesetzt von Herrich Schäffer. Ein vorzügliches, zeitgemässes Werk.

44. Zetterstedt, Fauna insectornm lapponica. $8^{\circ}$. Hammone 1828. 1 vol.

42. Lepelletier de St. Fargeau und Audinet-Serville schrieben über Cimiciden in derEncyclopédie méthodique.

45. Schummel, T.E. und Stannius, F. II. Beiträge zur Entomologie, besonders in Bezug auf Schlesien. 2tes Heft, enthaltend: Versuch einer genauen Beschreibung der in Schlesien einheimischen Arten der Familie der Ruderwanzen. (Ploteres Latr.) in $8^{\circ}$. Breslau 1852. mit Abbildungen.

44. Perty, M. Delectus animalium articulatorum, que in itinere per Brasiliam collegerunt J. B. de Spix et C. F. de Martius. fol. Monachi 1850 . 
15.5. Guérin, Insectes in: Dupperrey voyage autour du monde, fait sur la corvette la Coquille. Atlas. Paris 1830.

46. - Magazin de Zoologie. Darin, so wie auch in der

47. - Revue zoologique, Manches über Cimiciden, namentlich von Spinola und Laporte.

48. Bouché, P. F. Naturgeschichte der schädlichen und nützlichen Garteninsekten. $8^{\circ}$. Berlin 1853 . Weniges über Cimiciden.

49. Meyen, F. J.F. Beiträge zur Zoologie, gesammelt auf einer Reise um die Erde. 6te Abtheilung: Insekten, bearbeitet von $\boldsymbol{W}$. Erichson und $\boldsymbol{H}$. Burmeister in den Acta Academ. Cres. Leopold. Carol. nat. curiosorum. Vol. XXI. 4․ Bonn. 1854.

50. Leon-Dufour, Recherches anatomiques et physiologiques sur les Hemiplères. in $4^{\circ}$. Paris 1853 . avec pl. und

51. - dessen Aufsälze in den Annales de la Société entomologique de France.

52. IIerrich Scheeffer, Nomenclator entomologicus. Istes IIeft. Regensburg 1853. - Für Citate und Synonime fast unentbehrlich.

55. Laporte, F. L. Essai d'une classification systematique de l'ordre des Ilemiptères; in Guérin's Magazin de Zoologie.

5\%. Burmeister, H. Handbuch der Entomologie. Ilter Bd. 1ste Abtheilung: Rhynchota. $8^{\circ}$. Berlin $1854 \mathrm{u}$. 1855. - Ein ausgezeichnetes Werk.

85. IIope, Catalogue of Hemiptera etc. with short latin descriptions of the new species. $4^{\circ}$. London 1837. 


\section{- $30-$}

56. Westwood, J. O. Introduction to the modern classification of Insects, founded on the natural habits and corresponding organisation of the different families.

57. Mayazine of natural history .

58. Entomological Magazine.

59. Transactions of the entomological Society of London.

London 1807.

60. Kirby, In der Fauna boreali Americana.

Nach dieser einleitenden Schilderung im Allgemeinen gehen wir nun zu der schweizerischen FaUna der Cimiciden über.

\section{VI' ZUNFT: ACOCOREN. (LANDWANZEN.)}

Die Abweichungen des gesammten Baues bei den Gattungen dieser Zunft sind, wie auch Burmeister sagt, wirklich so manigfaltig, dass kaum ein, auf alle passender, auszudrückender Charakter hervorzuheben ist. Nicht einmal der Name (Landwanzen) ist ganz strenge bezeichnend, indem auch mehrere Gattungen, wie Hebrus, Velia, $H_{y}$ drometra $\mathbf{u}$. a., eigentliche Wasserbewohner sind (die zwar nicht im Wasser selbst leben und schwimmen, sondern blos anf der Oberfläche desselben herumlaufen).

Noch am deutlichsten sind sie wohl durch die meistens 4gliederigen, langen, ganz frei hervortretenden, niemals versteckten Fühler von den eigentlichen Wasserwanzen zu erkennen. Ueberdiess entscheidet auch der Totaleindruck beider Zünfte in der Art, dass wir an den Geocoren un- 
willkürlich etwas Käferartiges, an den Ilydrocoren hingegen etwasCicaden- und Libellenähnliches wahrzunehmen nicht verläugnen können.

Die Nahrung der Geocoren besteht bei den meisten Arten aus blossen Pflanzensäften, bei wenigen anderen aus kleinen Kerfen und selbst aus dem Blute höherer Thiere.

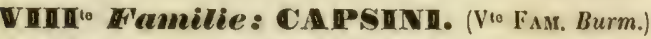 \\ BLINDWANZEN. \\ (Astemmites. Laporte.)}

Diese in der Schweiz so ungemein artenreiche Familie ist unstreitig auch diejenige, die sich durch die zartesten und zierlichsten Formen auszeichnet. Als behende, muntere, stets flüchtige Thiere finden wir die Blindwanzen weit und oft in so grosser Individuenzahl verbreitet, dass wir über ihre so verborgene Fortpflanzung wirklich erstaunen müssen. Sie leben vorzüglich an sehr sonnigen, hochbegrasten Ilügeln und Waldabhängen, auf blumenreichen Wiesen, in Gärten auf Doldenblumen und niedrigem Gesträuche, wo sie sowohl die Blüthensäfte einsaugen, als auch auf kleinere Insekten beständige Jagd machen. Man findet sie nicht weit über die Hügelregionen hinauf. Zwischen 4denn alle lieben eine gemässigte Temperatur. Grosse Ilitze ist ihnen ebenfalls nicht zusagend, daher die 'Tropenländer am wenigsten Arten besitzen. Die meisten erscheinen bei uns mit den letzten Maitagen, mindern allmälig von Mitte Augusts an, bis sich endlich in den ersten Novembertagen im Freien gar keine mehr zeigen. 
Famulen - Cunnakter. Keine Nebenaugen. Fühler 4 gliederig, borstenförmig; das zweite oft spindelförmig verdickt und immer das längste. Schnabelscheide hgliederig, bis ans Ende der Brust reichend. Thorax trapezisch. Schildchen stets vorhanden, gross, doch die Mitte des Ilinterleibes nie überragend. Flügeldecken lederartig, mit einer demSchildchen parallel laufenden Längsfalte(Clavus), einer abgesetzten, dünnern, meist anders gefärbten Spitze (Appendix), an welcher eine noch dünnere, meist durchsichtige Ilaut (Membrana), anhängt*), in welcher zwei bogenförmige Adern eine grössere und kleinere Zelle bilden.

Der Leib weich; die Füsse sehr zart gebaut, mit drei Tarsengliedern.

Burmeister theilte die Capsinen in 7 Gattungen. Es scheinen aber Ileterotoma, Allus, Labobs und Halticus weniger zu Gattungen als zu blossen Gruppen sich zu eignen; daher auch IIerrich Schäffer unter dem generischen Namen Capsus sie vereinigt. Fabricius vermischte als Miris, Capsus und Lygaus oft die heterogensten Gebilde. Fallèn's Gattungen Miris, Capsus, Plyyiocoris sind der Art, dass sie keine standhaften Trennungsmomente darbieten. IIerrich's Eintheilung ist scharf und durchgreifend; nur wäre eine Aufstellung von Gruppen, welche die ungemein schwierigen Bestimmungen in seiner so artenreichen Gattung Capsus bedeutend erleichtern würde, um so zweckmässiger gewesen, als w ohl im ganzen Insektenreiche kcine Abtheilung in so seltsam abweichenden Formen des Typus,

") Nur bei einigen wenigen Arten mit abgestutaten Fliggeldecken fehlt Appendix und Membran, z. B. Bryocoris pteridis. 


\section{- $\mathbf{3 3}-$}

im Ilabitus und im Baue der einzelnen Glieder, in solchem Maasse sich auszeichnet.

Gruppen mit Namen aufzustellen, bin ich, als Faunist eines einzelnen, engbegrenzten Landes, schon darum nicht berechtigt, weil jede Eintheilung ohne Zusammenhang mit den übrigen, noch bekannten Arten ganz nuzzlos und der Wissenschaft entgegen ist. Blos kann ich durch Zusammenstellung der äusseren Aehnlichkeiten eine natürliche Reihenfolge zu bilden suchen, aus der man, beim Bestimmen, sich dennoch zurecht finden wird.

Nach Herrich's Schema (dem ich noch Cryptostemma beizähle) wären die Capsinen in folgende Gattungen einzutheilen :

I. Kopf, von oben gesehen, länger als breit, horizontal; der vertikal stehende Clypeus durch eine Querfurche geschieden.

1 ste Gallung: Mtiris.

II. Kopf, von oben gesehen, breiter als lang, vorn abschüssig.

A. Thorax an den Seiten breit gerandet.

\section{2te Gallung: copus.}

B. Thorax an den Seiten ungerandet.

a) $\mathbf{1}^{\text {tes }}$ Fühlerglied so lang, oder länger, als Kopf und Thorax zusammen. 5te Gattung:

Pleytocoris.

b) $\mathbf{1}^{\text {tes }}$ Fühlerglied kürzer, als Kopf und Thorax zusammen. Lte Gattung: Cupsus.

C. Thorax mil ausgeschweiften Seitenrändern. Mem

bran mit 2 durch einen Quernerv in der Mitte verbundenen Längsnerven. Ste Gallung:

Cryptostemma. 
Ite Gatrung : MiRIS. Fabr.

\section{M. Calcaratus. Fallèn.}

l'allèn. Hemipt. Suec. 151. ॐ̆.

IIuln. Wanz. Ins. Fig. 8. Miris dentata.

IIerrich Sch. Nomencl. ent. $1^{\text {tes }}$ Heft, pag. 47, 81.

Länge $5^{\prime \prime \prime}$. Hattbraun oder grasgrün; die einzige Mirisart mit 2 Dornen an den Hintersehenkeln.

Eine der frülzzeitigsten Arten dieser Gattung; erscheint schon vor Mitte Mai in grosser Menge auf allen Wiesen und Abhängen; vom Stroligelben bis in's Grasgrüne varierend. In der Schweiz bis auf 4000 Fuss ü. M. fast allenthalben gemein.

\section{IT. erraticus. Limu.}

Limn. Fauna Suec. 961 .

Fallèn. IIemipt. Suec. 132. 6.

Monogr. Cim. 111. 6.

Wolff. IV. pag. 156. Tab. XVI. fig. 15\%. Foem. Miris hortorum.

IIahn. Wanz. Ins. fig. 165. 164 .

IIS. Wanz. Ins. III. Bd. pag. 40.

- Nomenclat. ent. pag. 47, 81.

Länge 4'"'. Grün. Kopf, Thorax und Schildchen mit schwarzen Streifen. Zweitheilige Verlängerung des Kopfes, Fühlerglied 1 so lang als der Thorax und stark behaart.

Von Ende Juni an den ganzen Sommer hindurch stellenweise gemein, an andern Orten nur einzeln. In Monat August im Emmenthal an steinigten IḦ̈geln oft in erstaunlicher Menge. 


\section{$-85-$}

\section{Ir. Inevlgatus. Linn.}

IIahn. Wanz. Ins. fig. 165. Miris virens.

IS. Wanz. Ins. fig. 259

Fabr. Syst. Rhynch. pag. 253. № 2. Miris levigat.

- Entomol. system. IV. pag. 184. 2.

Fallin. Hemipt. Suec, pag. 130. 4.

- Monogr. Cim. pag. 109. 4.

Linn. Syst. Nat. II. pag. 750. No 101. Cim. lævigat.

Burmeister's Handb. II. pag. 265. 1.

Länge 4"'. Grünoder braungelb, Hinterschenkel vor' dem Ende dicker; das $1^{\text {te }}$ lang behaarte Fühlerglied kaum etwas länger als der Thorax.

Erscheint mit M. calcaratus um die Mitte Mai's in grosser Anzahl und ist wohl der gemeinste aller Miriden. Variert sowohl in Grösse als Färbung. Im Nai und Juni zeigt or sich meistens grün, im Juli strohgelb, im September röthlich.

\section{No. virens dinn. Wear.}

Haln. Wanz. Ins. fig. 161. Miris lavigat.

HS. Wanz. Ins. fig. 257.

Mahn. Fig 220. Miris ruficornis. (Ohne die Citate.)

Fabr. Syst. Rhynch. pag. 28/4. No 7. Miris virens.

- Entomol. syst. IV. pag. 185. № 6.

Limn. Syst. Nat. II. pag. 750. No 102. Cimex virens.

Burmeister zieht das Linnéische und Fabr. Citat zu Miris calcaratus, aber gewiss mit Unrecht.

Länge 4'I"'. Grün; braungelb oder röthlich, Schenkel gleich der vorigen Art; $1^{\text {tes }}$ Fühlerglied behaart, viel kürzer als der Thorax. 
Dem vorigen äusserst ähnlich und fast nur durch die kürzern Fühler, besonders des ersten Gliedes, und durch den hinten etwas breitern Thorax zu unterscheiden. Erscheint schon zu Ende Aprils auf Wiesen und grasreichen Ilügeln, doch weniger häufig als leevigatus und auch nicht so allgemein verbreitet.

Zürich. (Br.) - Champel bei Genf. (Buess.) - Bündten. (Amst.) - Baselland. (Menzel.) - Burgdorf, am Galgenbüht; einzeln auf dem Rigi Kulm 5550 Fuss ü. M. (Meyer.)

\section{III. holsatus. Habr.}

Ilalen. Wanz. Ins, fig. 162. Eine blosse Var. Miris albidus. IIS. Wanz. Ins. fig. 256

Fabr. Syst. Rhynchot. pag. 25\%. 4.

- Entom. syst. 4. pag. 184. 4.

Fallèn. Monogr. № 7.

- Hemipt. Suec. pag. 152. № 7.

Zetlerst. 1. 502. 4.

Burmeister. II. pag. 265.

IIS. Nomenclat. entom. 1stes IIeft, pag. 47 u. 81 .

Länge $3^{\prime \prime \prime} .1^{\text {tes }}$ Fühlerglied fast nackl. Gelbbraun oder grünlich; Aussenrand der Decken stets heller; Membran mit dunkelumzogenen Nerven.

Auf höheren Thalgründen und Waldabhängen stellenweise sehr häufig, an andern Orten selten; scheint sich am höchsten in die Alpenregion zu versteigen. In der Ebene schon zu Ende Aprils, auf den Alpen bis auf 6000 Fuss ii. II. noch im September vorkommend.

Genf. (Buess.) - Zürich. (Pr.) - Baselland. (Menzel.) - Bündten. (Amst.)-Schaffhausen. (Seiler.)-Bergli-Alp. (IIcer.)-Grosse Scheidegg, Wengeralp u. Handeck. Bei Burgdorf gemein. (Mcyer.) 


\section{$-32-$}

\section{NI. ruficornis. Fallèn.}

IIerrich Sch. Wanz. Ins. III. Bd. pag. 40.

IIahn. Wanz. Ins. fig. 200. Als Miris pulchellus, nicht aber seine M. ruficornis (Fig. 220), welche zu virens gehört.

Fallèn. Hemipt. Suec. pag. 155. № 8.

Zetterst. Fauna. №

IIerr. Sch. Nomenclat. entom. I $^{\text {tes }}$ IIeft, pag. 47 u. 82.

Länge 21/2'". Grün; die rothen Fühler von Körperlïnge; Schenkel gegen die Wurzel dicker.

Die kleinste, aber auch schönste Art. Kömmt in der Schweiz nur an wenigen Orten, und auch da nur selten vor. Um Burgdorf in Schächen längs der Emme 2 Exemplare am 25. und 28. Juni gefangen.

Nach Seiler und Amstein in Bündten. - Bei Basel. (Imhoff.) Bonneville (Coppier.)

(Man hüte sich wohl, rothfühlerige, kleine Exemplare von levigatus mit dieser Art zu verwechseln. -)

\section{ข. No. Iongieornis. Eall.}

IIerrich Sch. Wanz. Ins. fig. 258.

Fallèn. Monogr. Cim. № 5.

- IIemipt. Suec. $N^{0} \mathbf{3}$.

IIerr. Sch. Nomenclat. entom. $1^{\text {tes }}$ Ileft, p. 47 u, 81.

Länge $21_{2}^{\prime \prime \prime}$. Grün, Fühler sehr lang, das $1^{\text {te }}$ Glied länger als der Thorax und fast nackt.

Noch seltener als ruficornis, und ron mir erst 2mal, im Juni 1841, in einem Schachen an der Enme bei Burgdorf von hohem Grase ahgeschöpft.

Iliutiger bei Gellerkinden und Sissach, Kanton Basel. (Menzel.) 
II ${ }^{\text {te }}$ Gattung: LOPUS. IIahn und Herrich Sch.

\section{C. dolobratus. Lisu.}

IIahn. Wanz. Ins. fig. 160.

ISS. Wanz. Ins. fig. 261. 262.

Zetterst. Fauna ins. lappon. № 1 .

Fallèn. Monogr. pag. 107. № 1 .

- Hemipt. Suec. pag. 128. № 1 .

Fabr. Syst Rhynch. pag. 184. № 5 . Miris lateralis.

WVolff. III. pag. 113 u. 116. Tab. 11. fig. 109 u. 110.

Miris abbreviatus. Foem. larva.

Schrank. Enum. № 549.

- Fauna boica. No 1165 .

Burmeist. Handb. II. pag. 267. Phyt. dol.

IIS. Nomencl. ent. I. pag. 47 u. 85. Lopus.

Länge $4{ }^{\prime} / 4^{\prime \prime \prime}$. Behaart, Fühler schwar', am gleichfarbigen Thorax und Schildchen gelbe Streifen und Zeichnungen. Decken gelblichroth oder rothgelb mit hellerem Aussenrande.

Noch unentwickelte Individuen zeigen sich schon nach der Mitte Maimonats; mil den ersten Junitagen erscheinen sic ausgebildet, zuerst fast lauter Weiber, dann von der Mitte dieses Monats an beide Geschlechter oft in unsäglicher Menge an Felsbördern, auf Waldwiesen und grasreichen Abhängen. Die Weiber sind weniger zahlreich. - Die Regensburger-Exemplare müssen wenigstens nach IIerrich's Abbildung und Länge-Angabe kleiner sein, als die schwei- 
zerischen, was ich auch bei Miris virens und lcevigutus nachtråglich $\mathrm{zu}$ bemerken habe.

Genf häufig. (Buess.) - Ebenso um Basel. (Imhoff.) - Getterkinden. (Menzel.) - Schaffhausen. (Sciler.) - Bündten. (Amst.) - Bei Zürich nicht gemein. (Bremy.)-Sehr gemein um Burgdorf am Gyrisberg, Oberthal am Plecrwald; Sumiswald, Napfabhang, Simmenthal und ganz besonders am Fusse des Jura bei Solothurn, Lengnau, Neuenstadt. Gyslifluh bei Aarau, Bern am Gurten und Lengenberg. (Meyer.)

\section{0. ferrugatus. Fallèn.}

Fallèn. Monogr. Cimic. № 2. Miris ferrugat.

Fabr. Syst. Rhynch. 1. Miris dolobratus.

IIerrich Sch. Wanz. Ins. fig. 265.

- Nomencl. entom. I. pag. 47 u. 84.

Länge $4 \%$ ' 1 . Dem Vorigen zum Verwechseln ähnlich, jedoch durch blassere, mehr okergelbe oder fahle Färbung, breitern gelben Mittelstreif auf dem Thorax, kürzere Behaarung, sowie auch durch viel kürzeres 2tes Fühlerglied $\mathrm{zu}$ unterscheiden.

Erscheint mit $L$. dolobratus zu gleicher Zeit (nach dem 20. Juni), ist aber viel seltener und auch nicht so allgemein verbreitet.

Champel bei Genf. (Bucss.) - Gelterkinden, Kant. Basel. (Menzel.) - Um Burgdorf an den grasigsten Abhängen des Oberthals manche Jahre ziemlich häufiğ (Neyer.)

(Mit dieser Art verwechsle man nicht Plyylocoris fervugatus (IIahn, Fig. 104), welche zum Genus Capsus gehört und identisch ist mit Caps. ferrugatus Fabr. und Cimex roseo maculatus Degéer.) 


\section{E. tumicatus. Fabr.}

Fabr. Syst. Rhynch. pag. 255. № 148. Lygæcus tunicatus. - Entomol. syst. 151.

Fallèn. Monogr. cim. 41.

Germar's Fauna ins. 5. 25. Miris tunicatus.

Ilerrich Sch. Nomencl. entom. $1^{\text {tes }}$ Heft, pag. 47 u. 88.

Länge 41/4"'; lang gestreckt; oben flach, auf grüngelbem Grunde karminroth übertüncht und schwärzlich punktirt. Aussenrand der Decken, Körper und Beine gells. Enden der Schienen, Fühler, Innenrand des Appendix und Membrannerv purpurroth. - 5tes Fühlerglied an der Basis gelb.

Eine sehr schöne, wie es scheint, ziemlich weit verbreitete, dennoch aber seltene und immer nur ganz einzeln vorkommende Art. Man findet sie erst nach der Mitte Septembers bis zum 10 ten oder 1 5̈ten $0 k$ tober auf Nesseln und Ilaselgesträuchen, besonders an sonnigten Waldrändern. - Variert vom Grasgrünen bis in's lebhafteste Karminrothe.

Burgdorf, am Schlossfelsen und an der Gysnau. (Meyer.) Waadt, und Champel bei Genf. (Buess.) - Basel. (Imhoff.)

\section{U. albo-striatus. Halkg.}

IIahn, Wanz. Ins. fig. 72. Lopus albomarginatus.

Herr. Sch., Nomencl. entomol. $1^{\text {tes }}$ Heft, pag. 47 u. 82. Fabr., Syst. Rhynch. pag. 245 . № 24. Capsus alboniarginat.

Fallìn, Monogr. Cim. Suec. pag. 681 . № 2. Capsus albomarginat. 
Fabr., Etom. Syst. IV. pag. 180. № 164. Lygæus albomarginat.

Burmeist., Handb. II. pag. 271. Phytocoris albostriatus.

Länge 5"'; schwarz oder dunkelbraun, behaart, mit gelblichen und röthlichen streifenartigen Zeichnungen am Kopf, Thorax, Schildchen und Decken.

Von Mitte Juni bis gegen Ende Juli an sehr wenigen Stellen der mittleren und nordöstlichen Schweiz, besonders in bergichten Gegenden, an sonnigen, gras- und gebüschreichen Abhängen, und wo er vorkömmt, ziemlich gemein.

Zürich am Uto auf jungem Eichengebüsche schr häufiğ. (Bremy.) - Burgdorf auf dem Galgenhügel, gegen den Pleerwald im Korn, in Menge mit Gothicus, auch am Fusse des Napfs, beim Riedbad hinter Sumiswald sehr gemein. (Meyer.)

\section{T. gothieus. Fabr.}

Linn., Syst. nat. II. pag. 726. № 72. Cimex gothicus.

- Syst. nat. 1. pag. 728. 83. Eine blosse Varietät, Cimex superciliosus.

Fabr., Syst. Rhynch. pag. 2/44. № 20. Capsus goth. - Ent. Syst. 4. pag. 180. № 162. Lygeus goth.

Fallèn, Hemipt. Suec. 117. 4.

- Monogr. Cim. 3. (Capsus.)

Wolff, I. pag. 55, u. Tab IV. fig. 55. Lygæus goth.

Panzer, Fauna insect.

Burmeist., Handb. der Entomol. II. pag. 271.

Herr. Sch., Nomencl. ent. $1^{\text {tes }}$ Hft. pag. 47. 84.

Hahn, Wanz. Ins. fig. 5. (Lopus.)

Länge $5^{\prime \prime \prime}$; schwarz, mit lebhaft rothgelber Spitze des Schildehens und der Flügeldecken. 
Am ganzen Jurazuge und in hïglichten Gegenden der mittleren und nordöstlichen Schweiz von Anfang Juni bis zu Ende Juli mehr oder weniger häufig. - Dass diese Art, wie IIalın sagt, auf der grossen Brennnessel (Urtica dioica L.) vorkomme, ist wohl nur zufällig. Ich fand sie stets an heissen, gegren Miltag gelegenen Abhängen im Getreide oder auf Ononis und Galium, auf welcher letzteren Pflanze sie besonders in grosser Individuenzahl vorkam und die Honigsäfte der Blumen aussaugte.

Zürich, an Uto. (Bremy.) - Burgdorf, im Oberthal. (Meyer.)

III Ge Gatrung: PIIYTOCORIS. Ilerrich Sch.

\section{Ph. populi. dimn.}

TAF. VII. Fig. 1 u. 4.

Linn., Syst. Nat. I. pag. 751. № 109.

Zetterst., Fauna ins. lapp. 8.

Fallèn, Hemipt. Suec. pag. 84. 61.

Fabr., Syst. Rhynch. pag. 257. 171. Lygæus pop.

Fallèn, Monogr. Cim. Suec. 59.

Fabr., Syst. Rhynch. 169. Var. tilix.

- Entomol. system. 173.

Fallèn, Monogr. 40 u. Hemipt. Suec. 17.

Burmeister, Handb. II. pag. 268.

HS. Nomencl. entom. I. pag. 47 u. 86.

Schellenberg, Wanzen. Tab. III. fig. 5. d.

Länge $3^{1 / 4} 11$; grünlich weiss, blassgrün oder rauchgrau, schwarz gescheckt. Appendix, mit Ausnalıme der dunkeln Spitze, stets blass. Fühler und Beine gescheckl. 
Im Mai, Juni und Juli noch unausgebildet ohne Decken, dann von Ende Juli an bis gegen Mitte Oktobers fast allenthalben entwickelt; aber stets nur einzeln, in Schächen und schattigen Orten, auf Weiden-, Pappel - und Eschengesträuchen. Variert in Farbe und Zeichnung ausserordentlich vom Weisslichen bis in's Dunkelmoosgrüne. Die ziemlich seltene Var. lilice Fabr. ist russigschwarz, mit hell- oder gelbröthlich bleibenden Stellen. (Taf. VII. Fig. 4.)

Burgedorf, gemein. (Meyer.) - So auch um Bern. (Ougsburger.) - Bei Zürich, am Uto. (Bremy.) - Basel. (Imhoff.)

\section{Ph. uImi. Linn.}

Limn., Syst. Nat. II. pay. 751. № 110. u. Fauna Suec. 96\%. Fallèn, Monogr. No 47. Lygaxus ulmi.

- Itemipt. Suecix (Phytoc.) No $2 \%$.

Fabr., Syst. Rhynch. pag. 256. 17. Miris ulmi.

- Ent. Syst. IV. pag. 188. Miris ulmi. № 16.

IIahn, Wanz. Ins. fig. 234.

II $\mathrm{rr}$. Sch., Nomencl. entom, pag. 47 u. 88.

Ob auch Miris tongicornis Wolf. icon. cim. fig. 149 zu dieser oder vielmehr zur folgenden Art gehört, ist nicht mit voller Sicherheit zu bestimmen.

Länge $5^{\prime \prime \prime}$; rolhgelb mit braunen Zeichnungen, Kopf, Thorax und Schildchen mit karminrothen, länglichen Streifen.

In der mittleren und' nördlichen Schweiz, nach der Mitte Juli bis Ende Kugusts, an sehr sonnigen, gebüschreichen Ablıängen, auf niedrigem Eichengebüsche, an heissen Ilïgeln und abgeholzten Waldabhängen oft in grosser Menge. 
Bei Zürich und am Irchel einzeln. (Bremy.) - Basel. (Imhoff.) - Baselland, bei Gelterkinden gemein. (Menzel.) - Malans in Bündten. (Amstein.) - Burgdorf auf dem Binsberg, Oberthal, Plateau des Galgenhügels und andern Stellen äusserst häufig. (Meyer.)

\section{IPI. divergens mithi.}

TAF. I. Fig. 1.

Fig. a. Länge von diverg. - Fig. b. Länge von ulmi.

Meyer in d. Entomol. Zeitung von Stettin. Jahrgang 1841, № 6 , pag. 87.

Länge $3^{1 / 2}{ }^{11}$.

Diese Art wurde wahrscheinlich von allen Autoren mit Ph. ulmi zusammengeworfen, von welcher sie sich aber durch folgende Merkmale deutlich unterscheidet: Durch bedeutendere Grösse, länger gezogene und überall gleich breite Flügeldecken, ein längeres erstes Fühlerglied, durch dunklere, mehr zimmtbraune Färbung und verworrene Zeichnung, durch einen gleichfarbigen, statt orangegelben Kopf, den Mangel der gelben Mittellinie und Seitenstriche, so wie auch der 2 karminrothen Längsstreifen über Kopf und Thorax, die wir bei allen Individuen von Ulmi meistens deutlich wahmehmen; - endlich auch durch den verschiedenen Aufenthalt und die frühere Erscheinungsperiode.

Diveryens ist weit allgemeiner verbreitet als $u l m i$, und findet sich fast allenthalben; erscheint stets 14 Tage bis 3 Wochen früher, als ulmi, und findet sich mehr auf Weiden- und Pappelgesträuchen, in Schächen und grossen Gärten, als auf wilden Anhöhen. 
Bündten, häufig. (Amstcin.) - Zürich. (Bremy.) - Basel und Landschaft. (Imhoff und Menzel.) - Genf. (Buess.) - Burgdorf, in Schächen an der Emme, auch im Oberthal gegen den Pleerwald sehr gemein. (Meyer.)

IV te Gattung: CAPSUS. Herrich-Sehüffer.

\section{C. contaminatus. Fallèr.}

Fallèn, Monogr. Cim. Suec. pag. 76. № 29. Lyg. cont. - Hemiptera Suecix (Phytocoris) 5.

Zetterst., Faun. ins. Lap. 3.

IIahn, Wanz. Ins. fig. 76. Lygus contaminatus.

IIerr. Sch., Nomencl. entom. pag. 49 u. 83.

Länge $2{ }^{3 / 4}{ }^{\prime \prime \prime}$; hellgrasgrün. Flügeldecken über dem Appendix mit dunkler Mackel und verloschenen dunkeln Flecken um den Rand der Membran.

Erscheint im Juli einzeln in Gesellschaft von C. nassatus und limbalus in Gesträuchen auf der Ebene, in Schächen und Waldwiesen; in unsäglicher Menge aber im August auf den niederern Bergen der Molosse-Formation auf Almus viridis; auf dem Bantiger und Gurten von $2500-5000$ Fuss ü. M. Am Rigi noch bis 5000 Fuss hoch.

\section{C. Spinolse miht.}

TAF. I. Fig. 2.

Entomol. Zeit. von Stettin. Jahrgang 1841, №6, p. 86. Länge $23 / 2^{\prime \prime \prime}$;

Ich kann auf diese hier selir gemeine Art in keinem Autor eine Beschreibung oder Abbildung finden. Dem 
Vorigen sehr nahe, aber kürzer, gedrungener, über die Mitte breiter und gewölbter, überall lebhaft glänzend, ohne alle Zeichnung; mikroskopische Behaarung. Augen schwarz. Membran durchscheinend graulich weiss. - Im Tode wird der Kopf, ein Theil des Thorax und das Schildchen gelb.

Von Anfangs Juli bis Ende Augusts in Gärten auf Spirea salicifolia und Ceonothus americanus in Menge.

Burgdorf, sehr häufig. (Meyer.) - Champel, bei Genf. (Buess.) Bündten. (Amstein.)

\section{C. Incortum mỉhi.}

TAF, VI. Fig. 2.

Länge $21^{\prime \prime \prime}{ }^{\prime \prime \prime}$.

Dem Spinole ganz nahe, noch näher dem contaminatus, lebhafter, grasgrün, und ohne schwarzen Fleck über dem Anhang; Membran dunkler, wolkig, besonders innerhalb der Zellen, an welchen auch am Aussenrande gegen die Spitze hin ein schwärzlicher, bogenförmiger Schatten bemerkbar ist. Nerv der Membran stroligelb. Das äusserste Tarsenglied schwarz.

Sehr selten; um die Mitte Juli auf Erlengebüsch in sumpfigen Wiesen.

Schaffhausen. (Seiler.) - - Burgdorf, im Oberburger-Einschlag. (Meyer.) - Genf und Champel. (Buess.)

Bei den 2 vor mir liegenden Genfer-Exemplaren ist die Membran weniger dunkel, und statt der dunkeln Ausfüllung der Zellen steht nur I verflossenes Fleckchen. Der Innenrand der Membran ist anfänglich tief schwarz gesäumt. 


\section{$-4 \%-$}

\section{C. brevicollis milli.}

TAF. I. Fig. 4.

Länge $2{ }^{3} / 4^{\prime \prime \prime}$.

Icli kenne von dieser ausgezeichneten Art nur cin einzelnes Exemplar von Buess aus Genf.

Grösse von C. Spinolce oder limbatus, aber oben flacher, sehr blass olivengrün; über die Decken zicht sich ein, gegen den Appendix zu breit werdender, dunkler Streifen, fast wie bei $C$. chenopodii Fall. (binotatus IIahn, fig. 105). Appendix selbst, hellgrün, durchsichtig, von dem lederartigen Theil stark und deutlich abgesetzt. Membran hellbräunlich grau. Beine grün, Ilinterschenkel schwarz punklirt. Fühlerglied 1 grün, 2 gegen die Spitze, und 5 und 4 ganz röthlich.

Auffallend ist an dieser Art der kurze, flachgedrückte, in der Mitte durch eine tiefe Querfurche getheilte Thorax, dessen Vorder- und Ilinterrand gerade abgeschnitten, ganz von der gewöhnlichen Form dieser Gruppe abweicht.

\section{C. limbatus. Giallè̀.}

Fallèn, Monogr. Cim. pag. 85. № 54. Lygxus limbatus. Germar, Fauna insect. 15. 20. Miris limb. Fallèn, Hemipt. Suec. pag. 92. No 52. Phyt. limb. IIahn, Wanz. Ins. fig. 77. Lygaus limbatus. Burmeister, Handb. der Entomol. II. pag. 271. Ilerrich Sch., Nomencl. entom. I. pag. 85.

Länge $2 \frac{1}{2}{ }^{\prime \prime \prime}$; fast unbchaart, hellgrasgrün, Hinterrand des Thorax, das Schildchen und Innenrand der Flügeldecken breit schwärzlich. Schenkel gegen die Spitze röthlich, mit 2 dunklern Ringen. 
In der Schweiz nicht allenthalben, doch an den Fundorten gemein. - Erscheint mit $C$. nassatus und furcatus von Mitte Juni bis gegen Ende August in Schächen auf allen Weidenarten.

Burgdorf, längs der Emme. (Meyer.)

\section{C. affinis *). HIS.}

TaF. I. Fig. 5.

Fallèn, Monogr. Cim. Suec. pag. 75. № 28. Lygacus pabulinus.

Zetterst., Fauna. Phytocoris pabulinus.

IIerr. Sch., Nomencl. pag. 82. Capsus affinis.

Länge $5^{\prime \prime \prime}$; kleiner, schmäler, gestreckter als contaminatus, unbehaart, glänzend, ohne Zeichnung der Flügeldecken; Nerv der Iembran grün und unter demselben öfters ein länglicher, schwärzlicher Fleck. Fühlerglied 1 grün, 2 gegen die Spitze, 5 und 4 braun.

Fast allenthalben auf Weiden- und Erlengebüsch in den Monaten Juni, Juli und August, vom Flachlande bis in die Alpenregion hinauf.

Champel, bei Genf. (Buess.) - Zürich, am Uto u., Albis. (Br.) Malans, in Bündten. (Amstein.) - Bei Böekten, K. Basel. (Menzel.) Burgdorf, in den Schächen an der Emme; auch am Rigi bis 5000 Fuss. ü. M. und in den Thälern von Uri und Schwyz sehr gemein. (Meyer.)

\section{C. pabulinus. Einne}

TAF. I. Fig. 3.

Fig. 3. b bezeichnet das Längenmaass der grossen Varietät, a die Länge des gerwöhnl. Pabulinu s.

Linn., Syst. Nat. II. pag. 727. № 85. Cimex pabulinus. Degéer, Ins. III. pag. 293. № 31.

*) Herrich's neu eingeführter Name war für diese Art um so nothwendiger, als Fallèn und Zetlersi. sie für die folfyende ganz verschiedenc gehalten und dadurch die Synonimic verwirrt haben. 
Fabr., Syst. Rhynch. pag. 254. № §. Miris pabulinus. - Entom. Syst. IV. pag. 184. № 5.

Burmeister, Handb. der Entomol.II. pag. 270. Phyt. pabul. IIahn, Wanz. Ins. fig. 74. Lygaxus pabulinus.

IIerr. Sch., Nomencl. entom. I. pag. 85.

(IIaln citirt hier irriger Weise auch den Fallèn'schen Lygreus pabulinus monogr. pag. 75 . № 28 , der aber, wie oben bemerkt, identisch mit $C$. affinis ist.)

\section{Länge $3^{1 / 2}{ }^{\prime \prime \prime}$.}

Eine schöne, in Form und Grösse dem $C$. chenopodii am nächsten stehende Art ; lebhaft grasgrün, mattglänzend und durch die im Leben grünen Adern der dunkeln Nembran ausgezeichnet.

Ziemlich selten, und nur im Juni und Juli an hochbegrasten Waldabhängen vorkommend; stellenweise gesellschaftich.

Genf, am Salève und Voirons. (Meyer und Buess.) - Am Golthardt im Wäldchen ob Andermatt und im Maderanerthal. (Bremy.) Burgdorf, auf dem Leuen und im Sommerhauswald; Solothurn an der Stygelos-Rysi am Jura. (Meyer.)

An letzterem Orte fand ich am §. Juni 1841 längs dem Felsen gegen den Nesselboden ungemein grosse Exemplare von $4 y_{2}^{\prime \prime \prime}$ Länge, über deren eigene Artrechte ich wegen Mangel genügender Beobachtungen an der fast unzugänglichen, gefalırvollen Stelle noch ungewiss bin. Die viel lichtere und längere Membran, die bedeutendere Grösse und die hohe Aufenthaltsregion von stets $4-5000$ Fuss ü. M. machen mir indess diese Form als blosse Varietät sehr zweifelhaft. Imho/f fand sie auch auf der Gemmi und auf dem Pilatus in ganz analogen Exemplaren; und sollten 
deren Artrechte sich wirklich bestätigen, so möchte ihr der Name $G$. alpestris mihi zukommen.-

\section{C. massatus. Fullèn.}

Fallèn, Monogr. Cim. pag. 76. № 31. Lygæus nassatus. Fabr., Syst. Rh. pag. 256 № 167.

- Entom. Syst. IV. pag. 174. № 155.

IIaln, Wanz. Ins. fig. 78. (Lygus.)

HS., Nomencl. ent. I. pag 49 u. 85 .

Länge $3^{\prime \prime \prime}$; hellgrün, schr fein behaart. Aussenrand der Decken, so auch Fühler und Füsse, gelblich.

Von Mitte Juni bis Ende August, aber nicht allenthalben, auf Weidengebüschen mit fureatus und limbatus.

Um Zürich sparsam; am Rigi gemein. (Bremy.) - Schaffhausen. (Seiler.) - Burgdorf, in den Schächen in Unzahı. (Meyer.)

(IIahn's Lygus icterocephalus, fig. 75", ist gewiss nur ein Exemplar mit gelb gewordenem Kopfe; eine Erseheinung, die nach dem Tode bei allen Arten dieser Gruppe sehr gewöhnlich ist.)

\section{C. Moralis. Hathe.}

Haln, Wanz. Ins. lig. 81.

IIerr. Sch., Nomencl. ent. pag. 49 u. 84.

Länge $1^{3 / 4}-2^{\prime \prime \prime}$; hellgrüngelb, fein weisslich behaart; dem pabulinus Zett. sehr nahe, doch kleiner, blasser und matter glänzend. Fühler und Brust auch im Leben gell.

Die IIahn'sche Figur ist sehr missrathen; die Behaarung zu stark und die Färbung allzublass.

Anfangs August sparsam auf Haselgesträuchen an Waldsäumen. 
Champel, bei Genf. (Buess.) - Zürich nicht selten. (Bremy.) Schaffhausen. (Sciler.) - Burgdorf, am Sommerhauswald und an der Nordostseite des Schlossberges. (Meyer.)

\section{C. bipunctatus. Brabr.}

Fabr., Syst. Rhynch. No 1\$8. Lygaus bipunct.

- Entom. Syst. $N^{0} 129$.

- Syst. Rhynch. No 157. Var. quadripunct.

- Entom. Syst. No. 128.

Fallèn, Hemipt. Suec. pag. 78. No 2. P'hytoc. bipunct. IIerr. Sch., Wanz. Ins. fig. 298.

- Nomencl. entom. I. pag. 50 u. 82.

Burmeister, Ilandb. Il. pag. 270. - Dieser Autor zieht auch Lyg. fraxini Fubr. Syst. Rhynch. pag. 256, No 162 hicher, der aber eine ganz andere $\mathrm{Ar}$ t ist.

Länge 51/41"'; gelblichgrün, fein schwärzlich behaart; Thorax mil 2 schwärzlichen Punkten. Decken des Mannes oft mit röthlichen Långsstreifen.

Im Monat Juli auf lichten Grasplätzen im Gchölze zienlich selten.

Zürich. (Bremy.) - Schafthausen. (Scilcr.) - Baselland. (Menzel.) Genf, gemein. (Buess.) - Burgdorf, lä̀gs der Emme in Schächen gesellschaftlich. (Mcyer.)

Kömmt mit 2, mit /t und auch olne schwarze Punkte auf dem Thorax vor. Die Flügeldecken sind beim Manne meistens röthlich angelaufen.

\section{C. Anenopodii. Frallèn.}

Fallèn, Monogrr. Cim. № 25. Lygaus chenopodii.

- Monogr. Cim. No 27. Lygmus binotatus.

- Hemipt. Suec. No 1. Phytocoris chenopodii. 


\section{$-52-$}

Fallèn, Hemipt. Suec. № 5 . Phytocoris binotatus. Fabr., Syst. Rhynch. № 158 . Lygxus binotalus u. 4 punctatus var. № 157.

Hahn, Wanz. Ins. fig. 105. Phytocoris binotatus.

Herrich Sch., Nomencl. entom. I. pag. 50. 82. Capsus chenopodii.

Panzer, Fauna ins. Germ. Miris lævigatus 95. 21.

Länge 4'"; schmutziggrün. Thorax mit 2 schwärzlichen Mackeln. Decken mit unten breiter werdendem Längsstreif. Appendix blassgelb. Schenkel punk tirt.

Von Mlitte Juni an den ganzen Sommer bindurch auf Bergen und in Thälern allenthalben in unsäglicher Menge, und in allen Abstufungen von der blassesten bis zur lebhaft braunen Zeichnung des Thorax und der Flügeldecken.

\section{C. ferrugatus. Fubr.}

Fabr., Syst. Rhynch. № 165. Lygxus ferrug.

- Entom. Syst. IV. pag. 175. No 152. Lygaxus ferrug. Fallèn, Monogr. Cim. Suec. No 42. Lygaus ferrug.

- Hemipt. Suecix. pag. 86. № 19. Phyt. forrug.

IIaln, Wanz. Ins. fig. 104. Pliytocoris ferrugatus. Schae/fer, icones, Tab. 15. fig. 9.

Deyéer, Mémoires III. 195. 52. Cimex roseo-maculatus. Herrich Sch., Nomencl. entom. I. pag. 50 u. 84. Burmeister, Ilandb. 11. pag. 270.

Länge 51/2"'; grünlich oder ohergelb nit rosenrothen Längsstreifen.

Nicht überall, aber wo er vorkömmt, riemlich häufigg.

Champel, beì (ienf. (Buess.) - Schalfhiusen, aun lianden (Seiter.) Baselland, an den Bergen um Gellerkinden. (Mrenzel.) - Zu Lude 
Juli in grosser Menge an den grasreichen Abhängen der höchsten Emmenthaler-Berge, Napf und Iloch-Enzi, so auch bei Bern an der Engebalde. (Meyer.)

\section{C. setulosus. Allernich Seh.}

TAF, II. Fig. 1.

IIerrich Sch., Wanz. Ins. IV. fig. 380.

Länge 31/4'"'; schmutzig grünlichgelb; borstenförmig behaart; mit schwarzen Flecken und Streifen des Thorax und Schildchens.

Dass diese neue, und wie es scheint, höchst seltene Art auch in der Schweiz vorkömmt, überzeugte mich ein, leider sehr verdorbenes Exemplar, das mir IIr. Seiler von Schaffhausen unter seiner diessjährigen dortigen Ausbeute, ohne nähere Angabe des Fundortes, einsandie.

Das Geschlecht kann ich nicht mehr unterscheiden. Das Exemplar weicht in mehreren Punkten von Herrich's Abbildung ab. Fühlerglied 2 ist von gewöhnlicher Stärke, nicht so verdickt. Vordertheil des Thorax gelb, mit 2 schwarzen Querstreifen, die sich auf der Mitte nicht errcichen; Ilinterrand-Ecken des Thorax, sowie auch 2 bogenförmige Flecken vor dem Grunde des Schildehens schwarz. - Im Uebrigen genau mit der citirten Abbildung von Herrich übereinstimmend.

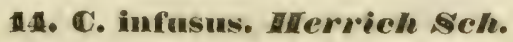

IIS., Wanz. Ins. IV. fig. 581.

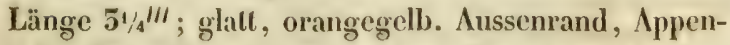
dix, eine Doppellinie über den Kopf, Thorax und Schildchen, sowie auch die Schenkel lebhaft roth. 
Auch diese Art ist bei uns einheimisch, obschon sehr selten. - An heissen gegen Mittag gelegenen, verwilderten Abhängen.

Champel, bei Genf, gegen die Arve hinunter. (Buess.) - Bern, an der Engehalde (Ougspurger), woher meine 3 Exemplare sind.

\section{C. coryli. Hinn.}

Linn., Syst. Nat. I. 2. pag. 735. № 121. Cimex coryli. - Fauna. 974.

Fabr., Syst. Rhynch. 234. 150. Lygæus coryli.

Fallèn, Hemipt. Suce. pag. 90. № 27. Phytocoris coryli.

- Monogr. Cim. Suec. № 49. Lyg. coryli.

Hahn, I. fig. 16. Phylus pallipes.

Herrich Sch., Nomencl. ent. I. pag. 52 u. 85.

Burmeister, Handb. II. pag. 268.

Länge $21 / 3$ "I'; schmal; fein behaart; schwarz. Fühler und Füsse blassgelb. Membran mit hellem Fleck unter der Spitze des Appendix.

Eine sehr weit, fast über ganz Europa verbreitete Art; erscheint im Juni und Juli überall auf Iaselstauden, mehr oder weniger häufig.

\section{C. avellange mihi.}

TAF. IJ. Fig. 2.

Meyer, In der entomol. Zeitung v. Stettin. Jahrgang 184, № 6, pag. 83.

(Erst nach der Vollendung meiner II. Tafel erhielt ich das VI. IIeft des VI. Bandes von IIerrich's wanz. Ins., in welchem sich nun unser C. avellana unter Fig. 670 ebenfalls abgebildet findet.) Länge $2 \frac{1}{2} 3^{\prime \prime \prime}$. 


\section{$-55-$}

In Grösse und Habitus dem C. coryli vollkommen gleich, und nur durch die röthlich olivenbraune Färbung, die röthlich angelaufene Wurzel der Flügeldecken und den stets blassrothen Appendix verschieden; bestimmt eigene Art. Viel seltener als coryli, doch zu gleicher Zeit und an den nämlichen Stellen vorkommend.

Burgderf, am Schloss - und Gyrisberg. (Meyer.) - Eine blasse Varietät bei Zürich auf Erlengebüschen. (Bremy.)

\section{C. melanocephalus. Eime.}

Linn., Syst. Nat. 88. Ciniex melanoc.

Fallèn, Hemipt. Suec. pag. 89. № 26. Phytoc. revestitus.

- Monogr. Cim. Suec. No 48 . Lygacus revest.

Fabr., Syst. Rhynch. 254. 8. Miris pallens.

IIerr. Sch., Nomencl. ent. I. pag. 85. Capsus melanoc. IIaln, Wanz. Ins. (Lygus.) fig. 79.

Burmeister, Handb. II. (Phytocoris) pag. 268.

Länge 2-21/3"1; schmal; röthlich strohgelb; unbehaart. Kopf und Leib) glänzend schwarz. Membran mit schwärzlichem Aussenrande.

Ueberaus selten. Im Juni an sehr wenigen Stellen der Schweiz auf Haselstauden im Ilügellande.

Burgdorf, auf dem Gyrisberg. (Meyer.)

Diese Art variert auch mit gelbem oder bräunlichem Kopfe.

\section{C. plagiatus. Elerrich Sch.}

IIS. in Panzer's Fauna ins. 155. 10. ein Weib, und IIS. wanzenart. Ins. VI. fig. 587, ein Mann.

Länge $21 / 4$ "' ; blassröthlich gelb; behaart. Mit hinten breitem, schwarzem Striemen auf jeder Decke. 


\section{- 56 -}

In der Schweiz ist mir kein anderer Fundort bekannt, als Burgdorf, wo er sich von Anfangs Juni bis Mitte Juli an einer einzigen Stelle, in einem Schachen an der Emme, in ziemlicher Menge auf niedrigem Erlengesträuch vorfindet. Der Mann ist sehr selten.

\section{C. angustus. IIerrich Sell.}

TAF. II. Fig. 3.

Nomencl. ent. I. pag. 49.

Länge $13 / 4$.

Für diese Art halte ich eine kleine, dem C.floralis nahe stehende Wanze. Etwas kleiner, flacher. Kopf gross, breit, die grossen schwarzen Augen seitlich hervorragend. Fühler lang, borstenförmig, überall gleich dick. Behaarung blos mikroskopisch. Hoch orangegelb sind : Fühler, Kopf, Thorax, Schildchen, Brust und die Schnabelscheide. Strohgelb : Hinterleib und Beine. Die Flügeldecken sehr blass, durchscheinend strohgelb, in's Grünliche ziehend. Membran gestreckt, glashell, lebhaft irisirend. Zellennerv gelblich.

In der Schweiz bis jetzt blos von mir einige Male aufgefunden. Burgdorf auf dem Gyrisherg aufHaselgebüschen. Ein Exemplar am 18. Juli, ein zweites am 8. August 1841.

\section{C. vittipennis. Iterrich Sch.}

HS., Nomencl. entom. I. pag. 52. 88.

- Wanz. Ins. fig. 305.

Fallèn, Monogr. Cim. pag. 98. № 4.

- C. mutabilis mas ? stria media longitudinali pallidiori. 
Dieses letztere Citat künnte vielleicht auch zu C. pilosus Hahn gezogen werden.

Länge $3^{\prime \prime \prime}$; schwař; stark weisslich und schwarz behaart. Flügeldecken mit blassem, verloschenem Längsstreif längs dem Clavus. Fühlerglied 1 und die Beine falb. Membran braun gefleckt.

Von Anfang Juni bis Mitte Juli einzeln an sonnigten, hochbegrasten Waldrändern, Feldbördern und an Berg-. abhängen.

Zürich, an Bergen. (Bremy.) - Burgdore, im Oberthal. (Meyer.)

\section{C. parallelus milk.}

TAF. VI. Fig. 3.

Ich bin nicht ausser Zweifel, ob diese, in die Gruppe von $C$. mutabilis, pilosus und vittipennis gehörige Art vielleicht schon irgendwo beschrieben ist; allein ich kann sie nirgends mit Bestimmtheit auffinden.

\section{Länge $11 / 2 " 11$.}

Gestalt und Habitus von vittipennis, Kopf breiter den kurzen, mattglänzenden Thorax seillich weit überragend. Kopf, Fühler, Thorax, Schildchen, Körper und Beine schwarz; letztere mit bräunlichen Schenkelspitzen. Flügeldecken überall gleich breit, mattglänzend, dunkelpurpurbraun. Membran braun; dunkel angeraucht.

Scheint sehr selten; zuerst von Bremy erhalten, dann am 28. Juli 1842 von mir selbst auf dem Rigi Kulm 5530 Fuss ü. M. und an der Nordseite des Staffels bei $5000 \mathrm{~F}$. in mehreren Exemplaren erbeutet. 


\section{$-58-$}

\section{C. unbratilis. Ancllèn.}

Fallèn, Monogr. Cim. Suec. pag. 101. No 10. Caps. umbratilis.

- Hemipt. Suec. No 11.

Fabr., Entomol. Syst. IV. pag. 178. № 155. Lygaxus umbrat.

Limn., Excl. cit.

Ilerrich Sch., Nomencl, entom. I. pag. 48 u. 88.

Wanz. Ins. III. fig. 266. Foem.

Länge $21 / 2^{\prime \prime \prime}$; schwar' oder schwarzhraun; Flügeldecken und Clavus auf röhlilichem Grunde schräg weiss linirt; über dem Appendix ein weisses Querband. Basis der Fühler und die Beine rostroth.

Aeusserst selten; an gebüschreichen Bergabhängen und kleinen Gehölzen an Jurazuge.

Genf. (Buess.) - Lengnau, Kanton Bern, von Dekan Studer in der Sammlung des Berner-Museums.

\section{C. mutabilis. Frallèn.}

Fallèn, Hemipt. Suec, pag. 118. No §. Phyt. mutal.

- Monogr. Cim. pag. 94. No 4. Lygacus nutab. Hahn, Wanz. Ins. II. fig. 180. Ein Weib.

Ilerr. Sch., Nomencl. entom. I. pag. 8引.

(IIahn's mutabilis II. fig. 225, (Fallen's hemipt. No 12.) ist eine andere, in der Natur mir noch unbekannte. Art.)

Länge 21/3"'. Matt, schwarz mit dichten, anliegenden lichten Häärchen bedeckt.

Im Juni und Juli auf Wiesen, an grasreichen Abhängen und auf niedrigem Gebüsche; aber überall nur sparsam. 


\section{- 59-}

Burgdorf, auf der Almend. (Meyer.) - Zürich, in Wäldern. (Br.) - Baselland, im Wolfsgraben bei Sissach. (Menzel.)

\section{C. pillosms, Hatem.}

IIahn, Wanz. Ins. II. fig. 181.

IIerrich Sch., Nomencl. I. pag. 52. 86.

Länge 21/3"'; schwarz, lang behaart. Flügeldecken am Innenrande verloschen hellisraun.

Auf Hügeln und Bergal)hängen der mitlern und nördlichen Schweiz; im hohen Grase sehr selten und einzeln im Monat Juli.

Basel. (Imhoff.)-Basselland, in Wolfsgraben bei Sissach. (Menz.) - Im Jura, Nesselboden ob Solothurn; Burgorf, am Gyrisberg. (Meyer.)

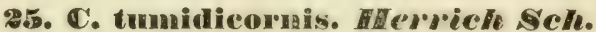

HS., Wanz. Ins. III. fig. 507.

- Nomencl. entom. 1. pag. 88.

Länge 21/3"'; schwarz, dicht mit gelblichen Schuppenhäärchen besetzt. Thorax querrunzlicht. $2^{\text {tes }}$ Fühlerglied verdickt.

Ueberaus selten.

Am Jura, Kanton Basel, (ielterkinden. (Menzel.) - Schafhausen, am Randen. (Seiler.)

\section{C. Inolosoricens, IEahn.}

II. Wanz. Ins. I. fig. 17. (Polymerus.)

IIerrich Sch., Wam\%. lns. VI. Jites Ileft, pag. 4s, zicht diese Art mit Unrecht als Synon. zu variabilis Fall., welcher letztere eine ganz verschiedene: 
Art und von Mahn unter Fig. 224 richtig abgebildet ist.

Meyer, In der entomol. Zeitung von Stettin 1841, № 6 , pag. 84. Unter ambignus.

Länge $2^{\prime \prime \prime}$; dick, hoch gewölbt, dunkel schwarzbraun, schuppenartig goldgelb behaart. Spitze des Appendix und ein Querband vor demselben röthlich. Schenkel und Schienen mit dunkelm Ringe.

Von Mitte Juni an bis gegen Ende Juli an manchen Stellen der Schweiz, auf schattigen, hochbegrasten Waldlücken, in Schächen unter Gebüschen und ähnlichen Plätzen des Ebenlandes ziemlich gemein.

Burgdorf, längs dem Gyrisherg-Schachen in tiefem Grase häufig. Meyer.) - Schaffhausen. (Seiler.) - Zürich, bei 1)übendorf und in den Eichenhainen bei Dietikon, nicht selten. (Brerny.) - Genf, am Fusse des Salève. (Buess.)

(Capsus nigrita Fallèn, IIerrich Sch., wanz. Ins. VI. $5^{\text {tes }}$ Heft, fig. 101, ist nichts als eine sehr gewöhnliche Abänderung von diesem IIolosoriceus.)

2\%. C. ambiguus. F̂tatèn.

Fallèn, Monogr. Cimic. Suec. pag. 89. № 64. (Lygaus.) - Hemipt. Suecix pag. 99. № 44. (Phytocoris.) Zelterst., Fauna ins. lapp. 491. 14. (Pliytocoris.) IIerrich Sch., Wanz. Ins. VI. fig. 602. Foem. (Caps. ambiguus.)

- Nomencl. entom. pag. 82 excl. Cil. Polymer. Holosoriceus IIalm, welchen Ilerrich mit Unrecht damals hieher gezogen.

Herrich Sch., (wanz. Ins. VI. IIItes IIeft, pag. 4h), zieht auch IHalnn's Phyt. lugubris, fig. 22\%, als Mann zu 
C. ambiguus; aber mehrere von mir zu Ende Juli am RigiStaffel gefangene, und mit IIahn's Art völlig übereinstimmende Exemplare, gaben mir die Ueberzeugung, dass lugubris eine blosse Varietät von $C$. arbustorum ist, die in einer Ilöhe von 5000 Fuss ü. M. auf allen Schwyzer- und Urneralpen häufig vorkömmt, und nur durch bedeutendere Grösse und dunklere Färbung von den Exemplaren der tieferen Regionen sich auszeichnet.

Länge 1\%/8'I; schwarz oder schwarzbraun; dicht, schuppenartig gelblich behaart. Beim Manne der Grund, beim Weibe der ganze Appendix und die Beine rothgelb. Unter dem rothgelben Nerv der Membran ein glasheller Fleck.

Eine sehr weit verbreitete, obschon nicht allenthalben häufig vorkommende Art. - Variert in's Braunrothe; besonders findet man Weiber mit lebhaft rothgelben Beinen, Kopf, Vordertheil des Thorax und Appendix. - Fallèn var. $\beta$ pag. 89, № 64. - (IIonogr. Cim.)

Erscheint schon in den letzten Maitagen, den ganzen Monat Juni hindurch in Baumgärten oft in ungeheurer Menge, besonders auf Zwetschgen- und Apfelbäumen.

Burgdorf, beim Bad Kriegstetten und in den Gärten um Solothurn ausserordentlich gemein. (Meyer.) - Seltener um Genf. (Butess.) - Schaffhausen. (Seiler.)

\section{C. Gyltenhalii. Fullèn.}

Fallien, Monogr. Cim. № 61. Lygxus Gyllenh. - Hemipt. Suec. No 40. Phytocoris Gyllenh. Herrich Sch., Wanz. Ins. III. fig. 510.

Nomencl. entom. I. pag. 52. 84 .

Länge 1 1/2"'. Kurz, dick und gewölbt. 
Schwarz. Niembran stark abwärts geneigt. Schuppenartig gelblich behaart. Appendix rostroth. Beine und Fühler rothgelb; erstere an den Schenkeln schwarz geringelt.

Schon von Ende Aprils bis Anfangs Septembers fast allenthalben bis auf 5500 Fuss ï. M. auf Galium-Arten gemein.

In unzählbarer Menge an der Stygelos-Rysi am Jura bei Solothurn, so auch an einigen steinigten Stellen des Oberthals bei Burgdorf. (Meyer.)

\section{C. Nagnicornis. vallèn.}

TAF. II. Fig. 4.

Fallèn, Monogr. Cimic. Suec, pag. 99. No 7. Caps. magn. Hahn, Wanz. Ins. I. fig. 67.

Herrich Sch., Nomencl. entom. I. pag. 85.

Schellenberg, Taf. IV. fig. 2. C.

Länge $1 \frac{1}{2}{ }^{\prime \prime \prime}$.

Schwarz; im Leben in's Violette schillernd. Gelblich behaart. Fühlerglied 2 spindelförmig verdickt, 5 und 4 dünn, gelblich. Die Ilinterschienen schwarz geringelt.

Mit dieser Art scheint auch die folgende, ihr sehr ähnliche und weit gemeinere, zusammengeworfen zu sein. Die Ilahn'sche Abbildung ist nach cinem verwischten Exemplare gemacht; stellt aber deutlich durch die punktirten Schienen den Maynicornis vor. Der wahre Magnicornis ist selten; doch fand ich ihn cinzeln an einem Waldsaume ob Sumiswald gegen den Schweikhof, wo ich ihn am 6. September 1859 in mehreren Lxemplaren von Erica vulgaris abschöpfte. Etwas häufiger kam er mir im Juli 1842 b) Altdorf 2000 Fuss ü. M., am Rigi bis 1800 Fuss ü. MI. und im August auf den Krauchthaler Bergen in Tannwäldern vor. 


\section{- 68 - \\ a1). C. mali milei.}

'TAR. II. Fig. 5.

Meyer, In der entomol. Zeitung v. Stettin. Jahrgang 1841, № 6 , pag. 87 , als Capsus pyri mihi.

Länge $13 / 411$.

Stets etwas grösser als magnicornis; Thorax in die Quere convexer; Beschuppung viel gröber und dichter; Decken, und besonders dic Membran dunkler; die Hinterschienen gar nicht oder zuweilen nur unmerklich punktirt. In allen übrigen Theilen dem magnic. zum Verwechseln ähnlich; doch ist die Verschiedenheit, besonders bei Beobachtung lebender Exemplare, in der Natur nicht zu verkennen.

Zu Ende IIai und Anfangs Juni findet man das lebhafte, ungemein flüchtige Thierchen noch als Puppe mit rothem Hinterleib, in den ungerollten Blättern kleiner Apfelbäume, dann aber vom 6. oder 8 . Juni hinweg bis um die Mitte Augusts als ausgebildete Wanze in so grosser Menge, dass man mit jedem Zuge des Schöpfgarns eine Anzahl von den Apfelblättern abstreifen kann. (Buess.)

Burgdorf, in Gärten und Baumgärten gemein. (Meyer.) - Genf.

\section{B1. C. pulverulentus. Id.}

Burmeister, IIandb. II. pag. 276. Halticus pulverul.

Länge $12 / 3^{\prime \prime \prime}$.

Schwarz; allenthalben dicht weisslich schuppenartig behaart.

In die Gruppe von C. spissicornis, magnicornis, mali etc. gehörend, dem letztern ziemlich nahe stehend, doch 
bedeutend grösser und mit weisslichen Häärchen oben ganz dicht überwachsen. Ich besass diese Art schon länger von Waltl aus Passau, und habe sie nun auch von Buess aus Genf erhalten. - Fundort : Champel.

\section{3\%. C. spissicornis. fabr.}

Fabr., Syst. Rhynch. 246. 28. Caps. sp.

- Ent. Syst. Tom. IV. № 168. Lygæus sp,

Panzer, Fauna II. 16.

Schellenberg, Land- und Wasserwanzen. Taf. III. 4. IIerrich Sch., Nomencl. I. pag. 52 u. 87.

Burmeister, Handb. II. pag. 276.

Länge $21^{1 / 4}$; schwarz, behaart. Beine gelb. Fühlerglied 2 spindelförmig verdickt. Membran dunkel irisirend.

In der Sclıweiz überhaupt selten und nur in den wärmern Gegenden längs dem Jura vorkommend.

Champel, bei Genf. (Buess.) - Baselland, am Bettenberg, bei Böckten. (Menzel.)

(Die Aufenthaltspflanzen dieser Art scheinen sehr verschieden. Panzer gibt die Nadelbäume an, Burmeister die Silberpappel und den Wermuth. Worauf Menzel und Buess sie fanden, kann ich nicht angeben.

\section{C. arbustorum. Fabr.}

TAF, III. Fig. 1.

Fabr., Syst. Rhynch. No 17/. Lygæus arb.

Fallèn, Monogr. № 68.

- Hemipt. Suec. No 52. Phytocor, arb.

IIerrich Seh., Nomencl. I. pag. 82. 


\section{- $85-$}

Herrich Sch., Wanz. Ins. III. fig. 500.

IIaln, Wanz. Ins. fig. 223. Phytocoris lugubris.

Länge 2"I'; belıart, schwarz; Flügeldecken überall gleich breit, in's Olivenbräunliche übergehend. Kopf breit, am Grunde mit hellbraunem Querband.

Eine, wegen den 2 nachfolgenden, sehr ähnlichen Arten, schwer zu bestimmende Wanze, die überdiess in dem bald hellern, bald dunklern Farbenton so abändert, dass hier mehr der Totalhabitus über die Artenrechte entscheidet. Auf Taf. III. stelle ich daher alle 5 Arten zusammen, bei deren Ansicht die stabilen Unterschiede Niemand bezweifeln wird.

Arbustorum zeigt sich einzeln im Juni und Juli in der ganzen Schweiz in Gärten auf kleinen Obsthäumen, auf Gebüschen und Blumen, an sonnigten, grasreichen Waldrändern und Abhängen.

(Phyloc. lugubris IIahn, Fig. 225, ist nur eine dunklere und etwas grössere Abart, die sich Ende Juli am Rigi und auf den Urneralpen in einer Höhe von 4-5000 Fuss ï. M. ziemlich häufig vorfindet.)

\section{C. hortensis milti.}

'AAF, III. Fig. 2.

\section{Länge $13 / 4 "$.}

Stcts etwas kleiner und eyrunder als der Vorige; tief schwarz; zuweilen nur mit einem schwachen purpurnen Schimmer auf den Flïgeldecken, nie aler sind dieselben in's Olivenfarbige übergehend. Kopf kleiner, Thorax vorn mehr verengl. 


\section{- BB -}

An den gleichen Stellen, wie arbustorum, jedoch schon früher erscheinend und viel gemeiner.

\section{C. hrunnipennis mith.}

TAF. III. Fig. 3.

Dem C. brunnicernis IIS. (Nomencl. ent.) nahe, und noch näher den hellsten Exemplaren von $C$. arbustorum. Bei manchen Individuen ist die Färbung fast orangegelb; doch bleibt der Kopf meistens schwarz; der weisse, durchscheinende Fleck der Membran deutlich und scharf begrenzt; der Zellennerv orangegelb. - Das olivengrüne Weib hielt ich früher für eigene Art, bis mich Beobachtungen in der Natur von der Identität überzeugten. Im Umrisss stimmt es ganz mit arbustorum. Kopf gewöhnlich schwarz; Punktirung der Schenkel schwächer als bei den vorigen Arten.

Gemein in Gärten auf $V$ erbascum, auch auf Urtica dioica an Waldrändern; erscheint nach der Mitte Juni bis Ende Juli:

Burgdorf, am Sommerhauswald. (Meyer.)

\section{C. Crassicornis. Hahn.}

IIaln, II. fig. 176. Mas. Phytocoris crassicornis. Ierrich Sch., Wanz. Ins. III. fig. 508. Capsus crassic.

- Nomencl. ent. I. pag. 87. Caps. terminalis.

Länge $13 / 4$. (Das Weib.)

Mann länglich, parallel; schwarz. Appendix oben und unter seiner Spitze auf der Membran gelblich weiss. Fühler schwarz. $2^{\text {tes }}$ Fühlerglied verdickt. Weib mehr eirund. 
Füliler dünn. Appendix am. Grunde und unter der Spitze weisslich durchscheinend.

In hügelichten Gegenden der mittlern Schweiz von Mitte Juni bis Ende Juli, aul Galium-Arten, an sonnigten und steinigten Abhängen stellenweise ziemlich gemein.

Burgdorf, im Oberthal häufig; zu Ende Juli auf dem Nesselboden am Jura bei. Solothurn. Auch in den Thälern von Uri. (Meyer.) Sohafthausen. (Seiler.)

\section{3\%. C. roseus. Fallien.}

Fallèn, Monogr. Cim. Suec. № 630 . Lygxus roseus.

Falir., Syst. Rhynch. № 178. Lygaus roseus.

- Entom. Syst. suppl. pag. 542.

Fallèn, Hemipt. Suec. № 47. Phytocoris.

Herrich Sch., Nomenel. entom. I. pag. 49 u. 86. (Capsus roseus und Capsus signatipes.)

- Wanz. Ins. III. fig. 287.

- Wanz. Ins. VI. fig. 604.

Herrich Sch. zieht auch Halin's variabilis, Fig. 22/, zu dieser Art, und zwar mit Unreeht; denn obschon derselbe den dunkeln Exemplaren von roseus selir nahe steht, so bin ich durch Vergleichung von mehr als 100 Individuen von der wirklichen Verschiedenheit ganz ausser Zweifel, zu dem auch dic IJahn'sche Abbildung ziemlich getreu den wahren variabilis darstellt. Dagegen ist Signatipes Iterrich aus der Artenreihe wieder auszustreichen, da er sieh nur als frisch entwickelter, noch ganz blasser roseus erwiesen hat.

Länge $13 / 4=$ 


\section{- B8 -}

Rothgelb bis dunkel kirschbraun. Appendix purpurroth. Beine schwarz punktirt und gedornt.

Roseus ist in der Schweiz sehr selten, und mir als Fundort bis jetzt nur eine einzige Stelle, auf dem Gyrisberg bei Burgdorf, bekannt, wo er sich von Anfangs Juni bis um die Mitte Juli an einem Felsen auf Acer campestre in grosser Menge vorfindet.

\section{C. vastabilis. Fullèn.}

TAF. III. Fig. 4.

Fallèn, Hemipt. Suec. № 45. Phyt. variab.

- Monogr. Cimic. Suec. № 62. Lygaus variab. II alen, Wanz. Ins. III. fig. 22/4. Phytoc. varial. IIerrich Sch., Nomencl. entom. I. pag. 52 u. 88.

- Wanz. Ins. VI. III. pag. 44.

Ilier wird variabilis mit Hahn's Polymerus holosericeus verwechselt.

Länge $1 \frac{1}{1} 2^{\prime \prime \prime}$.

Goldgelb behaart. Kopf, 'Thorax und Schildchen braun. Decken falb, nach hinten zu dunkelbraun. Appendix dunkel purpurroth, unter seiner Spitze auf der Membran ein weisser Fleck. Schenkel bis zur Spitze braun. Schienen punktirt und gedornt. Die dunkel kirschloraunen Exemplare sind von den dunkeln des $C$. roseus fast nicht zu unterscheiden.

Aufangs Juni gesellschaftlich in schaltigen, verwilderten Gräben, an Waldsäumen in tiefem Gras und Gebüsche doch nur an wenigen Stcllen und allgenein selten.

Burgdorf, an der Strasse nach Krauchthal. (Meyer.) - Bei Schaffhausen. (Seiler.) 


\section{- $89-$}

\section{C. varians mifh.}

Meyer, Inder entomol.Zeitung v. Stettin. Jahrg. $1841, \mathrm{~N}^{\circ} 6$. Herrich Sch., Wanz. Ins. VI. fig. 605. Mas.

Långe $2^{\prime \prime \prime}$.

Röthlich gelb oder olivenbraun; blass behaart; vor dem Appendix ein durchscheinendes Querband. Schicnen schwarz gedornt

Das von Herrich abgebildete Männchen, welches ich ihm mit einer Reihenfolge von Uebergängen zusandte, ist eines der allerhellsten; gewöhnlich zieht die Färbung mehr in's Grünlichbraune bis in's Olivenfarbige; doch bleibt immer, auch bei den dunkelsten Exemplaren, der Appendix der Flügeldecken lebhaft roth, oder rothgelb mit weissem Querbande.

Zu Ende Mai bis Ende Juni an einigen Stellen der Schweiz, besonders im Hügellande, an sonnigten, abgeholzten und verwilderten Waldabhängen, auf und unter jungem Tannwuchs, häufig auch auf Epilobium augustifolium und hohen Carex-Arten.

Burgdorf, im sogenannten Sommerhausloch, Maienmooswald gegen Lissach und am Gyrisberg. (MIeyer.) - Baselland, bei Gelterkinden. (Menzel.)

\section{C. modestus mili.}

TAF. III. Fig. 5.

Länge 1'I'.

Der kleinste aller mir bekannten Capsinen, kaum so gross als pteridis und rerbasci. Kurz oval; Thorax breit, vor'n abgerundel, abschüssig. Kopf breit angezogen, abwärts gerichtet, daher von oben kaum sichıbar. Fühler 
von Körperlänge, dünn, blass, bräunlich. Hinterschenkel stark verdickt. Färbung des ganzen Thierchens oben und unten sehr dunkel, einfarbig purpurbraun.

Aeusserst selten. Ich kenne nur 2 Exemplare, und habe sie am 14. Juni 1840 auf dem Gyrisberg bei Burgdorf von Gesträuche geschlagen.

\section{C. fureatus. H. S.}

Herrich Sch., Nomencl. ent. I. pag. 52 u. 84.

Wanz. Ins. IV. fig. 408 u. 409.

Länge $13 / 4 "$.

Glatt, schwarz, braun oder rothgelb; mehr oder weniger gelbe Zeichnungen über Kopf, Thorax, Schildchen und Decken. Spitzen der Decken stets blassgelb. Ausserordentlich in hellerer, dunklerer oder bunter Farbe und Zeichnung abändernd.

Nicht allenthalben in der Schweiz vorkommend, aber stellenweise in übersehwenglicher Menge, auf allen Weidenarten an Bächen und Flussufern, von Mitte Juni bis Ende Augusts.

Burgdorf, längs der Emme. (Meyer.) - Um Basel. (Imhoff.) Schafhausen. (Seiler.)

\section{C. verbasci. Uterrich Sch. in litt.}

$$
\text { TAF. IV. Fig. } 1 .
$$

Länge $1 \frac{1}{1} \mathbf{3}^{\prime \prime \prime}$.

Unbehaart. Flach, länglicher, aber kaum grösser als der bekannte $C$. filicis. Appendix und Membran nicht abwärts geknickt. In Form und Umriss dem Furcalus am 


\section{- ร1 -}

nächsten; Thorax kürzer, vorn breiter; Kopf stumpf, vorn abwärts gebogen. Färbung: Unten glänzend pechschwarz, oben glatt, glänzend grünlichgrau. Fühler von halber Körperlänge, glänzend strohgelb. Glied 1 vor der Spitze und 2 an der Basis schwarz. Kopf röthlich, soauch derHinterrand des Thorax. Appendix der Decken durchsichtig mit einer deutlichen, schwarzen Grube. Membran gross, glashell, lebhaft irisirend. Beine fahl grünlich, überall schwarz punktirt; Schienen stark gedornt; Hinterschenkel verdickt.

Erscheint um die Mitte Juli, meistens in ziemlicher Anzahl, in Gärten und Feldern auf Wollkraut (Verbaseum thapsus).

Burgdorf, gemein. (Mfeyer.) - Schaffhausen. (Seiler.) - Basel. (Imhoff.) - Genf. (Buess.) - Bonneville. (Coppier.)

\section{C. flicis. Limn.}

Linn., Fauna Suec. 919. Cimex filicis.

- Syst. Nat. pag. 212. 720.

Wolff, II. pag. 46. № 45. fig. 45. Acauthia filic.

Fallèn, Monogr. Cim. pag. 92. $\mathrm{N}^{\circ} \mathbf{7 4}$. Lygæus filicis.

- Hemipt. Suec. pag. 108. № 61. Phylocoris. filic. Ilahn, Wanz. Ins. II. fig. 172. Phytoc. filicis. IIerrich Sch., Nomencl. entom. I. pag. 51 u. 84. Caps. filic.

Länge $11^{\prime \prime \prime}$.

Kurz, eiförmig, glänzend; heller oder dunkler pechbraun; Kopf, Fühler und Aussenrand der Decken heller.

Eine sehr weit verbreitete, obschon nicht überall vorkommende Art; erscheint schon vor Mitte Mai bis gegen Ende Augusts gesellschaftlich auf Farnkraut (Polypodium felix Linn.) an lichten Waldabhängen. 
Zürich, auf dem Albis sparsam. (Bremy.) - Burgdorf, auf dem Leuen und Pleerwald sehr gemein. (Mcyer.) - Matt, im Kant. Glarus, 2560 Fuss. ü. M., am Gotthardt häufig. (IIeer.)

\section{C. rubieundus. Fallèn.}

Fallèn, Monogr. Cim. Suec. № §5. Lygxus rubicundus. Ilahn, fig. 80. Lygus rubricatus. - Capsus aurantiacus mihi, olim.

\section{Länge $2^{\prime \prime \prime}$.}

Glänzend, hoch rothgelb; nur mikroskopisch behaart. Fühler etwas mehr als von halber Körperlänge, dünn, borstenförmig, gelblich. Beine weilläufig und schwach gedornt. Hinterschenkel gegen die Spitze blutroth. Augen vorstehend, schwarz. Kopf, Thorax und Schildchen sehr fein chagrinartig, lebhaft rothgelb; Decken etwas blasser, durchscheinend. Appendix an der Basis schmal, farblos; äusserste Spitze am Jnnenrande dunkel blutroth. Membran angeraucht, irisirend; Zellennerv rothgelb.

Unten: Brust und Bauch gelblich; die Seiten röthlich.

Drei mehr in's IIornbraune übergehende Exemplare mit dunkeln Randmakeln der Membran und gelblichem Zellennerv, welche ich am 26. Juni von jungen Föhren im hiesigen Plecrwald abschöpfte, scheinen mir blosse Liokalvarietäten.

Im Ganzen wenig verbreitet, und nur an einzelnen Stellen des IIügellandes im Juni bis Anfangs Septembers auf jungen Tannen, an gebüschreichen Waldabhängen vorkommend.

Champel, bei Genf. (Buess.) - Gegend von Basel. (Imhoff.) Burgdorf, auf dem Leuen; auch in wahrer Unzahl in den Tannwäldern des Lindenthals und an den nordöstlichen Abhängen des Bantigers, doch nicht über 2800 Fuss hinauf. (Mcyer.) 


\section{C. rubricatus. Fithèn.}

Fallèn, Monogr. Cim. pag. 91. No 70. Lygxus rubricat.

- Hemipt. Succ. No 43 . Phytocoris rubricatus.

IIahn, Wanz. Ins. I. fig. 18. Lygæus rubricatus. Lygus rufescens.

Herrich Sch., Nomencl. entom. I. pag. 49 u. 86.

Länge $2 \frac{1}{2}{ }^{\prime \prime \prime}$.

Roth- oder braungelb; Kopf und Vordertheil des Thorax zuweilen blassgelb. Appendix stets dunkelroth. Schenkel mit 2 braunrothen Ringen. Fühler kurz.

Von Ende Mai bis Mitte Augusts auf Weidengebüschen an Flüssen und Bächen; an manchen Orten in der Schweiz gemein, und vielfach in der Färbung vom hellsten Rothgelb bis in's Braunrothe abändernd.

Um Schafhbausen. (Seiler.) - Um Zürich gemein. (Bremy.) Genf nưr einzeln. (Buess.) - Burgdorf, in den Schächen länģs der Emme, aber nicht alljährlich in gleicher Menge. (Meyer.) - Bündten (Amstein.)

\section{C. atomarius mihi.}

TAF. IV. Fig, 3 ,

\section{Länge $21 / 4^{\prime \prime \prime}$}

Gestalt von rubicundus Fall., nur wenig grösser, Decken überall gleich breit. Brust pechsehwar'z; Bauch hellbraun. Schnabelscheide, Beine und Fühler hellgrünlichbraun; letztere von halber Körperlänge. Die Schenkel gegen die Spitze rostroth gefleckt oder geringelt; Schicnen schwach gedornt, aber nicht punklirt. Kopf abwärts geneigt; zwischen den Augen schwarz; am Hlinterrande hellbraun gesäumt. Thorax, Schildchen und Flügeldecken hellgrünlich- 
braun oder bräunlich-olivenfarbig, überall, mit Ausnahme des Schildchens, welches einen dunkeln Längsstreifen führl, mitzerstreuten pechschwarzen Atomen übersäet. Membran matt, braunfleckig.

Neu, und wohl eine der seltensten Arten, von welcher mir nur 2 Exemplare bekannt sind. Eines fieng ich am 6. September 1839 auf dem Ramisberg, hinter Trachselwald, (Enmenthal). Das andere sah ich in der Sammlung des IIrn. Dr. Imhoff, (aus der Umgegend von Basel).

\section{C. Salicellus miki.}

Herrich Sch., Wanz. Ins. VI. fig. 603 .

Länge $1^{3 / 4} / 11$ 。

Eine ungemein schöne, zart gebaute Art; $\operatorname{dem} C$. sanguincus ziemlich nahe stehend, obwohl etwas länger und schmaler; matt, hellbräunlich grau, rosenroth angeflogen. Kopf und Vordertheil des 'Thorax gelblich; Hintertheil, das Schildchen und die Flügeldecken mit braunen Atomen bedeckt; auf den Letztern bilden sic 3-4 Längsreihen kleiner Ringelchen. Appendix weisslich opal; am Innenrande nur zuweilen mit blutrothem Rande. Membran weisslich irisirend, mit 3 dunkeln Flecken. Fühler nicht völlig Körperlänge, strohgelb; Glied 1 mit 2 dunkeln Ringen. Beine gelblich; Schenkel von der Mitte gegen die Spitze grob schwarz punktirt, an den Ilinterschenkeln so dicht, dass sie einfarbig dunkel erscheinen. Schienen stark gedornt und schwar\% punktirt. Die zwei äussersten Tarsenglieder schwarz.

Unten alles blass, weisslich. 
Herrich's Abbildung, Fig. 608, ist nach einem einzelnen, von mir erhaltenen Exemplare gemacht; nur ist die Zeichnung des Thorax und Schildchens etwas zu grell und die Punktirung der Flügeldecken zu zerstreut, daher nicht die natürlichen Ringelchen darstellend. - Gestalt und Umriss übrigens sehr getreu.

Selten; mit dem nachfolgenden Sanguineus von Anfangs bis Mitte Augusts einzeln auf Weiden- und Haselgebüsch vorkommend.

Burgdorf, längs der Emme und am Sommerhauswald; im Kant. Uri an pllanzenreictien Waldabhängen bei Altdorf. (Meyer.)

\section{C. coccineus. Westerh.}

$$
\text { TAF, IV. Fig. } 5 .
$$

\section{Länge $13 / \iota^{\prime \prime \prime}$.}

Unter diesem Namen erhielt ich von Hrn. von Ougspurger eun einzelnes, angeblich an der Engehalde bei Bern gefangenes Exemplar, das sich von unserem salicellus durch grössere Breite, mehre eirunde Form, deutliche Behaarung, lebhaft hochrothe Färbung mit regelmässigen runden, blassern Flecken der Decken und unpunktirte Schenkel und Schienen unterscheidet. Die Zeichnung und Vertheilung der Farben ist aus der Abbildung ersichtlich. Die Membran ish an meinem Exemplare zerrissen.

\section{C. sanguineus. Fabr.}

Fabr., Syst. Rhynch. N ${ }^{\circ}$ 179. Lygaus sanguineus.

- Entomr. Syst. 144.

Fallèn, Monogr. Cim. $N^{\circ} 66$. Lygæus. 
Fallèn, Hemipt. 48. Phytocor.

Ilerrich Sch., Nomencl. I. pag. 51 u. 87.

- Wanz. Ins. III. fig. 286.

Länge $11 / 211$.

Sehr zart; gelblich weiss mit purpurrothen Punkten und schneeweissem Anhang. Auf dem Thorax zuweilen streifenartig gezeichnet. Beine schwarz punktirt. Ein äusserst zartes, weiches Thierchen, dessen schöne Färbung jedoch nur selten so lebhaft ist, wie sie Herrich darstellt.

Sehr einzeln auf Weidengebüsch an Flüssen in den letzten Julitagen mit furculus und salicellus.

Burgdorf, in Schächen an der Emme (Meyer.) - Bei Zürich. (Bremy.)

\section{C. chorizans. Eullèn.}

\section{TAF, IV. Fig. 4.}

Fallèn, Monogre. Cimic. № 55 . Lygaxus chorizans.

Panzer, Fauna ins. Germ. 18. 21. Lygaxus (schr schlechte Abbildung).

Ilerrich Sch., Nomencl. entom. I. pag. 50 u. 85. Capsus chorizans.

Länge $13 / 4$.

Lang gestreckt, schmal, hell gelblichgrün, fein weiss behaart; Flügeldecken und M(embran spangrün gefleckt; letztere prächtig irisirend.

Es gibt auch Exemplare, auf deren Flügeldecken die grünen filecke ganz verschwunden, und Andere, wo sie in grössern Mlackeln verllossen sind.

Für die ganz missrathene, und meines Wissens cinzige Abbildung von Panzer, schien es mir gut, eine bessere zu licfern. 
In der Schweiz an einzelnen, sonnigten Stellen im Ilügellande, zu Anfang bis Ende Augusts an Waldsäumen auf Haselgesträuchen, oft gesellschaftlich, doch nicht allerwärts einheimisch.

Burgdorf, am Sommerhauswald und am Schlossberg sparsam. Ende Juli am Lowerzersee ziemlich häufig. Gemein an der Südseite des Bantigers bis 3000 Fuss ü. M. (Meyer.)

\section{C. viridulus, Fallèn.}

TAF. VII. Fig. 2.

Fallèn, Monogr. Cim. Suec. pag. 90. № 69. Lygæus viridulus.

- Hemipt. Suec. pag. 105. No 54 . Phytocoris virid. IIaln, Wanz. Ins. II. fig. 221. Phytocoris virid.

Ilerrich Sch., Nomenel. entom. I. pag. 50 u. 88, Capsus vịidulus.

Länge fast $2^{\prime \prime \prime}$.

Glänzend, bleichgrün, fein schwarz behaart. Fühlerglied 1 in der Mitte und 2 am Grunde mit dunkelm Ring. Beine schwarz punktirt.

Eine der gemeinsten, von Mitte Juni an bis im August auf allen Wiesen, Grashalden und Feldbördern in überschwenglicher Menge vorkommende Art.

\section{C. Jortulanus milei.}

TAF, VII. Fig, 3.

Länge $13 / 4=$.

Es scheint mir diese niedliche Wanze mit viridulus zusammengeworfen zu sein, für welchen auch Ilerrieh Sch. 


\section{$-78-$}

mir seiner Zeit sie bestimmte. Oeftere Beobachtungen in der Natur und die Vergleichung von etwa 120 Individuen haben mir für die Trennung volle Gewissheit gegeben. Hortulanus unterscheidet sich von viridulus: 1) durch geringere Grösse ; 2) durch frischeres, lebhafteres Grüngelb, welches besonders an Kopf und Thorax sich auch nach dem Tode gleich bleibt, und durch den Mangel des Glanzes; 3) durch den fehlenden dunkeln Ring am ersten und zweiten Fühlergliede; 4) durch die unpunktirten Schenkel und Schienen.

Im Juni und Juli gesellschaftlich mit viridulus, an sehr heissen Feldbördern und Abhängen, besonders auf Ononis spinosa.

Burgdorf, im Oberthal ziemlich häufig. (Meyer.)

\section{C. prasinus. Healene.}

IIahn, Wanz. Ins. III. fig. 233. Phytocoris prasinus.

Länge $1 \%$-2 2'1".

Grasgrün, sparsam behaart. Kopf, Vordertheil des Thorax, des Schildchens, die Aussenränder der Decken und der Appendix gelb. Hinterschenkel verdickt.

Im Ganzen wenig verbreitet.- In der mittlern Schweiz, im Gebiete der Molasseformation, im August an sonnigen Felsen und Abhängen auf Erica vulgaris.

Burgdorf, am Bätwylberg, Lochbach, Taubenflühli und Binsberg; in ungeheurer Menge auf den Höhen des Lindenthales; auf der Bantigerkette von 2800-3200 Fuss ü. M. (Meyer.)

\section{C. molliculus. Faltèn.}

Fallèn, Monogr. Cim. Suec. № 55 . Lygæus molliculus.

- Hemipt. Suec. NN 12. Phytocoris molliculus. 
IIerrich Sch., Nomencl. ent. I. pag. 49. 85. Capsus molliculus.

- Wanz. Ins. VI. fig. 589. Capsus mollic.

Länge $21 / 4-2 \frac{1}{2}{ }^{\prime \prime \prime}$.

Matt, deutlich behaart; blass okergelb. Kopf und Thorax vorn grünlich. Decken verloschen braun gefleckt.

An steinigten, verwilderten, überwachsenen Abhängen der mittlern und nördlichen Schweiz; an einigen Stellen häufig, besonders auf Digitalis lutea und Verbascum thapsus von Anfangs bis Ende Juli.

Burgdorf, im Oberthal, gemein. (Meyer.)-Gelterkinden, Kant. Basel, etwas seltener. (Menzel.)

\section{C. seladonius. Fallèn.}

Fallèn, Monogr. pag. 77. № 34 . Lygæus seladonius.

- Hemipt. Suec. $\mathbf{N}^{0} 11$. Phytocoris selad.

Herrich Sch., Nomencl. entom. I. pag. 49 und 87. Caps. seladonius.

- Wanz. Ins. VI. fig. 5990.

Länge $23 / 4-5^{\prime \prime \prime}$.

Glanzlos, stark schwarz behaart. Blass graulich oder grünlich blau, Kopf, Vordertheil des Thorax und des Schildchens oft orangegelb.

An den gleichen Stellen mit molliculus, doch weniger häufig. Von Ende Juni an bis Mitte Augusts auf Galium mollugo und verum.

Burgdorf, an den sonnigten Abhängen im Oberthal.

\section{C. albipennis. Fallèn.}

Fallèn, Hemipt. Suec. pag. 107. № ̋9. Phytocoris albipennis. 
IIahn, Wanz. Ins. II. fig. 177. Phytocoris albipennis. IIerrich Sch.. Nomencl. entom. I. pag. 82. Capsus albip.

Länge $1 t / 2 " 1$.

Schwarzgrau, behaart. Im hellumzogenen Anhang ein schwarzer Fleck. Hinterschenkel schwarz; Schienen schwarz punktirt und gedornt.

Von Ende Juni bis Ende Juli in der mittlern Schweiz in Pflanzplätzen und Gärten auf Artemisia abrotanum, Pontica und vulgaris gesellschaftlich.

Um Burgdorf gemein. (Meyer.)

\section{C. alienus. Zherrich Seh.}

IIS., Wanz. Ins. III. fig. 271.

- Nomencl. ent. I. pag. 48.

Länge $13 / 4=$.

Glänzend graubraun punktirt. KopfundFühlerschwarz. Einfassung der Augen, Ilals, Mittellinie des Thorax und Seiten des Schildchens gelblichweiss.

Von Mitte Mlai an bis Ende Juli an sonnigten, blumenreichen Abhängen der mittlern Schweiz gemein. Ein Weib fand ich schon am §. Nai auf Pfingstnelken.

Burgdorf, auf dem Gyrisberg und in den Pflanzplätzen des Oberthals in ausserordentlicher Menge. (Meyer.)

\section{C. annulatus. Wolfr.}

Wolf, Fig. 156. Gerris annulata.

Herrich Sch., Nomencl. I. pag. 48 u. 82. Caps. annulat. - Wanz. Ins. III. fig. 270.

Länge. 11/2。 


\section{- 81-}

Dem Vorigen äusserst ähnlich, doch kleiner, und sogleich durch die etwas dickern und weiss geringelten Fühler und die 2 dunkeln Punkte vor und unter dem Appendix zu erkennen. Von der vorigen Art fast nur durch geringere Grösse und die weiss geringelten 2 ersten Fühlerglieder verschieden.

Vom 20. Juni an bis gegen Ende Juli an den gleichen Stellen auf Ononis spinosa $L$.; doch weit weniger häufig.

Um Zürich nicht selten. (Bremy.) - Basel gemein. (Imhoff.) Burgdorf, im Oberthal und auf dem Gyrisberg. (Meyer.)

\section{C. Thunbergia fallèn.}

Fallen, Hemipt. Suec. pag. 105. №56. Phytocoris Thunb. Germar, Fauna. 15. 19. Miris Thunb. Hahn, Wanz. Ins. I. fig. 75. Lopus Hieracei.

IIerrich Sch., Nomencl. entom. I. pag. כ̋0. 87. (Capsus.) Länge $2^{\prime \prime \prime}$.

Behaart, gelbloraun, Kopf und Thorax mit blassgelben Mittel-, und Decken mit gelblichen, schrägen Längsstreifen. Beine schwarz punktirt.

An sonnigten, hochbegrasten Hügeln und Bergwiesen von Ende Mai an bis gegen Ende Augusts; stellenweise in Menge.

Zürich, am Uto. (Bremy.) - Am Lägerberg, bei Baden, und um Schaffhausen. (Seiler.) - Baselland, um Sissach. (Menzel.) - Am Jura, bei Solothurn; in den Emmenthaler-Bergen am Napf, Hoch-Enzi, Farnli, Arni u. a. O. selir gemein; Burgdorf, auf dem Gyrisberg in grosser Mengo. (Meyer.)

\section{C. maculipennis. BrS.}

TAF. V. Fig. 1.

Herrich Sch., Nomencl. ent. I. pag. 50. u. 85 5. Länge $11 / 4-11 / 211$. 
Grüngelb. Ilintertheil des Thorax und Spitze spangrün; Decken unregelmässig schwarz gefleckt. Membran schwarz, mit gelblichweissen Nerven. Fühler und Beine dunkel olivengrün oder schwärzlich, und letztere weder bedornt noch behaart.

An heissen, steinigten Ilügeln der mittlern und nördlichen Schweiz von Mitte Juni bis Mitte Juli auf Ononis spinosa $L$. und arvensis $L a m$.; stellenweise ziemlich gemein.

Zürich, auf dem Irchel und Uto. (Bremy.) - Burgdorf, auf den Galgenhügeln, gegen das Oberthal, zahlreich. (Meyer.) - Um Basel auch nicht selten. (Imhoff.)

(Nur bei frischen Exemplaren haben die Flügeldecken viele schwarze, unregelmässige Flecken, welche aus flachliegenden, starken IIaaren gebildet sind und sich leicht abwischen.)

\section{B. C. bilineatus. Fullèn.}

Fallin, Monogr. Cimic. Suec. pag. 102. № 15.

Zetterstedt, Insect. Lapp. №

Iterrich Sch., Nomencl. entom. I. pag. 50 u. 82.

Wanz. Ins. III. fig. 285.

Länge $2^{\prime \prime \prime}$.

Schwarz behaart, grünlich grau. Der schwarze Kopf mit gelben Mondflecken. Schildchen gelblich, mit schwarzem Mittelstreife. Nerven der Membran weisslich, in denselben und um den Appendix schwarzfleckig. Fühler und Beine schwarz.

In der Schweiz selten.

Bündten. (Amstein.) 


\section{$-83-$}

\section{6\%. C. solitarius mihi.}

Länge $23 / 4^{\prime \prime \prime}$.

TAF, V. Fig. 4 .

Gestalt und Umriss von C. molliculus. Grösse von pabulinus Zett. Kopf klein, in eine stumpfe Spitze auslaufend. Augen wenig hervorragend. Die dunkelolivenfarbigen Fühler von halber Körperlänge. Beine etwas heller gleichfarbig, ungedornt und nicht punktirt. Moosgrïn, mall und glanzlos; die Flïgeldecken durch aufliegende IIäärchen dunkel schattirt; vor dem Appendix cin dunkler Fleck. Membran rauchgrau; innerhalb dem weisslichen Zellennerv schwarz; um den Rand 5 schwärzliche Flecken, wovon der miltelste der grösste.

Unten cinfarbig, grasgrün, glanzlos.

Von dieser anschnlichen, sehr seltenen Art sind mir blos 2 weibliche Exemplare bekannt, die ich am 19. Juli 1841 in einem wilden Bergtobel im Sommerhauswald bei Burgdorf rom dichtem Gesträuche von Stachys sylsatica und Polypodium felix abschöpfte.

\section{B3. C. collaris. Fallèn.}

Fallèn, Hemipt. Suec. pag. 12:. No 19.

- Monogr. Cim. pag. 105. No 18.

Wol/f, Icon. cim. fig. 15\%. Gerris errans.

Ilukn, Wanz. Ins. II. fig. 205. Cyllocoris collaris.

Ilervich Sch., Nomencl. ent. I. pasg. 85.

Länge $21 / 4$.

Lang, durchscheinend, bräunlich; Decken punktirt, mit schwärlichen Nerven, einigen Längsflecken und schwärlichen Spitzen. Thorax gestreckt, rom halsförmiç verengt, mit 2 glänzenden Querwulsten. Schenkel punktirt. 
An einzelnen gebüschreichen Stellen der mittleren Schweiz im Ilügellande; auch am Jura in der Nähe von Sümpfen und moosigten Weiden. Am häufigsten in den Schächen und an gebüschreichen Waldsäumen des ganzen Emmenthals; von Anfangs Juni an bis um die Mitte Oktobers auf verschiedenen blühenden Pflanzen, besonders auf Stachys sylvatica $L$. Im October verfliegt sich diese niedliche Wanze bis in die obersten Stockwerke der Iläuser linauf, wo Blumentöpfe vor den Fenstern stehen, Ich fand sogar noch am 26. Dezember sehr schöne Exemplare auf Blumen in meinem Zimmer.

Burgdorf, am Gyrisberg, an der Schlossfuh, Sommehrauswald; bei Goldbach und anderen Stellen gemein; Solothurn, am Fusse des Jura, nur einzeln.

\section{C. pallidus. \#levmich Soh.}

HS., Wanz. Ins. III. fig. 269.

- Nomencl. entom. I. pag, 48 u, 86 ,

Länge $2 s / 2$ '

Blass hornfarbig, durehscheinend, gelblich behaart; ohne Zeichnung der Decken. Thorax halsförmig gestreckt. Fühlerglied 1 mit rothen Ringe; zwischen den Augen ein dunkler Fleck.

Im Mai bis Mitte Juni noch unentwickelt, meist gesellschaftlich. Von da an ausgebildet und bis gegen Ende Augusts an schalligen, gebüschreichen Abhängen, in wildenTobeln und an Waldrändern desIlïgellandes stellenweise sehr gemein. Lebt auf Eschen, Erlen, Feldahorn, Pappeln und Ilaselgesträuchen. 


\section{$-85-$}

Um Zürich und östlicher sehr selten. (Bremy.) - Einzeln am Fusse des Jura, bei Solothurn; in grosser Menge um Burgdorf, im Schlossgraben und auf Eschen am Fusso des Gyrisbergs. (Meyer.)

\section{C. virgula. Iferrich Selh.}

IIS., Wanz, Ins. III. fig. 268.

- Nomencl. entom. I, pag. 48 u. 188.

Länge $12 / 3$ '

Milchweiss, mit gelblichem Clavus, Appendix und Beinen. Kopf schwarz, mit gelblichen Mondflecken. Karminroth ist : ein Ring am 1 ten Fühlerglied, ein Querband des Thorax, die Spitze des Appendix und die Nerven der Membran.

Sehr selten, und stets nur einzeln in der wärmeren Schweiz in Gärten und an sonnigten Hügeln von Anfangs Juli bis Mitte Augusts auf Lonicera etrusca, caprifolium und sempervirens.

Um Genf. (Buess.) - Burgdorf. (Meyer.) - Basel. (Imhoff.)

\section{C. caricis. Fullèn.}

Fallèn, Monogr. Cimic. Suec. pag. 102. № 14.

- Hemipt. Suec, pag. 123. No 15.

Mahn, Wanz. Ins. II. fig. 184. Cyllecoris caricis.

Ilerrich Sch., Nomencl. entom, I. pag. 52 u. 85.

Länge $2^{\prime \prime \prime}$.

Schwarz. Decken braun ; die Beine gelblich.

In der mittlern Schweiz im Juli in Gärten und an sonnigten Abhängen auf Verbascum und Carex-Arten, doch selien.

Burgdorf, im Oberthal. (Meyer.) 


\section{6ร. C. ambulans. Fultèn.}

Fallèn, Monogr. Cim. Suec. № 18. Ilemipt. Suec. № 20. Herrich Sch., Wanz. Ins. III. fig. 53\$ - 557.

- Nomencl. entom. I. pag. 82. 83.

Länge $21^{\prime \prime \prime}$.

Schwarz, mit gelben Beinen und braunen, bei'm Manne lichtern, durchsichtigern Decken; doch schwärzlichem Clavus; bei'm Weil) das $2^{\text {te }}$ Fühlerglied elwas verdickt und das $5^{\text {to }}$ an der Wurzel weiss.

Sehr selten. Um die Mitte August's in wilden Felsgegenden auf Gebüschen und im hohen Grase. Meistens findet man blos unausgebildete Weiber.

Am IIohenrohnen 3000 Fuss ü. M. (Bremy.) - Burgdorf im Schlossgraben und am Leuen. (Meyer.)

\section{C. Alecolor. Fallèn.}

Fallèn, Monogr. Cimic. № 18.

IIerrich Sch., Nomencl. entom. I. pag. 49 u, 85.

IIahn, Wanzenart. Ins. I. fig. /4. Lopus chrysanthemi.

Länge $2^{\prime \prime \prime}$.

Hellgraubraun, ein Fleck auf dem Kopfe, der Grund des Schildchens und der Aussenrand der Decken gelblich. Fühler nackt und wie die Beine, dunkelolivenfarbig.

\section{C. elegantulus milki.}

TAF. V. Fig. 2.

"Länge $1 \% 31 "$.

Dem Caps. Markelii IIS. wanz. Ins. IV: fig. 406 , in allen Theilen äusserst nahe, doch nach dem angegebenen Längenmasse fast um die Iälfte kleiner und in der 


\section{$-8 r-$}

Färbung verschieden. Fühler ganz schwarz, Kopf etwas breiter und stumpfer, zwisehen den Augen mit 2 hellgrünen Flecken, Flügeldecken grasgrün statt gelblich. Membran und alles Uebrige völlig wie bei Markelii. Ich kenne von dieser neuen, äusserst seltenen Art nur ein einziges Exemplar, welches ich am 28. Juni 1840 , bei Burgdorf in einem Schachen an der Emme auf niedrigem Erlengesträuche mit $C$. plagiatus erbeutet habe.

\section{ต0. C. clavatus, thinn.}

Linn, Syst. nat. pag. 729. № 97. Cimex clavatus. Fallìn, Monogr. cimic. $\mathrm{N}^{\circ}$ 5. Capsus bifasciatus (ohne Diagnose).

Fabr., Syst. Rhynch. 2/2. 7. Capsus bifascalus (olıne Diagnose).

IIahn, Icones ad monogr. Cim. I. № 25. Philophorus bifase. IIerrich Sch., Nomencl. ent I. pag. 48 u. 85. (Capsus clavatus.).

- Wanz. Ins. III. fig. 26\%. (Capsus clavalus.)

Burmeister, IIandb. der Entom. II. pag. 266. (Phytocoris.) Länge $2^{\prime \prime \prime}$.

In Bau fast einer Ameise ähnlich. Metallisch schwarzgrün, Beine und Decken braun oder zimmetroth; letztere mit 2 silberfarbigen, schuppenartigen Querbinden. Augen stark rückwärts abstehend. $2^{\text {tes }}$ Fühlerglied etwas verdickt, das $3^{\text {te }}$ am Grunde weisslich, sonst, wie die übrigen Glieder, braun.

Fast überall in der Schweiz in den Ebenen und im Uügellande, von den letzten Maitagen an bis Mitte Augusts, 
auf Salixarten längs den Bächen und Flüssen, in Schächen und andern gebüschreichen Stellen sehr gemein. Fast zimmtbraune Exemplare findet man um die Mitte Juli auf kleinen Aepfelbäumen in Gärten. Ob eigene Art oder nur Localvarietät?

\section{ซึ. C. decoratus mihd.}

IIerrich Sch., Nomencl. entom. I. pag. 48 u. 83. Capsus bifasciatus.

- Wanz. Ins. III. fig. 265. Capsus bifasciatus.

Die von IIerrich zu dieser Abbildung gezogenen Citate von Fabr. und Fallèn gehören nicht zu dieser Art, sondern zu Phyt. bifasciatus IIahn. fig. 252. Da nun 2 verschiedenen Capsinen unmöglich der gleiche Name zukommen kann, so musste der eine geändert werden. Die Fabricischen und Fallèn'schen Diagnosen passen zwar sowohl auf die eine wie auf die andere Art; doch deutet Fallin's Ausdruck: antennis testaceis, eher auf den Ilahn'schen Phyt. bifasciatus, weil unser decoratus, mit Ausnahme des ersten Gliedes, schwarze Fühler hat.

Länge $21_{2}^{\prime \prime}{ }^{\prime \prime}$.

Schwarz, ertes Fühlerglied und die Beine rothbraun, Decken schwarzbraun, mit 2 schmalen, silberschuppigen Querbinden und 2 Silberflecken auf dem Schildchen. Uebrigens schmäler und gestreckter, als die vorige Art.

Viel seltener, als der vorige, aber nicht so allgemein verbreitet. Im Juli einzeln auf Ilecken an Wiesen, besonders in den Weingeländen der nördlichern Schweiz.

Zürich, bei Dübendorf. (Bremy.) - Um Schafthausen (Seiler.) - Zeilen im Frickthal (Menzel). 


\section{g2. C. angुulatus Éallèn.}

Frallè, Monogr. Cim. Suec. № 52. Lygreus ang.

- IIemipt. Suec. No 8. Pliytocoris ang.

Ilerrich Sch., Nomencl. ent. I. pag. 48 u. 82. Capsus ang.

Wanz. Ins. III. fig. 292. Capsus ang.

Länge $21{ }^{\prime \prime} / 11$.

Gestreckt. Thorax mil liefem Quereindruck und schwarzen, spitz aufgehobenen Ilinterrandecken. Grünspangrün; erstes Fühlerglied mit 2 dunkeln Ringen und weisser Spitze. Die Wurzel des 2ten schwarz. Die glashelle Membran mit 2 braunen Punkten, 2 Strichen und bräunlichem Schatten unter der Spitze des Appendix.

Von der Mitte Juni bis zu Linde Juli in Gïrten auf Ribes, Lonicera- und Spirea-Arten; auch in Schächen auf Weiden an manchen Orten der mittlern Schweiz in grosser Menge.

Um Burgdorf, in Gärten; im Kanton Uri, bei Altdorf, im Schächenthal und andern Stellen sehr gemein. (Meyer.)

\section{C. nubilus Herrich Sch.}

Panzer, Fauna Ins. 135.9.

Länge $1 \frac{21}{\prime \prime \prime}$.

Langgestrecht, schmal. Ilellgrasgrün, $f^{\text {tes }}$ Fülllerglied tief schwarz; ein schwarzer Fleck hinter den dunkellıaunen Augen. Membran glashell, irisirend, mit 2 schwärzlichen Zackenbinden.

In der Schweiz, wie es scheint, bis jetzt gar nicht bekannt gewesen. Findet sich bei Burgdorf gegen Ende Mai, his um die Mitte Juli in erstaunlicher Menge auf Stuchys s) Voulica an 2 Stellen im Gehölze an Fusse des Gyrisbergs, und in einem wilden Bergtobel des Sommerhauswaldes. 
Die Panzer'sche Abbildung scheint nach einem verblassten Stücke gemacht zu sein, da alle hiesigen Exemplare weit lebhafter grün sind. Nach dem Tode wird aber die Färbung goldgelb.

\section{C. triguttatus H. $_{\text {. }}$}

Linn., Syst. Nat. II. pag. 729. № 94 . Cimex 3 gultalus. Fallèn, Monogr. Cim. Suec. pag. 101. № 11. Capsus 3 guttatus.

- Hemipt. Succ.pag. 121. № 12. Capsus 5 guttatus. Fabr., Syst. Rhynch. 183. Lyg. 3 gutt. u. Entom. Syst. 146.

Ilahn, Wanz. Ins. II. fig. 183. Cyllecoris triguttalus. IIerrich Sch., Nomencl. entom. I. pag. 88. Capsus triLange $1_{2 / 3}{ }^{\prime \prime \prime}$. guttalus.

Schwarz, mit braunen Decken, auf welchen eine weisse, schwärzlich eingefasste Querbinde und ein solcher Fleck vor dem Ende sich auszeichnet. Die nackten Füsse, so wie auch das $1^{\text {to }}$ Fühlerglied röthlichbraun.

Eine äusserst niedliche, doch stets nur sehr einzeln vorkommende, seltene Art.

Bei Genf. (Buess.) - Zürich, sehr selten. (Bremy.) - Basel, (Imhoff.) - Baselland, an der Sissacher-Fluh auf Tannen. (Menzel.) Ein sehr schönes Exemplar fand ich am 5. Juni auf der Röthefluh ob Solothurn 3950 Fuss ü. M. und ein anderes Ende $\Lambda$ ugusts auf dem Bantiger bei Bern. (Mcyer.)

\section{כอั. C. histrionicus, Einen.}

Linn., Syst. Nat. pag. 728. 89. teste dom. Fallèn. Cim. histrion. 
Fabr., Entom. Syst. IV. pag. 182. № 170. Lygxus agilis. - Syst. Rhynch. pag. 247. № 51. Capsus agilis. Fallèn, Monogr. Cim. Suec. pag. 100. № 9.

- Hemipt. Suec. pag. 120. № 10.

Hahn, Wanz. Ins. II. fig. 182. Cyllecoris agilis.

Ilerrich Sch., Nomencl. I. pag. 48 et 84.

Länge $3^{1 / 3} \mathbf{s}^{\prime \prime \prime}$.

Gestreckt, schmal, glänzend, schwarz. Decken abwechselnd kastanienbraun, braunröthlich und weiss. Schildchen stets blassgelb. Appendix orange. Fühler und die Beine blass röthlichgelb.

Sehr verbreitet, doch in der Schweiz nicht allerwärts vorkommend. Erscheint in den letzten Maitagen, bis gegen die Mitte Juli, an dürren, heissen Feldrainen und höhern Viehweiden bis 3900 Fuss ü. M., sowohl einzeln, als gesellschaftlich, auf jungem Eichengebüsche.

Um Zürich, selten. (Bremy.) - Baselland, um Gelterkinden. (Menzel.) - Schaffhausen. (Seiler.) - Burgdorf, auf dem Gyrisberg, so wie auch einzeln auf dem Weissenstein ob Solothurn.

\section{ซ6. C. Havomaculatus Habr.}

Fabr., Entom. Syst. IV. pag - 182. № 169. Lygæus flavomac.

Wolff, III. pag. 114. № 108. Tab. 11. fig. 108.

Fabr., Syst. Rhyynch. № 50. Capsus flaromac.

Fallèn, Monogr. Cim. № 8. Capsus flavomac.

- Hemipt. Suec. № 9.

IIahn, Wanz. Ins. III. fig 233. Cyllecoris flavomac.

Panzer, Fauna Ins. 92. 16.

Länge $5^{\prime \prime \prime}$. 


\section{- 1) -}

Gestreckt, schwarz, mit 2 gelben Flecken anf jeder Decke. $1^{\text {tes }}$ Fühlerglied und die Beine röthlichgelb.

Allenthalben in der Schweiz von den letzten Maitagen an bis Mitte Augusts auf allen Wiesen und Abhämgen sehr gemein. Eine sehr ähnliche, von Ilerrich untersehiedene, neue Art (C. dislinguendus wanz. Ins. IV. fig. 58\%.) fand ich bis jelzt in der Schweiz nirgends einheimisch.

\section{ซร. C. sexgutdatus Nabr.}

Fabr., Syst. Rhynch. № 172. Lygieus sexguttalts.

- Entom. Syst. N ${ }^{\circ} 159$.

Fallèn, Hemipt. Suec. No 20. Pliyt. sexg.

IIerrich Sch., Wanz. Ins. III. fig. 295. Capsus sexg.

Nomencl. entom. I. pag. 48 und 87.

Länge $3^{1} / 2^{\prime \prime \prime}$.

Schwarz, Vorderrand und 5 Flecke des Thorax, Schildchen, Grundhälfte der Decken, und $\Lambda$ ppendix schwefelgelb; doch die Spitze desselben schwarz. Membran mit glasgelblicher Querbinde.

Ueberaus selten. Ich kenne nor 2 schwcizerische Ex('mplarc, eine von II errn Seiler; aus der Gegend von Srhafliausen, das andere in meiner Sammlung, ohne nähere $\Lambda$ ngabe des Fundorts.

\section{a8. C. binotntus Habr.}

Fabr., Syst. Rhynch. № 159. Lygaus binot. Fullèn, Monogr. Cim. № 27. Lygaxus binot.

- Hemipt. Suec. № 5 . Phytocoris binot.

IIerrich Sch., Nomencl. ent. I. pag. 50 und 82. Capsus binot. 
IIerrich Sch., Wanz. Ins. III. fig. 296. Capsus binot.

Länge $21 / 2-3^{\prime \prime \prime}$.

Grünlich oder vermischt orangengelb, mit schwarzen Flecken auf dem Kopfe und dem Thorax, einem schwarzen Längstreifen auf jeder Decke und stets gelbem Appendix. Varirt übrigens sehr stark, sowohl in Farbe als Zeichnung.

Fehlt in der mitllern und westlichen Schweiz fast ganz; ist häufiger in den nördlichen und östlichen Kantonen.

Um Genf, sehr selten. (B3uess.) - Schaffhausen, einzeln. (Seiler.) - In Bündten gemein. (Amstcin.) - Matt, im Kanton Glarus, 2560 Fuss ü. M. (Heer.)

\section{C. marginellus rabr.}

Fabr., Syst. Rhynch. No 14.Miris marg. u. Caps. script. № 52.

- Entom. Syst. IV. No 171. Lygus scriptus.

IIahn., Wanz. Ins, II. fig. 202. Phy tocoris scriptus.

IIerrich Sch., Nomencl. entom. I. pag. 48 und 83̈. Capsus marginellus.

Burmeister, IIandb. Entom. II. pag. 269. Phytocoris marginellus.

Länge $5^{1 / 2}{ }^{\prime \prime \prime}$.

Schwarz, mit 5 orangefarbigen Flecken auf dem Thorax, gelbem Clavus, Aussenrand und röthlichem Appendix. Fühler schwarz. Beine rom Pechbraunen bis in's Schwarze varirend.

Von der Mitte Juni hinweg, fast den ganzen Sommer durch, auf allen Wiesen, Ilïgeln und Feldrainen in unsäglicher Menge, bis 5000 Fuss ü. M. 
Diese Art ist ja nicht zu verwechseln mit einem 2 ten Lygaus scriplus des Fabr. (Syst. Rhynch. № 153), welcher von Herrich Sch. im IlIten Bd. der wanz. Ins, fig. 294. abgebildet, mir aber in der Scbweiz noch nirgends vorgekommen ist.

\section{C. striatus Linn.}

Linn, Fauna Suec. 960. Cimex striatus u. Syst. Nat. II. pag. 730. 105.

Fabr., Syst. Rhynch. pag. $253 . \mathrm{N}^{\circ} 15$. Miris striatus.

- Entom. Syst. IV. pag. 186.

Fallèn, Monogr. No 37. Lyg. striatus.

Fallèn, hem. 14. Phytocoris striatus.

Panzer, Fauna Ins. 95. 22. Lyg. striatus.

Sulzer, abg. Gesch. tab. 10. fig. 15.

Ilahn, Wanz. Ins. II. fig. 219. Phyt. striatus.

Länge $42^{\prime \prime \prime}$.

Schwarz, Thorax mit gelbem Grundfleck. Die Nerven der Decken gelb, Streifen bildend. Appendix orange. Beine rostbraun oder schwarz.

Erscheint gewöhnlich um den 20. Mai, bald einzeln, bald auch in kleinen Gruppen von 10-20 Individuen, meistens an gebüschreichen, sonnigten Waldsäumen, an wilden Abhängen und Feldrainen, in der ganzen Schweiz.

\section{C. striatellus fabr.}

Fabr., Syst. Rhynch. pag. 236. № 16\%. Lygæus striatellus.

- Entom. Syst. IV. pag. 173. № 153 Lygreus striatellus. 


\section{- D5 -}

Panzer, Fauna Germ. 93. 17. Lygæus striatellus.

Fallèn, Hemipt. Suec. pag. 84. № 15 . Phy tocoris striatellus.

IIahn, Wanz. Ins. II. fig. 218. Phytocoris striatellus. Länge $4^{\prime \prime \prime}$.

Grünlichgelb. Thorax mit 4 schwarzen Flecken und schwarzer Hinterrandbinde. Decken schwarz und gelb gestreift. Appendix gelb mil schwarzer Spitze.

Weniger allgemein als der Vorige, in der Regel $5-6$ Tage früher erscheinend, doch an ganz gleichartigen Stellen des Hügellandes vorkommend.

\section{C. Salvige Ilaten.}

IIahn, Wanz. Ins. II. fig. 217. Phyt. Salvix.

Länge $3 y_{2}^{\prime \prime \prime \prime}$.

Ueberall lehmgelb oder bräunlich. Membran weisslich, mit gelbem Zellennerv.

In der Schweiz überaus selten. Vor mehrern Jahren, und seither nie wieder, fand Bremy diese Art gesellschaftlich auf Epilobium rosmarinifolium an der Tüss bei Wülflingen, im Kanton Zürich.

\section{C. Iateralis rallèn.}

Fallèn, Ilemipt Suec. № 25. Phyt.

Mahx, Wanz. Ins. I. pag. 220. fig. 114. Phyt. (als Ph. apicalis.)

Fallèn, Monogr. № 46. Lygæus fulvomaculatus var. Fabr., Syst. Rhynch. 2/4. 18. Capsus seticornis.

- Entom. Syst. 160.

Burmeister, Handl). II. pag. 269. Phyt. seticornis. 


\section{- DB -}

IIerrich Sch., Nomencl. entom. I. pag. 83̈. Capsus lateralis.

Länge $\mathbf{3}^{1 / 2}{ }^{\prime \prime \prime}$.

Schwarz. Decken am Aussenrande blassgelb. Appendix, mit Ausnahme seiner schwarzen Spitze, gelblich oder roth. Schicnen braun, an den Enden schwarz.

Erscheint bei uns in der Regel nach dem 20. oder 22. Mai; gegen Ende Juni dann in grösster Anzahl, und verschwindet allmälig mit den ersten Septembertagen. Allenthalben in der Schweiz bis auf die höchsten Bergwiesen auf Nesseln, Brombeerstauden, Spiräen und im Grase, in den mannigfaltigsten $\Lambda$ bänderungen.

(Auffallend ist an dieser $\Lambda \mathbf{r t}$ der sehr angenehme Birngreruch, den sie selbst noch einige Tage nach der Tödtung ausduftet).

\section{C. fulvomaculatus. Gíllèn.}

Fallèn, Ilemipt. Suec. № 2h. Phyt. fulvomac.

- Monogr. Cim. No 46. var. $\beta$ Lygieus fulvomac.

IIerrich Sch., Nomencl. entom. I. pag. 48 u. 8h. Capsus fulvomac.

- Wanz. Ins. III. fig. 267. mas. Capsus fulvomac.

- Wanz. Ins. III. fig. 502. Fiom. Capsus fulvomac.

Länge $3^{\prime \prime \prime}$.

Schmutzig braun, goldgelb behaart. Kopf schwar, mit 2 rostrothen, und Thorax mit 2 bis 5 falldhraumen Mittelfecken. Appendix durchscheinend gelblich, Spitze breil schwarz; obenher röthlich angeflogen. Fühler und 
Füsse bräunlich. Fühlerglied 2 an der Spitze schwarz, Schenkel geflecht.

Im Juni und Juli einzeln mit lateralis und Plyt. divergens in Schächen, auf Salixarten.

Um Genf. (Buess.) Baselland, am Bettenberg bei Bäkten. (Menzcl) - Schaffhausen, gemein. (Sciler.) -Burgdorf, wicht selten. (Meyer) St. Gallen. (IIartmann.)

\section{C. bifasciatus Avab"}

Falbr., Syst. Rhynch. pag. 242. 7. Capsus bifase.

- Entom. Syst. IV. pag. 177. № 152. Lygxus bifase.

Ilahn, Wanz. Ins. III. fig. 252. Phytocoris bifasc. (aber nicht Capsus bifasc. IIS. wanz. Ins. III. fig. 265, welchen ich zu Vermeidung einer Collision unter № 69 als Decoratus angeführt habe).

\section{Länge $31 / 811$.}

Dunkelpechbraun, goldgelb behaart; Hinterrand des Thorax, Spitze des Schildchens, Aussenrand der Decken, 2 oft verloschene Querstreifen an demselben und die obere Hälfte des Appendix gelblich. Fühlerglied 2 bis zur Nitte verdickt, schwarz. Beine rostroth.

Von Anfangs Juni an den ganzen Sommer hindurch, auf IIügeln, Waldwiesen uud Alpweiden auf verschiedenen Gesträuchen, besonders auf Doldenblumen sehr gemein. Am Jura allenthalben; auch auf den Gurnigelbergen, bis auf 3700 liuss ï. M., stellenweise in wahrer Unzahl. 


\section{- 18 -}

\section{C. curvipes miki.}

TAF. V. Fig. 3.

\section{Länge $3^{\prime \prime \prime}$.}

Ich kam diese ausgezeichnete Wanze, wenn sie nicht als Mann zu thoracicus gehört, in keinem Autor beschrieben finden. In der Grösse steht sie dem fulvomaculatus, in Form und Umriss dem lateralis am nächsten.

Ganz eigenthümlich sind die braunen, behaarten und grobkörnigten Fühler, deren $2^{\text {tes }}$ Glied nur wenig länger als das $1^{\text {to }}$ ist, und mit einen nach unten gekehrten Lappen endigt, auf dessen Rande sehr starke weissliche Borsten stehen. Glied 5 gebogen und fast so lang, als 1 u. 2 zusammen. Glied 4 dünn cylindrisch, nicht länger als 1. Die Schenkel rothgelb, das hinterste Paar von der Mitte bis zur Spitze dunkelpechbraun. Schienen braungelb, schwach punktirt und bedornt. Spitze der Schienen und sämmlliche Tarsenglieder schwarz. Vorderschienen gegen die Spitze auf einmal stark einwärts gebogen; dic hintern ebenso, nur schwächer.

Dieser auffallende Bau der Fühler und Beine würden mich allerdings auf den Gedanken einer bloss individuellen Verkrüppelung oder Monstruosität gebracht haben, wenn ich sie nicht an allen mir zugekommenen Exemplaren ganz analog gefunden håtte.

Schnabelscheide hochgelb, nur bis zwischen das erste Schenkelpaar reichend. Kopf, der rauhkörnige oder chagrinirte Thorax und das Schildehen schwarz. Eine gelbliche Lienie zieht sich über die Länge des Kopfs, säumt den Ilinterrand des 'Thorax und geht durch seine Mitte bis zum glänzenden Querwulst. Spitze des Schildchens röthlichgelb. Flïgeldecken dunkel hornbraun, durchscheinend, 


\section{- D9 -}

deutlich behaart. Membran schwärzlich, irisirend. Vor dem schwarzen Appendix ein helles Querband. Vordertheil des Körpers unten tief schwarz. Trochantern hochgelb. Bauch roth; der sehr lange letzte Ilinterleilssing glänzend pechschwarz.

Von dieser neuen, seltenen Art kenne ich bis jetzt nur Männer. Sie erscheint um den 10. oder 12. Mai sehr einzeln im Grase an heissen Itügeln und Feldrainen um verschiedene Gebüsche.

Am Uto bei Zürich (Bremy). - An der Engehalde bei Bern (Ougsburger). - Um Basel (Imhoff). - Auf dem Gyrisberg bei Burgdorf (Meyer),

\section{8\%. C. pratensis Einn.}

Linn, Syst. Nat. pag. 728. No 86. Cim. prat.

- Fauna Suec. 949.

Fabr., Syst. Rhynch. pag. 25\%. 155. Lygaus prat.

- Ent. Syst. 1.26,

Fallèn, Ilemipt. Suec. 90. 28. Phytocoris prat.

- Monogr. Gim. № 50. (Lygæus.)

Panzer, Fauna 95. 19. Lygaus umbellatarum.

Burmeister, Handb. der Entom. Il. pag. 272. Phyt. prat. Hahn, Wanz. Ins. I. fig. 112. 115. Phyt, prat. u. campestr.

Ilerrich Sch., Nonrencl, entom. I. pag. 51. 85. 86. Capsus prat. u. campestris.

Länge $22^{\prime \prime \prime}$.

Eiförmigg, glänzend grünlich, röthlich oder rölhlichbraun, verschiedenartig gemischt. Schildehen gewöhnlich hellgelb, bald mit, bald ohne schwarze Zeichnungen. Schenkel mit 9 dunklern Ringen. 
Ich ziehe nit Burmeister die beiden Arten prat. 1. campestris. als identisch zusammen; denn die unzähligen Abweichungen in Farbe und Zeichnung geben keine Charactere, die zu einer Trennung berechtigten. Gewöhnlich haben die Männchen (IIahn's pratensis) röthliche Farben, und auf dem Schildchen steht ein gelblicher, herzförmiger Fleck. Die Weibchen sind mehr bräunlich oder olivengrünlich; manchmal auch blos hornfarbig, mit hellen Längsstreifen auf dem Sehidchen. (IIahn's campestris.) Doch ändern diese Zeichnungen, so wie auch die Farbe, so in's Mannigfaltige, dass sie beiden Geschlechtern tauschweise zukommen. Auf den Alpen werden sie besonders bunt, lebhaft braunroth, mit sehr schönen Thoraxstreifen; dies ist Panzer's Lyg. umbellatarum.

Der gemeinste aller Capsinen und schon von Ende Aprils an, allenthalben, wo nur Gras wächst, bis auf 4000 Fuss ü. M. in unsäglicher Menge vorkommend.

\section{C. ticinensis milei.}

TAF, VI. Fig. 1.

\section{Länge $5^{\prime \prime \prime}$.}

Nur schüchtern wage ich, diese Wanze als nene Art aufzustellen. Grösse und Habitus der grö̈sten Excmplare v. C. pratensis, der Kopf gestreckter, der Thorax vorn enger. Glänzend, unbeharer, oben lebhaft braunroth; blos die Fühler und Appendix der Decken heller. Spitze des Kopfs, 2 rundliche Flecke des Thorax, das ganze Schildchen, ein breiter Mittelstreif des Bauchs, dunkelhraun oder pechschwarz. Membran bräunlich; in und um den 


\section{- 101 -}

dunkelkirschrothen Zellennerv etwas blasser, durchscheinend. Die Beine fehlen an den einzigen Exemplare aus Lugano, welches IIerr Professor IIeer mir zur Benutzung mittheilte; wesshalb sie auch in der Abbildung nicht illuminirt sind.

(Eine sehr ähnliche Wanze, mit braun geringelten Schenkeln und gelblichem Schildchen, erhiclt ich seither in mehrern Exemplaren von Ilerrn Geyer aus Karlsruhe.)

\section{C. fasciatus mihi.}

TAF. V. Fig. 5.

Nachdem unsere V, Tafel bereits abgedruckt und illuminirt war, erhielt ich das VI. IIeft des VI. Bandes v. Herrich Sch. wanz. Ins., in welchem unter fig. 671 unser $C$. fascialus abgebildet ist.

Meyer, in der entomol, Zeitung v, Stettin. Jahrgang 1841. № 6 . pag. 86.

Länge $21 / 4$.

Den kleinern Individuen von pratensis äusserst älınlich. Gestalt und Habitus ziemlich übereinstimmend, doch etwas flacher, Kopf und Thorax gestreckter, das ganze Thier ein Drittheil kleiner, als pratensis. Vorderleibunten tief schwarz, Hinterleil, grüngelb. Kopf, Thorax und Flügeldecken röthlich grüngelb. Hinterrand des Thorax, Clavus und eine breite Binde vor dem Appendix, so wie dessen Spitze carminroth. Membran graulich, durchsichtig, mit rothem Zellennerv. Spitze des Kopfs stets dunkel schwarzbraun, was sich bei pratensis niemals findet. Schildehen blassgelb, am Grunde oft schwärzlich und carminroth angelaufen, aber nie mit Strichen oder gelben herzförmigen Flecken. 
Beine und Fühler ausser der geringern Grösse ganz wie bei $C$. pratensis.

Im Nai, Juni und Juli gesellschafilich mit dem Vorhergehenden an sonnigten, grasreichen Feldrainen im Hügellande, nie auf Ebenen oder Wiesen; ändert blos in der mehr oder weniger deutlichen karminrothen Färbung etwas ab, und ist bei viel geringerer Individuenzahl auch nicht so allgemein verbreitet, wie pratensis.

Burgdorf, an den Abhängen des Oberthals. (Mcyer.)

\section{D0. C. thorncieus. Hallèn.}

TaF, VI, Fig, 5 .

Fallèn, Monogr. Cim. № 450 . Lygacus thoracicus.

- Hemipt. Suec. № 66. Phytocoris thorac.

IIerrich Sch., Nomencl. entom. I. pag. 52. 87.

Länge $5^{\prime \prime \prime}$.

Braunroth oder blass hornbraun. Kopf, Vordertheil des Thorax, Schildchen bis zur gelblichen Spitze, und die Spitze des helldurchscheinenden Anhangs schwarz. Kopf und Thorax mit gelber Mittellängslinie. Decken fein behaart, nach aussen zu hell hornfarbig. Fühler und Beine orange. Ilinterschenkel an der Endhälfte dunkelbraun. Schienen gefleckt und gedornt.

Aeusserst selten. Von mir erst 2 Mal erbeutet. Das erste Exemplar im Juni 1857; das zweite am 51. Mai 1840 unter einer Eiche im hohen Grase am Ireienmoos, bei Burgdorf. Ein drittes von Linder aus Genf.

Wahrscheinlich ist thoracicus das Weib, und mein curpipes (№ 86) der Mann einer und derselben Art, welcher, 


\section{- 103 -}

wenn es sich bestätigt, der alleinige ältere Name von Fallèn wieder zufällt.

\section{C. cervinus mihi.}

Ilerrich Sch., Wanz. Ins. VI. fig. 617.

Länge $2^{\prime \prime \prime}$.

Heller oder dunkler horngelb, glänzend, fein behaart, mit bräunlichen, bindenartigen Schattirungen. Schildehen mit 2 dunkeln Längsstreifen. Appendix fast glashell; an seinem Innenrande zuweilen purpurroth begrenzt. Augen breit, seitwärts abstehend.

Die hier citirte Abbildung ist nach einem von mir eingesandten Exemplare, und sehr getreu.

Um den 20. Mai bis Ende Augusts in ganz schaltigen, feuchten Thalgründen im Gehölze; an gleichen Stellen mit Capsus nubilus. Manche Jahre in ausserordentlicher Menge auf Lonicera xylosteum $L$.

Burgdorf, im Schlossgraben und am Fusse des Gyrisbergs. Ein Exemplar erhielt ich von Irn. Buess, von Champel, bei Genf. Sehr gemein an einer Berghalde ob Altdorf, im Kanton Uri, ebenso an den Kuinen von Attinghausen, auf Althea officinalis. (Meyer.)

\section{D2. C. punctulatus. Fallèn.}

TAF. IV. Fig. 2.

Fallèn, Monogr. Cim. Suec. № 61. Lygæus punctulatus. - Ilemipt. Suec. № 56. Phytocoris punetul. IIofmannsegg, Phytocoris varipennis.

Länge $12 / 3-2$ 'I'.

Fühler kurz. Leib eiförmig. Unten schwarz. Decken und ganze Oberseite glänzend braungelb oder olivenbraun, 
tief punklirt. Querwulst des Thorax, zwei Längsstreifen des Schildchens, ein Läugsfleck auf den Decken, zwei Schienenringe an den hintern und mittlem Beinen, die Spitze des Appendix und die Nerven der glashellen Membran schwarz. Appendix und Membran stark abwärts geknickt.

Vielleicht der frühzeitigste und späteste aller Capsinen; erscheint gleich nach dem 20. März, und findet sich bis gegen Ende Novembers einzeln im hohen Grase auf Wiesen, Feldern, Abliängen und selbst in den Städten an den Häusern.

Baselland, am Bischoffstein bei Gelterkinden, selten. (Menzel.) - Iäufiger um Genf.(Bucss.) - Bonneville. (Coppier.) - Bündten. (Amstein.) - Schafhausen. (Seiler.) - Um Burgdorf und Bern gemein. (Meyer.)

Eine ganz blasse, weisslichgelbe Varietäl mit braunrothen Augen, einem rothen Schenkelring und einem gleichfarbigen an den hintern Schienen, (doch nicht ein frischentwickeltes Exemplar), fing ich am 21. Juli auf Prunus domesticus. bei Burgdorf.

\section{C. unifaseiatus. drebr.}

Fabr., Syst. Rhynch. pag. 245. No 9. Capsus.

- Entom. syst. IV. pag. 178. No 135. Lygrus.

Fallè, Monogr. Cimic. pag. 80. № 44. Lygrus semiflavus.

- Hemipt. Suec. pag. 86. № 21. Phytoc. semill. Wolf, IV. pag. 154. Taf. 1引, fig. 48. Miris semiflav. IIahn, Wanz. Ins. I. fig. 107. Phytocoris semillav.

- II. fig. 169, 170. Phytocoris lateralis u. marginat. IIerrich Sch., Nomencl. I. pag. 51 u. 88. Caps. unifasc. Långe $\mathbf{3}^{\prime \prime \prime}$. 


\section{$-105-$}

Schwarz, gelblich behaart. Ilinterrand des Thorax, Spitze des Schildchens und verschiedenartige Makeln der Decken gelb. Appendix orange oder roth, am Aussenrand mil schwarzem Fleck. Nerv der dunkelbraunen Membran gelb. Fast allenthalben in der Schweiz in manigfaltigen Abänderungen ; von Anfangs Juni bis Lnde Juli, besonders an dürren, steinigten Bergabhängen, an Feldbördern und Alpenweiden auf Galium verum, molluyo und ochrolencum, IIegelschw., sehr gemein.

\section{C. Heseri. Eerrich Seh.}

IIS., Wanz. Ins. IV. fig. 407. pag. 78.

Länge $12 / 3$.

Schwarz. Decken durchscheinend bleichbraun; jede mit grossem, dunklerem Längsfleck. Schenkel schwarzbraun, an der Endhälfte röthlich orange. Schienen bleichgelb, schwarz punktirt.

Ueberaus selten, und bis jetat nur am Jurazuge an wenigen Stellen gefunden.

Basel. (Imhoff.) - Lengnau, Kant Bern. (Delian Studer.)

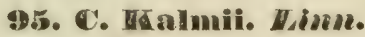

Fabr, Syst. Rhynch. 245. 11. Capsus gramineus?

Limn., Fauna. 948. Cimex Kalmii.

Fabr., Syst. Rhynch. pag. 245. No 10. Capsus flavovar.

- Entom. Syst. IV. pag. 178. № 15\%. Lygxus flavovarius.

Fallèn, Monogr. Cim. pag. 86. № \$5. Lyggrous flavovar.

- IIemipt. Suec. pag. 95. No 54. Phytoc. flavovar. Ilahn, Wanz. Ins. I. fig. 109. Phytoc. flavovar. 
Burmeister, Handb. II. pag. 172.

IJerrich Sch., Nomencl. entom. I. pag. 85, zicht auch IIaln's Pastinace als Synonim hieher, doch mit Unrecht. Dieser gehört zum nachfolgenden C. tripustulatus.

Gemein den ganzen Sommer hindurch auf allen Wiesen, doch stets nur einzeln. Aendert sehr ab in dunklerer oder verloschener Zeichnung und in grasgrüner oder bräunlicher Grundfarbe; und zu einer dieser Varieläten gehört wahrscheinlich Capsus gramineus Fabr.

\section{DF. C. tripustulatus. Frabr.}

Fabr., Syst. Rhynch. pag. 259. № 182. Lygxus. Fallèn, Ilemipt. Suec. pag. 96. № 38. Phytocoris. Mahn, Wanz. Ins.I. fig. 110 u. 111 (tripustulat. u.pastinacx). Fallèn, Ilemipt. Suec. pag. 94. № 58. Phytoc. Pastin.

- Monogr. Cim. pag. 86. No 57. Lygus Pastin. Fabr., Syst. Rhynch. pag. 258. № 175. Lygus transversalis?

Burmeister, Ilandb. II. pag. 273. Phylocoris tripust.

Länge $2^{\prime \prime \prime}$.

Grünlich oder rothgelb. Auf dem Thorax und den Decken ist Dunkelschwarz so vertheilt, dass die Grundfarbe Binden bildet. Appendix in der Mitte gelb oder orange; an der Spitze schwarz. Schenkel und Schienen dunkel geringelt.

Ueber das Zusammengehören von IIahn's Paslinace und tripust. habe ich laingst keine Zweifel mehr. Die sanftesten Uebergänge der Färbung, das gleichzeitige 


\section{- 10\% -}

Erscheinen und gesellschaftiche Beisammenleben auf Nesseln sind genügende Beweise der Indentitit.

Beide Varietäten erscheinen einzeln schon Mitte Aprils, dann in grösserer Menge in den Monaten Juni und Juli.

In der Schweiz allenthalben gemein.

\section{C. trifasciatus. Ereabr.}

Fabr., Syst. Rhynch. pag. 244. 46. Capsus trifasc.

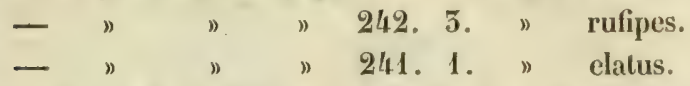

Panzer, Fauna Germ. 75. 20. Capsus elatus.

Wolff, Icones Cim. I. pag. 31. Tab. 4, fig. 51. Capsus elatus.

Länge $4 \frac{1 / 4}{\prime \prime \prime}$.

Gross, lang, eiförmig, braunroth, hochroth oder schwarz. Die hochrothe Varielät (elatus Panz.) mit schwarzem Kopf, Mittelfeld des Thorax, Clavus, 2 Binden über den Decken und Spitzen des $\Lambda$ ppendix. Fühler stark orange; Ende des zweiten Gliedes verdickt, schwarz.

Die ausnehmend starken Abänderungen dieser zierlichen Art ergeben sich aus obigen Citaten.

Einzeln um die Mitte Juni in mehreren hügelichten Gegenden der Schweiz auf Apfelbäumen. Die schwarze Varietäl (rufipes) ist die seltenste.

Burgdorf. (Meyer.) - Dübendorf. (Bremy) clatus Panz.—Zürich und am Uto. (Bremy.) - Grenf. (Buess.) - Baselland. (Imhoff und Menzel.). - Burgdorf, auf dem Gyrisberg und in Baumgärten. (Meyer.)

In Nadelholzwäldern, wie Burmeister sagt, hat man sie bei uns kaum je gefunden. 


\section{- 108 -- \\ 98. C. tricolor. Fubr.}

Fabr., Syst. Rhynch. pag. 246. 27. Caps. tricol. Panzer, Fauna. Fasc. 95. 20. Fubr., Syst. Rhynch. pag. 2/4/. 19. Caps. capillaris. Var. - " " 246.25." "danicus. „

Ilerrich, Wanz. Ins. I. fig. 9. Caps. danicus.

Länge $31_{4}^{\prime \prime} 11$.

Im Bau ganz dem Vorigen ähnlich, doch kleiner. Braunrothod. tiefschawar\%. Appendix hochroth od.orange; die Spitze stets schwarz. Fühlerglieder 1 u. 2 ganz schwarz.

Weit häufiger und allgeneiner verbreitet als der Vorige; doch in gleichen Abstufungen der Farbe und Zeichnung varierend.

In der ganzen Schweiz im Juli in Gärten auf Wollkraut, auch an Landstrassen, an Ilecken auf der grossen Brennnessel gemein.

\section{C. ater. Eime.}

Limn., Syst. Nat. 2. pag. 725. № 72. Cimex ater. Fabr., Syst. Rhynch. 2/1. 1. Capsus ater. IIaln, Wanz. Ins. I. pag. 126. Capsus ater. Fabr., Syst. Rhynch. 2142. 4. Capsus tyrannus. 245. 15. " flavicollis. Variet.

Schellenberg, Tab. II. lig. 5. IJahn, Wanz. Ins. I. fig. 6:3. Capsus flaricollis. Variet. Burmeister, Handb. II. pag. 27.

Herrich Sch., Nomencl. I. pag. 52. 82.

Länge $2 \frac{2}{3}{ }^{\prime \prime \prime}$.

Schwar\%, maltghlänzend; $2^{\text {tes }}$ Fühlerglied verdickt; 


\section{- 109 -}

ändert ab mit braunrothen Füssen, gleichfarbigem Kopf und Thorax.

In der ganzen Schweiz von Aafangs Juni bis um die Mitte Augusts auf sumpfigen Wiesen und Ialden am Boden umherhüpfend, und allenthalben ziemlich gemein.

\section{C. Mencecephalus. tim.}

Linn., Syst. Nat. 2. pag. 726. № 60. Cimex leucoc.

- Fauna Suec. 940.

Fabr., Syst. Rhynch. 252. 173. Lyg. leucoc.

Panzer, Fauna ins. Germ. 92. 12. Lygæus leucoc.

IIahn, Wanz. Ins. II. fig. 174. Phytoc. leucoc.

Fallèn, Ilemipt. Suec. pag. 111. № 67. Phytoc. leucoc.

Länge $2^{\prime \prime \prime}$.

Kurz, eiförmig, schwarzglänzend ; das $1^{\text {te }}$ Fühlerglied, der breite Kopf und alle Füsse röthlichgelb. Tarsen schwarz.

In Berggegenden, besonders an Steinhalden und dürren Abhängen der mittleren und nordöstlichen Schweiz, im Juni auf Galium-Arten, doch nirgends gemein,

Zürich. (Bremy.) - Bündten. (Amstein.) - Am Jura, bei Solothurn, und im Oberthal, bei Burgdorf. (Meyer.)

\section{0\%. C. Iuridus. Fullène.}

Fallèn, Monogr. No 78. Lygæus.

- Hemipt. № 69. Phytocoris.

Ilerrich Sch., Nomencl. entom. I. pag. 55 u. 85. Caps.

- Wanz. Ins. III. fig. 512. Caps.

Länge $2^{\prime \prime \prime}$. 
Kurz, eiförmig, rostgelb, fein blass behaart. Fühler rothgelb. Ueberall, mit Ausnalime des glaltglänzenden Kopfes und schwarzen Thoraxwulstes, tief punktirt.

Bei uns eine der seltensten Arten. Ich sah nur ein Exemplar aus Schaffhausen von Seiler.

\section{C. pulicarius. cullèn.}

Fallìn, Monogr. Cim. Suec. № 81. Lyģæus pulicarius.

- Hemipt. Suec. 71.

IIahn, Wanz. Ins. I. fig. 62. Attus pulicar.

Bnrmeister, Handb. II. pag. 277. Attus pulicar.

IIerrich Sch., Nomencl. entom. I. pag. 53 u. 86. Capsus pulicarius.

\section{Länge $s / 4$ 'II}

Klein, oval, schwarz. Fühlerglieder $2-4$ und Beine gelb. Hinterschenkel stark verdickt.

Diese niedliche, anderwärts gemeine Art ist in der Schweiz ziemlich selten, und findet sich nur einzeln im Grase auf Ilügeln und Bergwiesen vom Juni an bis Anfangs Septembers.

Kanton Basel, am Jura. (Imhoff.) - Auf der Ilandeck, im Oberhaslithal, auch im Emmenthal; bei Burgdorf auf dem Gyrisberg. (Meyer.) - Bonneville und Chamounix. (Coppier.)

(Ich versandte diese Art früher, als $C$. carbonarius $m$. nova. sp., und berichtige hiemit diesen Irrthum.-)

\section{C. pallicornis. Hdim.}

Linn., Fauna Suec. 894. Cicada aptera. Fallèn, Monogr. Cimic. 80. Lygæus p. 


\section{- 110 -}

Fallèn, Hemipt. Suec. 70. Phytocoris pallicornis. Fabr., Syst. Rhynch. pag. $113 . N^{\circ}$ 6. Salda pallicornis. IIahn, Wanz. Ins. I. fig. 61. Halticus pallicornis.

Burmeister, Handb. II. pag. 278.

Hahn's Attus arenarius (wanz. Ins. III. fig. $25 \%$ ) ist nur nur der Mann von dem stets ungeflügelten Weibe von pallicornis.

\section{Länge $1^{\prime \prime \prime}$}

Kurz, gedrungen, hinter der Mitte breit, einer IIaltica ähnlich ; schwarz, glänzend, schillernd. Die langen Fühler bis zur Mitte des 5 ten Gliedes gelblich. Schienen und Spitzen der schwarzen Schenkel gelb.

Im Juni und Juli auf allen Wiesen und lichten Waldplätzen der Schweiz in überschwenglicher Menge; der Mann ist seltener.

Die von Burmeister angeführte rothköpfige Varietät ist mit der nachfolgenden Art nicht zu verwechseln.

\subsection{C. wropingurs. Iterricte Sch.}

ISS., Wanz. Ins. VI. fig. 606.

Länge $1 \frac{1}{1}{ }^{\prime \prime \prime}$.

Dem Vorigen sehr ähnlich, doch gestreckter, Thorax vorn schmäler, Membran länger. Decken in's Bronzefarbige oder Röthliche schillernd. Kopf, und manchmal auch der Vordertheil des Thorax, rosigelb.

Im Ganzen viel seltener als der Vorige, und nur an wenigen Orten der Schweiz rorkommend, obschon gesellschaftlich mit demselben, im Juli auf Gesträtuche. Im Leben schillert das Thierchen in's Bronzefarbige. 
Burgilorf, am Turnplatz. (Meyer.) - Basel. (Imhof, ) - Bei den Basler-Exemplaren zieht sich die rothgelbe Farbe des Kopfes auch über den Thorax. - Genf, (Buess.) Ganz wie die von Basel. - Im Kanton Uri weit häufiger als pallicornis.

\section{C. rufifrous.}

Fallèn, Monogr. Cim. Suec. pag. 105. 19.

- Caps. ambulans. Var. $\beta .20$.

Herrich Sch., Nomencl. ent. I. pag. 86.

- Wanz. Ins. III. fig. 558.

Burmeister, Haudb. d. Entom. II. pag. 278.

Länge $11 / 211$.

Schwarz. Kopf gestreckt, roth. Fühler gelb, Glied 1 am Ende, 2 an der W urzel und am Ende schwarz. Beine gelb.

Zu Ende Juni bis um die Mitte Augusts sebr cinzeln und sparsam in tiefem Waldgrase und an schattigen, gebüschreichenAbhängen der mittleren u.nördlichen Schweiz.

Burgdorf, in den Schächen längs der Emme und am Pleerwald. (Meyer.)-Zürich, am Uto, selten.(Bremy.) Im Juli häufig ob Altdorf.

\section{C. saltator. Illalin.}

Hahn, Wanz. Ins. III. fig. 236.

Burmeister, IIandb. II. pag. 277? Halticus mutabilis.

Länge $2 \prime \prime \prime$.

Kurz, verkehrt eiförmig. Hinter der Mitte breit. Schwarz, dicht, gelblich, schuppenartig behaart. Fühler und Beine schwarz; Schienen braun. Flügel fehlen, Decken rund abgestutzt, den Hinterleib nicht bedeckend. 
Geflügelte Excmplare dieser Art sind mir niemals vorgekommen.

Im Juni, Juli und August in den meisten Gegenden der Schweiz auf Wiesen im Grase.

Um Burgdorf sehr gemein. (Meyer.) - Zürch sparsam. (Bremy.) - Basel. (Imhoff.)

\section{0\%. C. nitidus mille.}

Länge $1 \% 4^{\prime \prime \prime}$.

TAF, VI. Fig. 4.

Dem $C$. saltator sehr nahe, aber gedrungener, besonders der Thorax kürzer; keine Schuppenhäärchen, stark glänzend, tiefschwarz, von gewisser Seite in's Dunkelgrünblaue schillernd. Kopf zwischen den Augen mit einer Verticfung, sehr fein nadelrissig. Thorax und Schildchen grob punktirt, narbig, mit glänzendem Querwulst auf ersterem. Flügeldecken mit dicht eingedrückten Punkten, nicht so rund abgestutzt, wie bei saltator, sondern mehr gerade abgeschnitten. Der vorragende Ilinterleib tief glänzend schwarz, oben auf dem letzten Ringe vor der Spitze zwei Grübchen. Fühler und Beine ganz schwarz.

Professor Ileer fand diese, mir neu scheinende Art auf der Alp Urschein, im Unterengadin etwa 7000 fuss ü. M., und überliess mir ein Exemplar zur Benutzung.

\subsection{Wrevis. Honer.}

Panzer, Fauna ins. Germ. 59. 8. Lyganus brevis.

Länge $21 / 4=$

Grösser und breiter als der Vorige; Ilinterschenkel nicht so verdicht; matlglänzend, ohue Schuppenhaare.

Sehr selten.

Am Rigi. (Seiter.) - In lBündten. (Amstein.) 


\section{0:. C. pteridis. Aullèn.}

Fallèn, Ilemipt. Suec. pag. 152. No 1. Bryocor. pterid. Burmeister, Ilandb. d. Entomol. II. pag. 278. Halticus pteridis.

Germar, Fauna. 10. 15.

Fallèn, Monogr. Cim. No 20.

IIerrich Sch., Nomencl. entom. I. pag. 55 u. 86.

Länge 1'I!

Schr klein, schwarz. Fühlerglied 1 ganz und 2 bis gegen die Spitze gelblich; 2 Flecken am Kopf, und öfters ein Miltelfeld des Thorax bräunlich. Die rundabgestutzten Decken und die Beine braungelblich.

Bis jetzt nur in der nördlichen Schweiz in hohen Bergwäldern aufgèfunden.

Um Zürich sehr selten, am IIohenrhonen häufiger. (Bremy.) Um Basel. (Imhoff.)

Nach dem Absehlusse der Capsinen lernte ich noch folgende Art als Schweizerbürger liennen:

$V^{\text {te }}$ Gatenge: CRYPTOST EMIMA. Ilerich-Sch.

\section{1. alienum. HAS.}

Panzer, Fauna. 15\%. 11.

Länge $1 \frac{1}{3}{ }^{\prime \prime \prime}$.

Länglich eifürmig, flach. Fühler lang, diinn. Thorax sehr breit. Ganze Oberseite röthlich olivenfarbig; Decken mit deutlichem Schulteranhang. Appendix gross, mit 2 
Längsfurchen am Innenrande. Membran mit 2 dunkeln Längsstreifen. Beine gelblich.

Dass dieses neue, ganz ausgezeichnete Thier auch bei uns einheimisch ist, überzeugte mich ein frisches, sehr wohl erhaltenes Exemplar, welches IIr. Dr. Imho/f voriges Jahr in der Baslergegend gefunden, und mir, leider ohne nähere Beachtung und Notiz des Fundorts, zur Bestimmung mitgetheilt hat. - Es stimmt vollkommen mit IIerrich's Abbildung in Panzer's Fauna überein.

Ich war lange unsicher, zu welcher Familie diese sonderbare Form gehören möchte; obschon sie in keine einzige genau passt, so spricht doch die Bildung der Fühler, der Mangel der Ocellen, der deutliche und grosse Appendix der Decken und die 2 Zellennerven der Nembran für die nächste Verwandtschaft der Capsinen. 
Da auf der letzten Tafel die Namen nicht beigesetzt sind, so folgt hier die

\section{Erklärung zur Tafel VII.}

Fig. 1. Phytocoris populi L. (pag 42).

- 4. - - varietas. (pag. 43).

- 2. Capsus viridulus Fabr. (pag. 77).

- 3. - hortulanus Meyer (pag. 77).

\section{CORRIGENDA.}

Pag. V, Zeile 12, von oben, statt Imhot lies Imhoff.

* 415 a * " a 


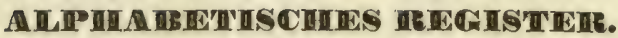

(Die in kleiner Cursivschrift gedruckten Namen sind Syuonime.)

Ueber die wanzenartigen Rhynchoten im Allgemeinen Systematische Eintheilung derselben

Fang und Conservation - _ _ _

Literatur

- - - - -

VIto Zunft der Rhynchoten: GEocouss.

VIIIto Familie: CapsinI. (Blindwanzen.)

Ite GAT'IUNG :

DidTES
albidus
calcaratus
dentuia
crraticus
hortorum
holsatus
lavigatus
longicornis
pulchellus
ruficornis
virens

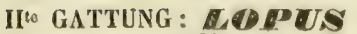

abbreviatus

albomarginatus

albostriatus

dolobratus

ferrugatus gothicus -

lateralis

superciliosus

tunicatus

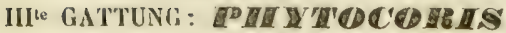

divergens

longicornis

populi

ulmi

tilice

IV te GATTUNG:

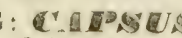

aftuis

alpertri

albipenn is

alienus

ambigus

ambulaus

ambulans var. $\beta$.

- -

$-\quad-$

$-\quad-\quad-$

- $\quad-\quad-30$

- - - - 34

$-\quad-\quad-36$

- - - - 34

- $\quad$ - $\quad$ - 34

$-\quad-\quad-34$

- $\quad$ - $\quad$ - 34

- $\quad$ - $\quad-\quad 36$

$-\quad-\quad-\quad 35$

- $\quad-\quad-37$

- $\quad$ - $\quad-37$

$-\quad-\quad-37$

$-\quad-\quad-35$

- $\quad$ - -38

- - - - 38

- $-\quad-\quad-40$

- - - - 40

- $\quad$ - $\quad 38$ u.39

- $\quad$ - $\quad$ - 39

- - - -41

- $-\quad-\quad-38$

- $\quad$ - $\quad$ - 41

- $-\quad$ - 40

- $\quad-\quad 42$

- - - 44

- - -43

- $-\quad-42$

- $\quad$ - 43

- -42

- - - 45

- $-\quad-48$

- $\quad-\quad 54$

- $-\quad-79$

. $\quad$ - $\quad$ - 50

- $-\quad-60$

- $\quad$ - $\quad$ - 86

$-\quad-\quad-112$ 


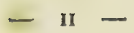

Pag.

IVie, GAITUNG: CARPSUS

\begin{tabular}{|c|c|c|c|c|c|c|c|}
\hline angulatus & - & - & - & - & - & - & 89 \\
\hline annulatus & - & - & - & - & - & - & 80 \\
\hline angustus & - & - & - & - & - & - & 56 \\
\hline apicalis & - & - & - & - & - & - & 95 \\
\hline aptera (Cicada). & & - & - & - & - & - & 110 \\
\hline arenarius (Attus & & - & - & - & - & & 111 \\
\hline arbustorum & - & - & - & - & - & - & 64 \\
\hline ter & - & - & - & - & - & - & 108 \\
\hline tomarius & - & - & - & - & - & - & 73 \\
\hline aurantiacus & - & - & - & - & - & - & 72 \\
\hline avellanae - & - & - & - & - & - & - & 54 \\
\hline bifasciatus. Fab & & - & - & - & - & - & 97 \\
\hline bifasciatus. Fall & & - & - & - & - & - & 87 \\
\hline bifasciatus. HS. & & - & - & - & - & - & 88 \\
\hline bilineatus & - & - & - & - & - & - & 82 \\
\hline binotatus. Fallè & & - & - & - & - & - & 51 \\
\hline binotatus. Fabr. & & - & - & - & - & - & 92 \\
\hline bipunctatus & - & - & - & - & - & - & 51 \\
\hline brevis & - & - & - & - & - & - & 113 \\
\hline brevicollis & - & - & - & - & - & - & 47 \\
\hline brunnipennis & - & - & - & - & - & - & 66 \\
\hline campestris & - & - & - & - & - & - & 99 \\
\hline capillaris & - & - & - & - & - & - & 108 \\
\hline carbonarius & - & - & - & - & - & - & 110 \\
\hline caricis - & - & - & - & - & - & - & 85 \\
\hline cervinus - & - & - & - & - & - & - & 103 \\
\hline chenopodii & - & - & - & - & - & - & 51 \\
\hline chorizans - & - & - & - & - & - & - & 76 \\
\hline chrysanthemi & - & - & - & - & - & - & 86 \\
\hline clavatus - & - & - & - & - & - & - & 87 \\
\hline coccineus & - & - & - & - & - & - & 75 \\
\hline collaris & - & - & - & - & - & - & 83 \\
\hline contaminatus & - & - & - & - & - & - & 45 \\
\hline coryli - & - & - & - & - & - & - & 54 \\
\hline crassicornis & - & - & - & - & - & - & 66 \\
\hline curvipes - & - & - & - & - & - & - & 98 \\
\hline danicus & - & - & - & - & - & - & $10 s$ \\
\hline decolor & - & - & - & - & - & - & 86 \\
\hline decoratus & - & - & - & - & - & - & 85 \\
\hline clatus & - & - & - & - & - & - & 107 \\
\hline elegantuius & - & - & - & - & - & - & $86 i$ \\
\hline errans & - & - & - & - & - & - & 83 \\
\hline fasciatus - & - & - & - & - & - & - & 101 \\
\hline ferrugatus & - & - & - & - & - & - & 52 \\
\hline filicis & - & - & - & - & - & - & 71 \\
\hline flavicollis - & - & - & - & - & - & - & $10 \mathrm{~s}$ \\
\hline flavomaculatus & - & - & - & - & - & - & 91 \\
\hline flevovarius & - & - & - & - & - & - & 105 \\
\hline lloralis - & - & - & - & - & - & - & 50 \\
\hline
\end{tabular}


IV'o GATTUNG: CAPSES

fulvomaculatus -

fulvomaculatus var. - $\quad$ - $\quad$ - $\quad$ - 95

furcatus - $\quad-\quad \ldots \quad-\quad$ - 70

gramineus - $\quad$ - $\quad$ - $\quad-105$

Gyllenhalii - $\quad$ - $\quad$ - $\quad$ - $\quad$ - 61

hieracei - $\quad$ - $\quad$ - $\quad$ - $\quad$ - 81

histrionicus - $\quad$ - $\quad$ - $\quad$ - $\quad$ - $\quad$ - 90

holosericeus - $\quad-\quad \ldots \quad-\quad \ldots \quad-59$

hortensis - $\quad$ - $\quad$ - $\quad$ - $\quad$ -

hortulanus - $\quad-\quad-\quad-\quad-78$

icterocephalus - $\quad$ - $\quad$ - $\quad$ - $\quad$ - $\quad$ - 50

infusus - $\quad$ - $\quad$ - $\quad \ldots \quad$ - $\quad$ - 53

Kalmii - $\quad$ - $\quad$ - $\quad-105$

lateralis Hhn. - $\quad$ - $\quad$ - $\quad$ _ $\quad$ - 104

lateralis Fallèn - $\quad$ - $\quad$ _ $\quad$ _ $\quad$ _ $\quad$ - 95

leucocephalus - $\quad$ - $\quad$ - $\quad$ _ $\quad$ - 109

limbatus - _ - _ _ - -47

lucourm - $\quad$ - $\quad$ - $\quad$ - $\quad 46$

lugubris - $\quad$ - $\quad$ - $\quad$ -

luridus - $\quad$ - $\quad$ - $\quad$ -

maculipennis - $\quad$ - $\quad$ - $\quad$ - 81

magnicornis - - $-\quad$ - $\quad$ - 62

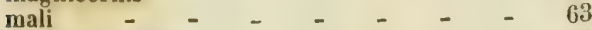

marginatus Hhn. _ $\quad$ - $\quad$ - $\quad$ - $\quad$ - 104

marginellus - $\quad$ - $\quad \ldots \quad \ldots \quad$ - 93

melauocephalus _ $\quad$ - $\quad \ldots \quad$ - 55

mudestus - $\quad$ - $\quad$ - $\quad$ - $\quad$ - 69

molliculus - $\quad$ - $\quad$ - $\quad$ -

mutabilis Fallèn - $\quad$ - $\quad$ -

mutabilis (IIlicas) - _ _ _ _ _

nassatus - $\quad$ - $\quad$ - $\quad$ - $\quad$ - 50

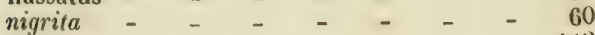

nitidus - $\quad$ - $\quad$ - $\quad \ldots \quad$ - 113

nubilus - $\quad$ - $\quad$ - $\quad$ - $\quad$ - $\quad$ - $\quad$ - 89

pabulinus L. - $\quad$ - $\quad$ - $\quad$ - 48

pabulinus Zett. - _ _ _ _ _ _

pallens (miris) _ _ _ _ _ _ _

pallicornis - $\quad$ - $\quad$ _ $\quad$ - 110

pallidus - $\quad$ - $\quad$ - $\quad$ _ $\quad$ - 81

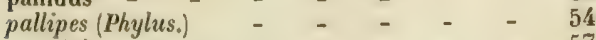

parallelus - $\quad$ - $\quad$ - $\quad$ - $\quad$ - 57

pastinace - $\quad$ - $\quad$ - $\quad$ - $\quad$ - 106

pilosus - $\quad$ - $\quad$ - $\quad$ - $\quad$ - 59

plagiatus - $\quad$ - $\quad$ - $\quad$ - $\quad$ - 55

prasinus - - $\quad$ - $\quad$ - $\quad$ - 78

pratensis - $\quad$ - $\quad$ - $\quad$ -

propinguus - $-\quad$ - $\quad$ - $\quad$ - 111

pteridis - $\quad$ - $\quad$ - $\quad$ - $\quad$ - 114

pulicarius - $\quad$ - $\quad$ - $\quad 110$ 


\section{$\therefore$ iv -}

IV to GATTUNG : CAPSUS

pulverulentus
punctulatus
quadripunctatus
revestitus -
roseo-maculatus
Roseri -
roseus -
rubicundus
rubricatus Ihn.

rubricatus Fallèn

rufifrons - -

rufipes

salicellus -

saltator -

salviæ - -

sanguineus

seladonius -

semiflavus

setulosus -

seticornis -

sexgultatis

solitarius - -

Spinolæ -

spissicornis -

striatellus

striatus

terminalis

Thunbergii

thoracicus

ticinensis -

transversalis

tricolor -

trifasciatus

triguttatus

tripustulatus

tumidicornis

tyranius -

umbellatarum

umbratilis

unisasciatus

variabilis -

varians

varipennis

verbasei

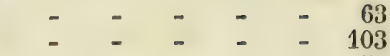

Pag.

$-\quad-\quad-\quad-51$

- $-\quad-\quad-55$

$-\quad-\quad-\quad-52$

$-\quad-\quad-\quad-105$

$-\quad-\quad-\quad-67$

$-\quad-\quad-\quad-72$

- - - - - 72

- - - - - 73

$-\quad-\quad-\quad-112$

- - - - - 107

$-\quad-\quad-\quad-74$

- - - - - 112

- - - $\quad-\quad 95$

$-\quad-\quad-\quad-75$

79

- 101

$-53$

$-\quad 95$
$-\quad 92$

-92
$-\quad 93$

- 83

- 45

- 64

- 94

- 94

-66
$-\quad 81$

- $\quad 81$

- $\quad 102$

- $\quad 100$

- $\quad 106$

- $\quad 108$

- $\quad-107$

- $\quad$ - 90

$-\quad-106$

$-\quad-59$

- $\quad 108$

- $\quad-\quad 99$

- $\quad-58$

- $\quad-104$

- $\quad 68$

$-\quad 69$
$-\quad 5$

- $\quad 103$

virgula - - - - - - - 85

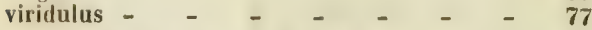

vittipennis - - - - -56

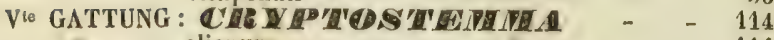
alienum - - - _ _ - -114 
TAB.I.

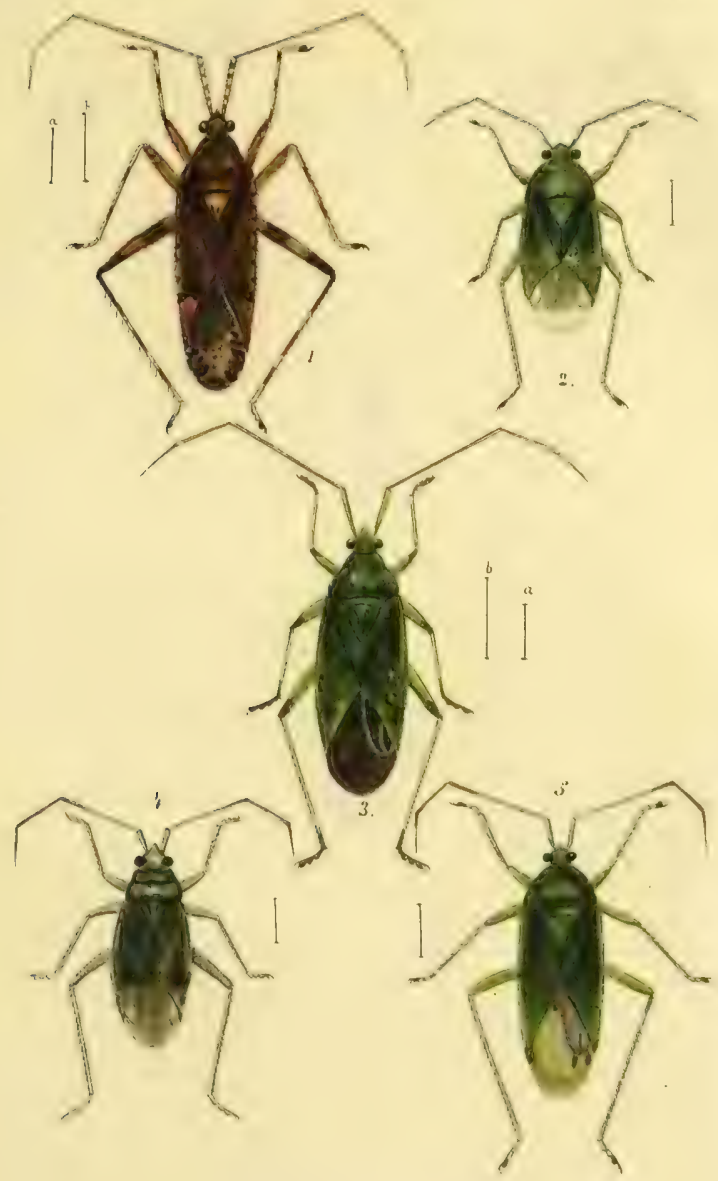

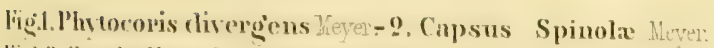

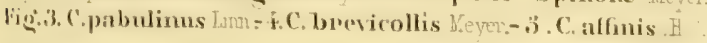



TAB.II

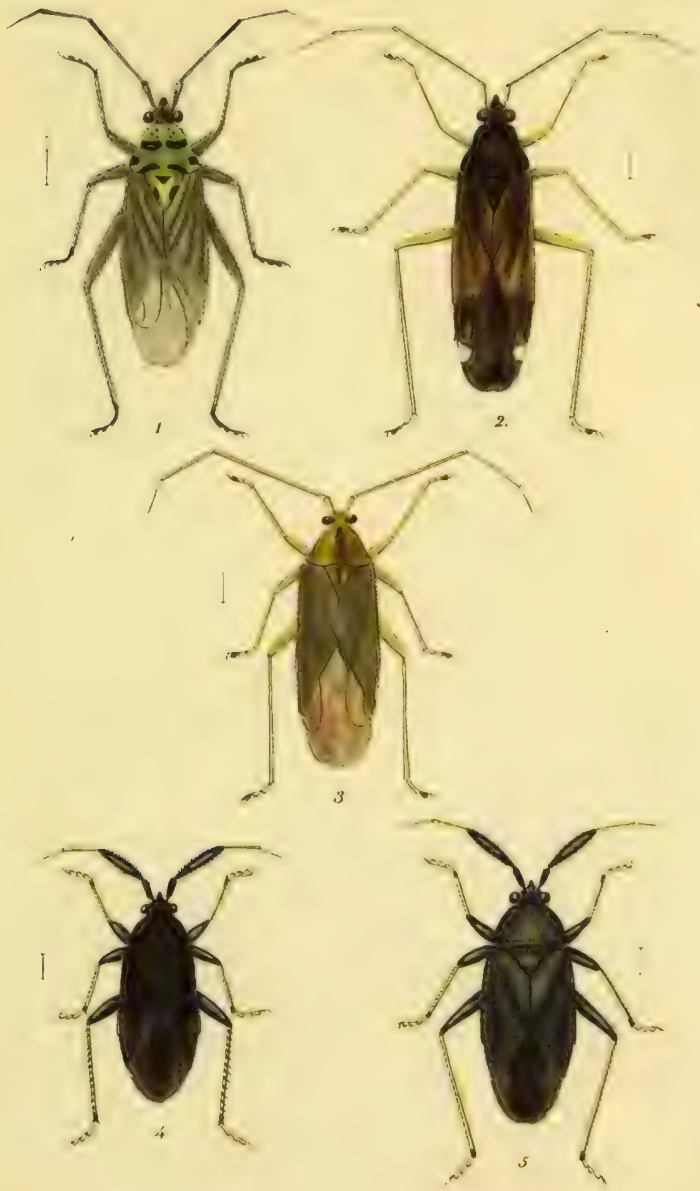

Fig. 1. Capsus setulosus HS. 2. C. avellane Meyer Fig. 3. C. angustus HS? 4.C. Maggnicomis Fall.J.C. mali Meve 

T.AB. III
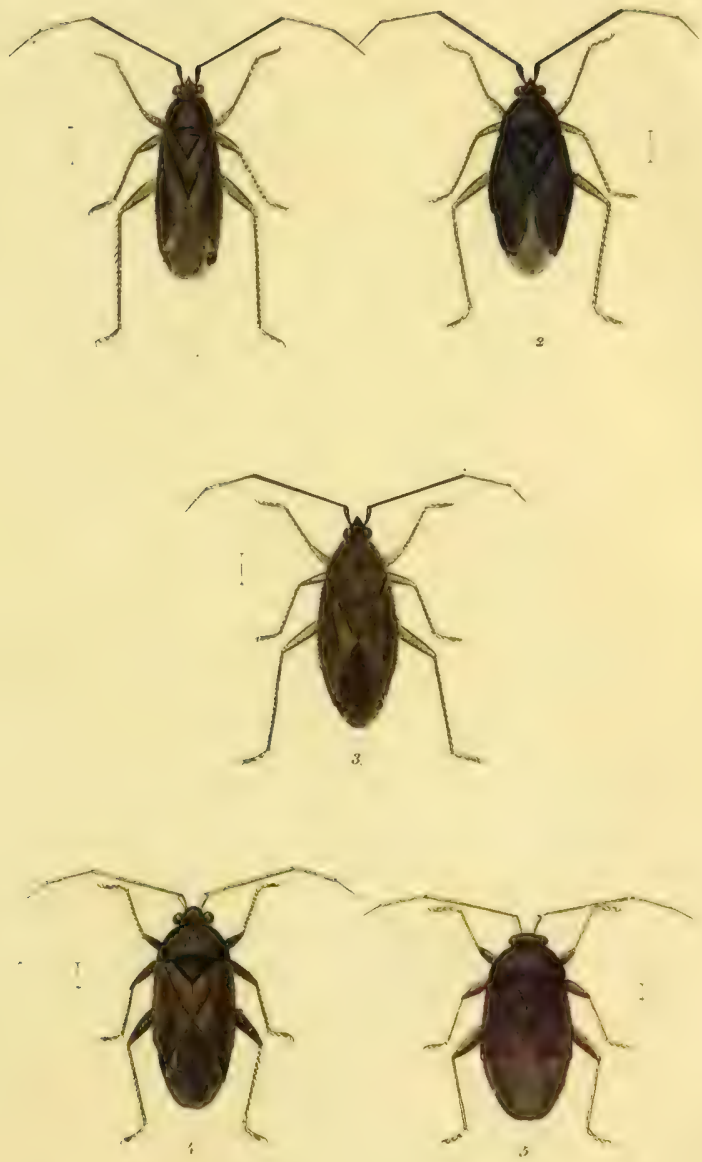

Kii.l.Capsus arbustorum Fabr. 2 C. hortensis Меуег

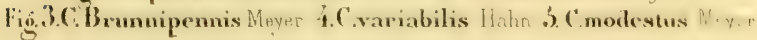



TAB.IV.
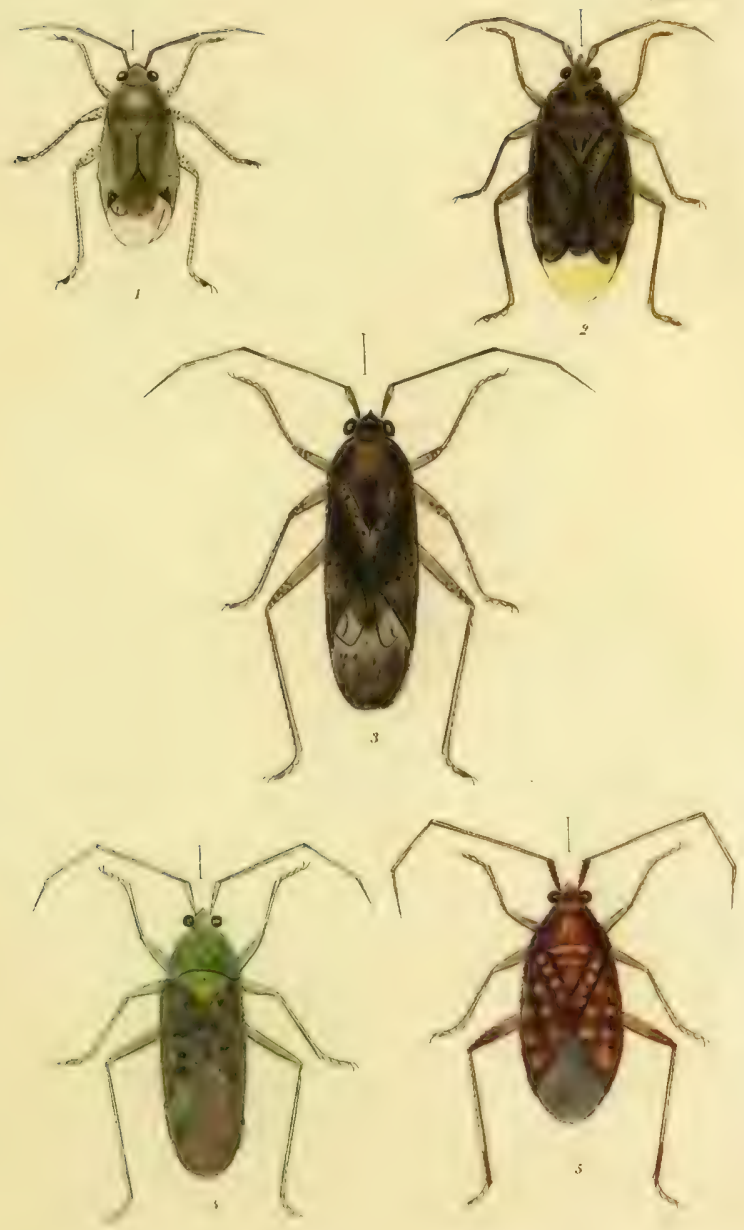

liig. 1. Capsus verbasci ils 2. C punculatus Fall liag.). C. atomarius Moyer A. C. chorizans Fabr 3. C.eoceinens Wastert 



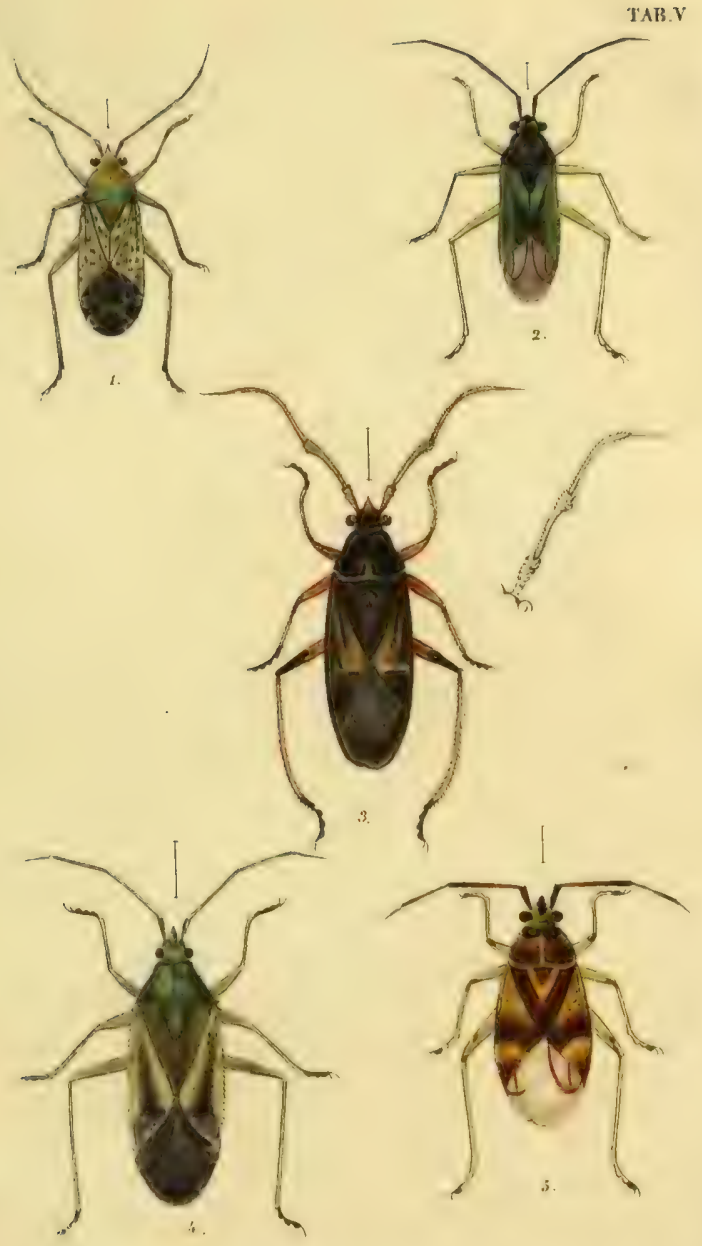

liig.l. Capsus maculipennis HI S. 2. C.clogiamulus Meyor Hig 3. C. curvipes Meyer. 1. C. solitavius Meyer 5. C. Casciatus Moyer 

TAB.VI.

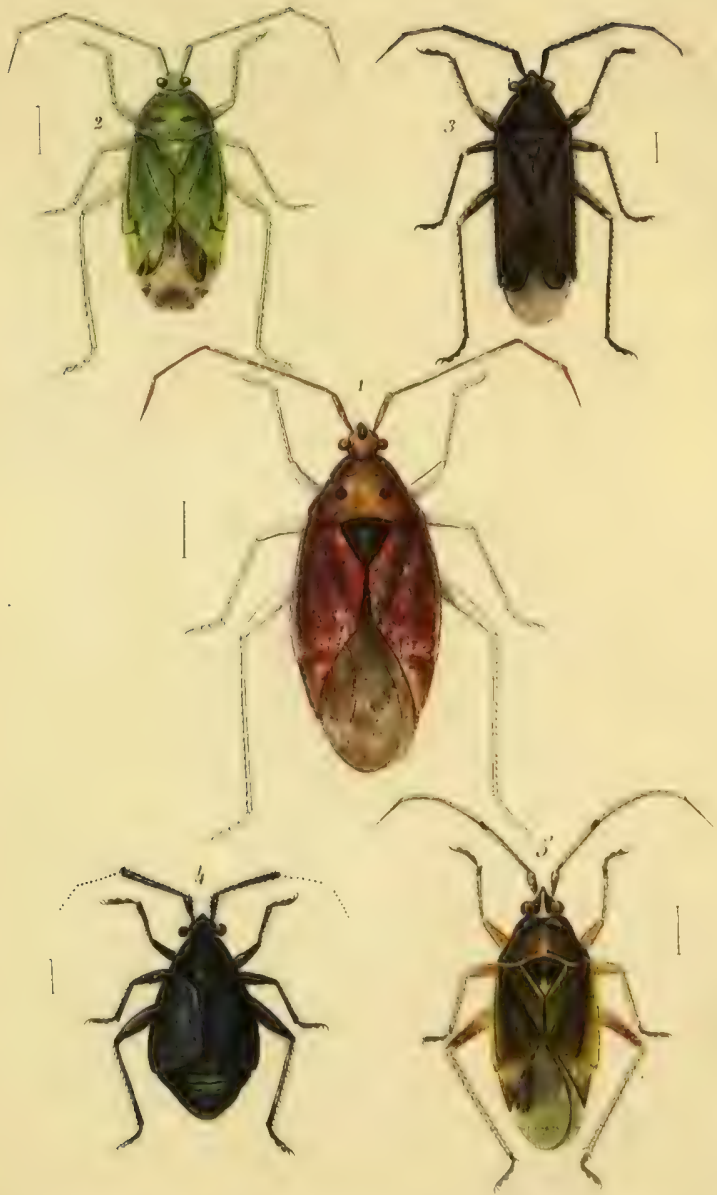

Vig.l.Capsus tieinensis Meyer- 2. C. Iucormu Ver .

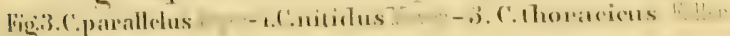





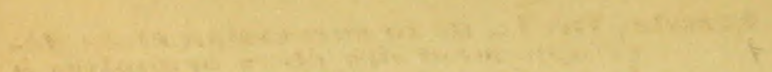

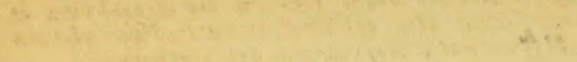

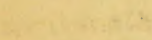

$x^{2}+2=$

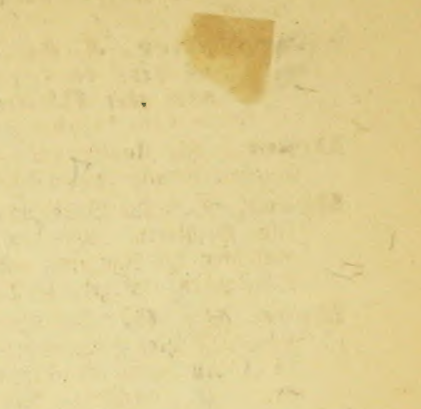

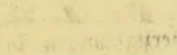

$$
\begin{aligned}
& \text { and } n
\end{aligned}
$$

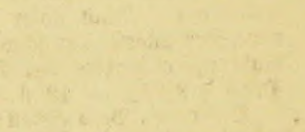

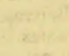

$$
\begin{aligned}
& x^{2}=
\end{aligned}
$$


Agassin, IDr. L.o, de ta succession et alu développement des êtres oryanisés ì la surface du globe terrestre dans les differems ages de la nulure.

$804 \mathrm{ggr} .-18 \mathrm{kr}$. $-60 \mathrm{Cmes}$

\section{Charpentier, J. de, Hssai sur lés Claciers sin sur the terrain erralique dh Has-}

Desor, E. Monographie des Galérites et des Dysasters (vide Agassiz Monographies d'Echinodermes $3^{\mathrm{me}}$ Livr.)

Desor, Die Befteigung oes Jungfrauforns burd) शgafíiz unb

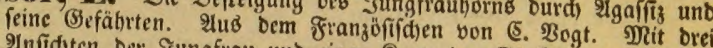
Infiditen ber Sungfrau uno einer Rarte oer (S) fetficher beơ Berner Sberlanbed. $8^{0} \mathrm{get}$. $15 \mathrm{ggr}$. $-1 \mathrm{ft}$.

ILeer, Dr. D. Die Räfer ber Sd)wei, mit befonberer Berüdfidtigung ihrer geographifdsen Berbreitung. 1ter Fhl. 3te Rieferung. (सus ben neuen Denfíd)riften 5 ter Bano befonders abgebrudt)

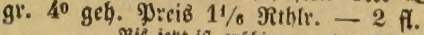

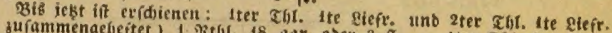

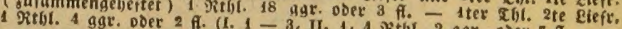

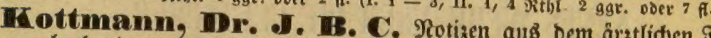

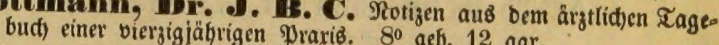

natures, nouveaux, de la Société hélvétique des sciences naturelles. 2ud) unter dem Titel: Demksehriften, Melle, ber allgemeinen id)weizerifd)en (Befellfd)aft für bie ge|ammten

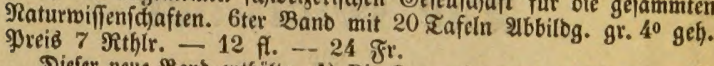

Diefer neue Banb enthält: 1) Die Generationsorgane von Unio und Andenta, zootomischer Beitrag von M. Neuw y ler, Mit 3 Tat. 2) Beiträge Mur Anatomie des Zitteraales (Gymmotus electricus); von G. V a lentin. Mit 5 Tal. 5) Recherches pour servir à l'histoire des Podurelles; par $\mathrm{H}$. Ni $\mathrm{i}$ -
colet. Avec 9 Planches, Alpes pennines; par Ches. 4) Materieaux pour servir a l'Hypsométrie des geognostischen Forschung und Darstellung des St. Gotthard bis $A r t$ ang und Darstellung des Alpendurchschnittes vom Die frubern Art am Zugersee; von Dr. Lu s ser. Mit 3 grossen Taf.

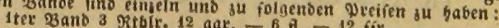

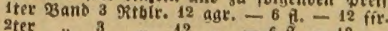

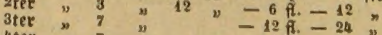

$\begin{array}{lllll}\text { ster } & * & 7 & n & -12 \mathrm{fi}-24 \\ 5 \mathrm{ter} & * & 7 & * & -12 \mathrm{fi} .-24\end{array}$ Morityd, A. Réflexions sur l'espèce broch. $12 \mathrm{ggr}$.

Pictet, F. J., histoire naturelle gènérale et particulière des Insectes Névroptères. 1' Avec 55 Planches soigneusement coloriées. gr. $8^{\circ}$ broch. (Génève) $181 / 2$ Rthlr. $-32 \mathrm{fl},-66$ ffrs.

La seconde famille : les Ephémères, est sous presse.

Sowerby, I. Mineral-Conchologie Grossbrittanniens, oder ausgemalte Abbildungen und Beschreibungen der SchalthierUeberreste, welche zu verschiedenen Zeiten und in verschiedenen Tiefen der Erde erhalten worden sind. Deutsch bearbeitet von D. Desor. Durchgesehen und mit Anmerkungen und 


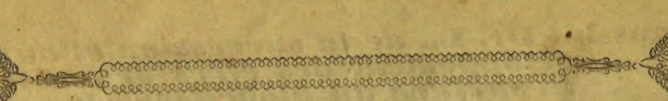

Berichtigungen versehen von Dr. L. Ag a s i z. Ite Liefr. mit 20 color. Tafeln. gr. $80 \mathrm{geh}, 2^{3 / 4}$ Rthle. 4 ก. $48 \mathrm{kr}$.

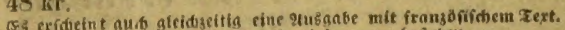

Dos volfeendige gisert wito aus 20 yefreungen beften.

Valentin, C. Aratomie des Gellinodermes. Première Monographie: Anatomie du genre Echinus, Vide Agassiz Monographies d'Echinodermes, $4^{\text {me }}$ Livraison).

Vogt, Ir. C. Untersuchungen über die EntwicklungsGeschichte der Geburtshelferkröte (Alyles obstetricans). Mit 3 lithogr. Tafeln. gr. $4^{0}$ geh. $1 \frac{2}{3}$ Rthlr, $-3 \mathrm{fl}$,

Vogt, Dr. C., l'Embriologie des Salmons, (vide Agassiz histoire naturelle des poissons d'eaux douce, 2te Livraison.)

\section{NEUES WERK ÜBER DIE GLETSCHER.}

Bei unถ ift unter ber গुreffe, uno wirb in 14 Tagen verfanbt:

\section{Die Oileticher}

unb

23eriud

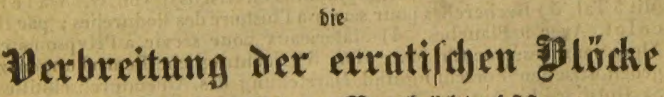
in geologifacn serbältuifen

зu begrünoen

Doll

\section{D. HUCE.}

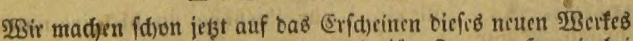

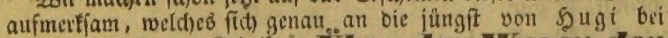
(5otta eridienene Sibrift: Uber das Wesen der

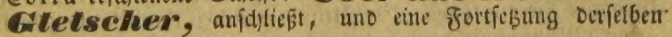
biloet.

Solotburu, Detl 25. Ditober 1842.

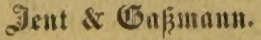

